\title{
Caracterización del efecto del reflejo olivococlear contralateral sobre la respuesta coclear humana
}

\author{
TESIS DOCTORAL
}

Enzo Luís Aguilar Vidal

Universidad de Salamanca

Julio de 2013 



Enrique Alejandro López Poveda, Profesor Contratado Doctor Permanente, del Departamento de Cirugía de la Universidad de salamanca, adscrito al Instituto de Neurociencias de Castilla y León y al Instituto de Investigación Biomédica de Salamanca,

\section{CERTIFICA}

Que la tesis doctoral titulada "Caracterización del Efecto del Reflejo Olivococlear Contralateral Sobre la Respuesta Coclear Humana" describe el trabajo de investigación realizado por D. Enzo Luís Aguilar Vidal en los últimos tres años y medio bajo mi dirección.

En esta memoria de tesis se presentan los resultados de una serie de experimentos psicoacústicos, fisiológicos y de simulación mediante un modelo computacional, desarrollados con el objetivo de conocer y caracterizar como la estimulación acústica recibida por un oído puede modificar la respuesta del oído contralateral. Los resultados presentados en este trabajo evidencian que los receptores auditivos humanos no funcionan de manera independiente si no que están conectados entre sí. Además se sugiere que esta variación en la respuesta del receptor auditivo es mayor en la región apical que en la región basal de la cóclea. Estos resultados invitan a una revisión de las teorías y los modelos de percepción auditiva actualmente utilizados para el desarrollo de tecnologías auditivas como audífonos e implantes cocleares, que suelen considerar el funcionamiento de nuestros oídos como fijos e independientes el uno del otro.

Por lo tanto, considero que esta tesis doctoral tiene la calidad y el rigor científico necesario para ser defendida en nuestra Universidad como requisito parcial para que D. Enzo Luís Aguilar Vidal opte al grado de doctor.

Salamanca, 11 de Julio, 2013 



\section{Agradecimientos}

Son muchas las personas que con su ayuda hicieron posible este trabajo. A todas ellas quisiera expresar mi gratitud. En primera instancia quisiera agradecer a mi tutor, Enrique, por su dedicación y constante apoyo. En él encontré más que un tutor: su riguroso trabajo y capacidad de análisis me han servido de ejemplo y motivación durante estos años para continuar con una carrera científica. Enrique siempre atendió mis inquietudes y valoró mis aportaciones.

Por supuesto, quisiera agradecer a mis compañeros de laboratorio que me ayudaron en las distintas etapas de este trabajo. En particular, a Almudena por su trabajo en el modelo computacional, a Peter por su ayuda en la recolección de datos, a Patricia por su ayuda en aspectos informáticos. Durante el desarrollo de esta tesis, tuve la oportunidad de trabajar día a día con ellos siempre en un entorno amable y generoso.

Este trabajo no habría sido posible sin la participación de los sujetos voluntarios. A todos ellos les agradezco su paciencia, su compromiso y su motivación.

Durante el curso del programa de doctorado pude compartir tiempo y experiencias con integrantes de otros laboratorios. Todos ellos me animaron y me aconsejaron. Las animadas conversaciones en los cafés de media mañana fueron siempre una oportunidad de intercambiar ideas sobre el quehacer científico y/o cualquier otro aspecto de la vida. Esta experiencia, además de agradable, fue muy enriquecedora.

Esté trabajo ha sido financiado por el Ministerio Español de Ciencia e Innovación (ref. BFU2009-07909) y por una beca predoctoral de la Comisión Nacional de Investigación Científica y Tecnológica de Chile. 



\section{Abreviaturas y acrónimos}

Entre paréntesis se indica el término inglés del que procede el acrónimo, en su caso.

2AFC: $\quad$ Doble alternativa y elección forzosa (two-alternative, forced choice)

ATT: $\quad$ Atenuación (attenuation)

BM: $\quad$ Membrana basilar (basilar membrane)

BW: $\quad$ Ancho de banda (bandwidth)

CAE: $\quad$ Conducto auditivo externo

CCE: Célula ciliada externa

CCl: Célula ciliada interna

CF Frecuencia característica (characteristic frequency)

COS: $\quad$ Complejo olivar superior

CWN: $\quad$ Ruido blanco contralateral (contralateral white noise)

DPOAE: Otoemisión acústica de productos de distorsión (distortion-product otoacoustic emission)

DRNL: Doble-resonancia no lineal (dual-resonance nonlinear)

$f_{M}: \quad$ frecuencia de la máscara

$f_{p}: \quad$ frecuencia de la sonda

GT: $\quad$ Gammatone

IOC: $\quad$ Curva de entrada-salida (input-output curve)

LOC: $\quad$ Olivococlear lateral (lateral olivo-cochlear)

LP: $\quad$ Paso-bajo (low-pass)

MEM: $\quad$ Músculo del oído medio (middle ear muscle)

MEMR: $\quad$ Reflejo muscular del oído medio (middle ear muscle reflex)

MOC: $\quad$ Olivococlear medial (medial olivo-cochlear)

MOCR: $\quad$ Reflejo olivococlear medial (medial olivo-cochlear reflex)

OAE: $\quad$ Otoemisión acústica (otoacoustic emission)

PTC: $\quad$ Curva de sintonización psicoacústica (psychoacoustical tuning curve)

SFOAE: $\quad$ Otoemisión acústica de frecuencia de estimulación (stimulusfrequency otoacoustic emission)

SNR Relación señal/ruido (signal/noise ratio)

SL: $\quad$ Nivel de sensación sonora (sensation level)

SPL: $\quad$ Nivel de presión sonora (sound pressure level)

TMC: $\quad$ Curva de enmascaramiento temporal (temporal masking curve)

TrOAE: $\quad$ Otoemisión acústica transitoria (transient otoacoustic emission) 



\section{Contenido}

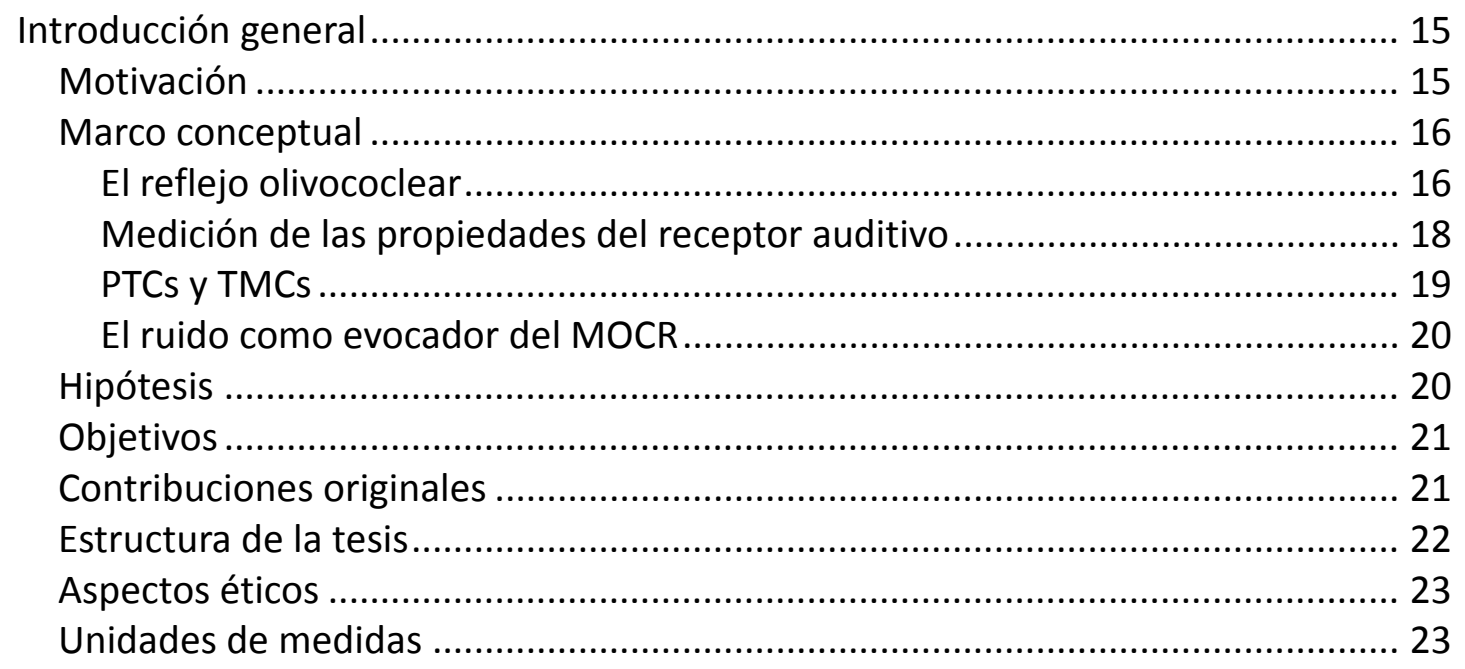

Efecto del MOCR contralateral sobre los umbrales absolutos de detección de tonos puros 25

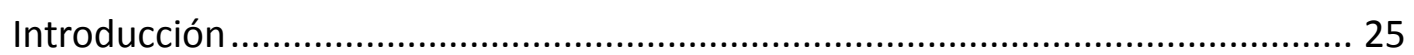

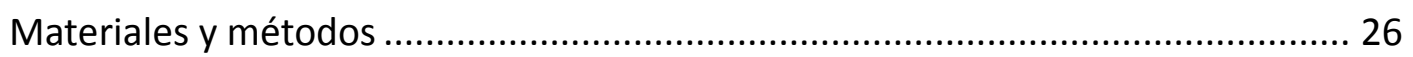

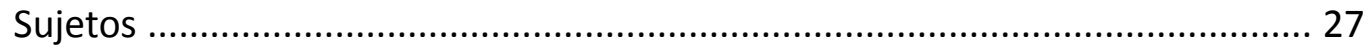

Procedimiento para la medida del umbral absoluto ........................................ 27

Prueba del reflejo del oído medio ........................................................................ 27

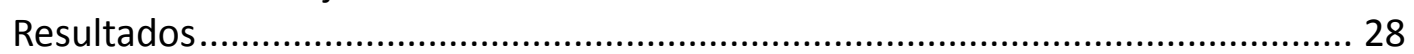

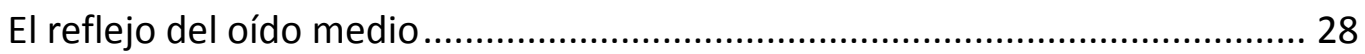

El efecto del CWN sobre los umbrales absolutos de detección de tonos puros 29

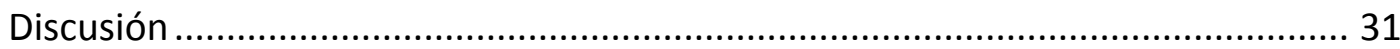

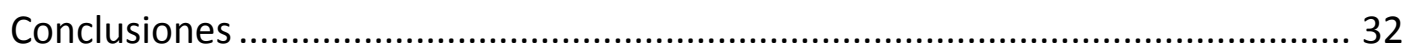

Efecto del MOCR contralateral sobre la tasa de recuperación del enmascaramiento

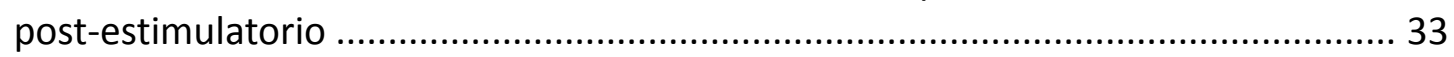

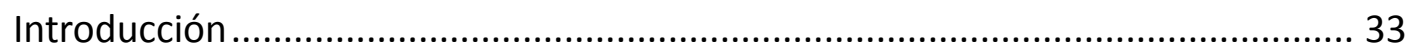

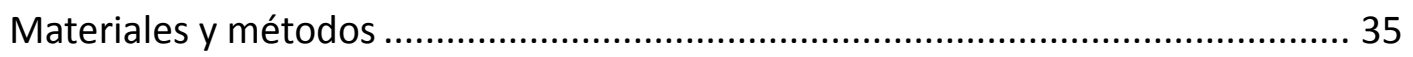

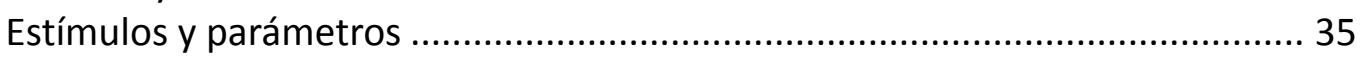

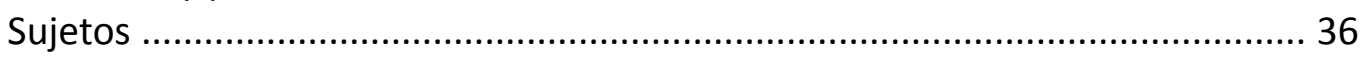

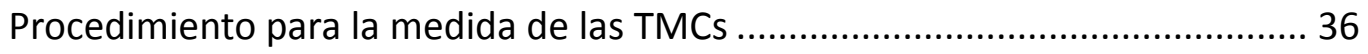

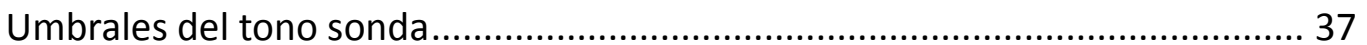

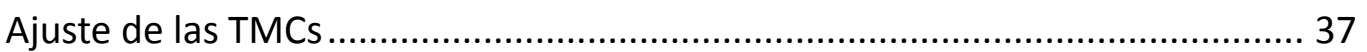

Obtención de las IOC psicoacústicas a partir de las TMCs ................................. 38

Prueba del efecto del CWN sobre la tasa de recuperación post-mecánica del 


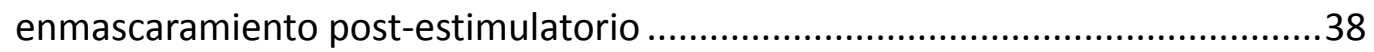

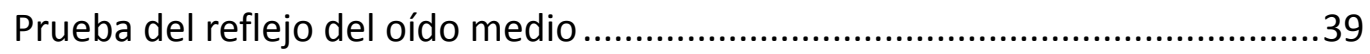

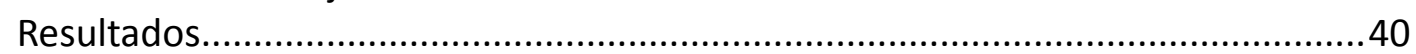

Control del reflejo del oído medio.................................................................40

Efecto del CWN sobre la tasa de recuperación post-mecánica del enmascaramiento post-estimulatorio. ..........................................................4

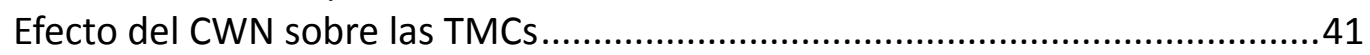

Efecto del CWN sobre las IOC psicoacústicas ..................................................4

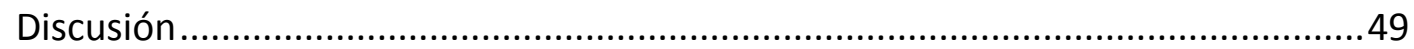

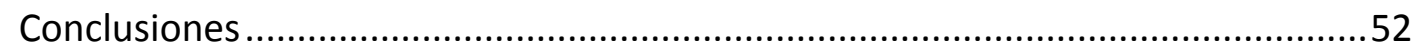

Efecto del MOCR contralateral sobre las curvas de sintonización psicoacústicas.......53

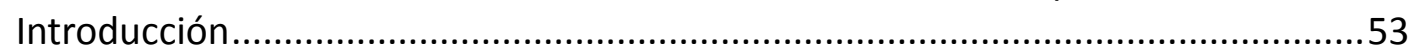

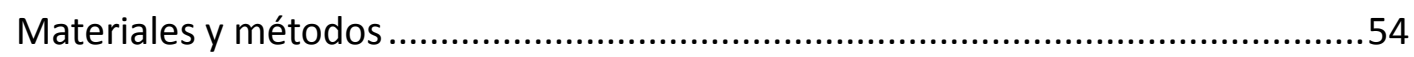

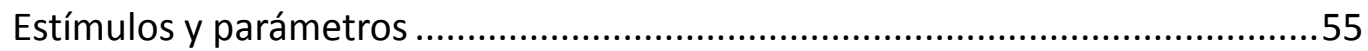

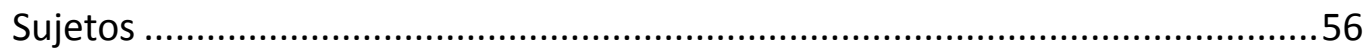

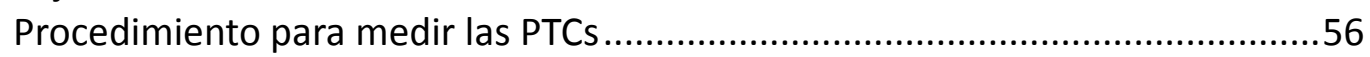

Umbrales del tono sonda .............................................................................56

Prueba de la tasa de recuperación post-mecánica del enmascaramiento post-

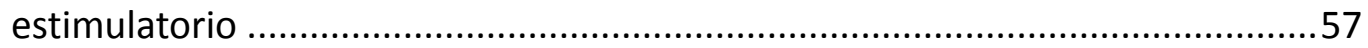

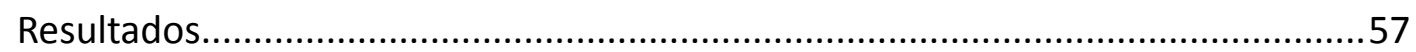

Efecto del CWN sobre la tasa de recuperación post-mecánica del enmascaramiento post-estimulatorio ..............................................................5 57

Efecto del CWN sobre las PTCs a nivel umbral ..............................................58

Efecto del CWN sobre las PTCs a niveles supra-umbrales ..................................60

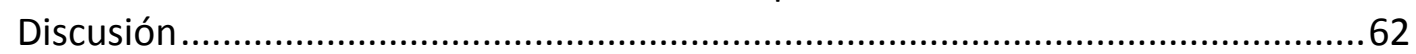

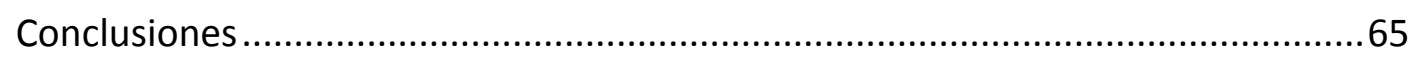

Análisis de las PTCs utilizando un modelo computacional de enmascaramiento post-

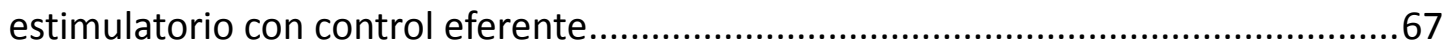

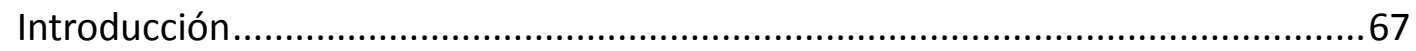

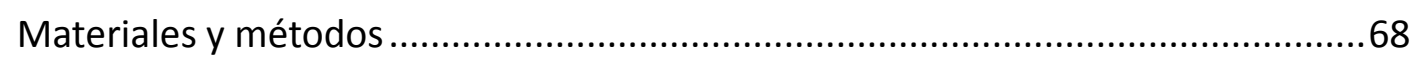

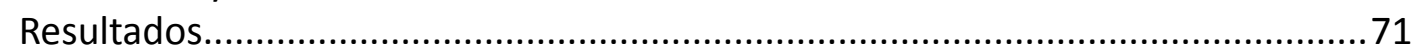

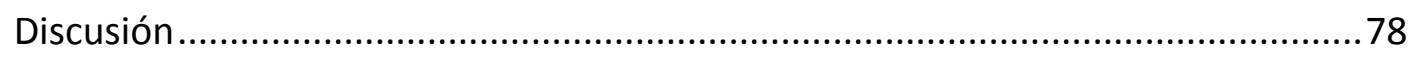

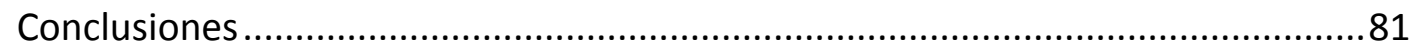

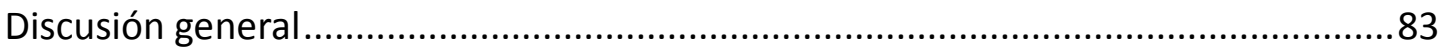

El efecto del MOCR contralateral es mayor en la región coclear apical que en la

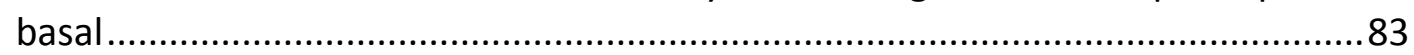

EI MOCR contralateral reduce la ganancia coclear y por tanto la sensibilidad

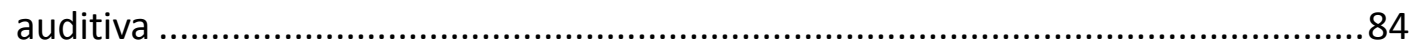

EI MOCR contralateral provoca una linealización de la función coclear de entrada-

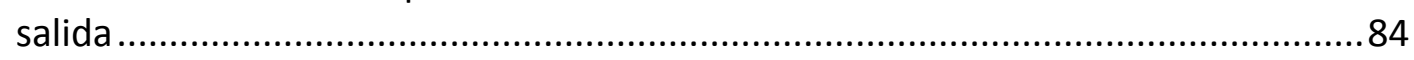

Las manifestaciones psicoacústicas del efecto del MOCR contralateral depende de las propiedades no lineales de la respuesta coclear humana ...............................85

Implicaciones teóricas, prácticas y tecnológicas .....................................................85 


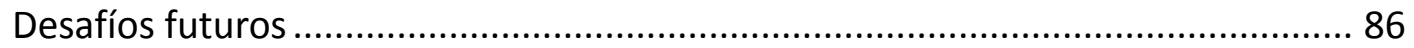

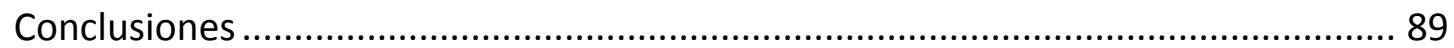

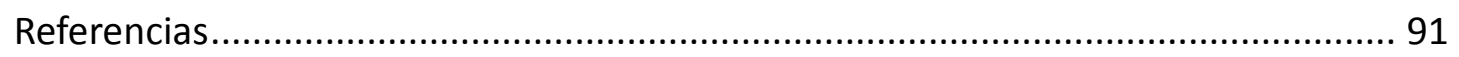

Publicaciones y comunicaciones resultantes de esta tesis ...................................... 99

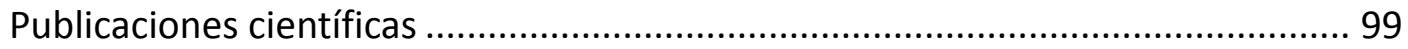

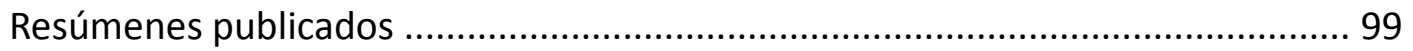

Comunicaciones en jornadas, congresos y seminarios ....................................... 99 



\section{Capítulo 1}

\section{Introducción general}

\section{Motivación}

En situación de escucha binaural, nuestros oídos no funcionan como dos receptores aislados el uno del otro, sino que están conectados mediante el reflejo olivococlear medial (MOCR) contralateral (Guinan 1996; Guinan 2006). Por tanto, el cerebro podría modular la respuesta de cada uno de los dos receptores auditivos, en función de la estimulación recibida por el oído contralateral mediante la activación del MOCR contralateral.

La función del receptor auditivo humano puede describirse como un banco de filtros no lineales actuando en paralelo (Irino y Patterson 2006; Lopez-Poveda 2005; LopezPoveda y Meddis 2001; Meddis et al. 2001; Meddis et al. 2010; Patterson et al. 2003; Sumner et al. 2003). Estos filtros tienen características como la compresión, la ganancia o la sintonización que dependen de la frecuencia y/o la intensidad. Estas propiedades han sido ampliamente estudiadas con técnicas fisiológicas directas de medición en mamíferos inferiores (Cooper 2004; Robles y Ruggero 2001). Sin embargo, al tratarse de técnicas invasivas, en humanos no es posible realizar estas mediciones. Pese a esto, existen algunas técnicas psicoacústicas basadas en el fenómeno de enmascaramiento, que permiten obtener una aproximación razonable a las características de la respuesta coclear en humanos (Bacon et al. 2004; LopezPoveda et al. 2007; Lopez-Poveda et al. 2003; Lopez-Poveda et al. 2005; Moore 2007; Nelson et al. 2001; Oxenham y Bacon 2003). El inconveniente principal de estas pruebas es que consumen demasiado tiempo como para emplearse con fines clínicos directos. No obstante, aportan información valiosa que puede ser utilizada para elaborar teorías sobre la percepción auditiva, así como modelos matemáticos de la percepción auditiva que pueden ser considerados al momento de diseñar prótesis auditivas como audífonos e implantes cocleares (Meddis et al. 2010).

En el desarrollo de modelos auditivos y sus aplicaciones, se ha asumido 
comúnmente que las características de la respuesta coclear humana son fijas, vale decir, las características extrapoladas mediante experimentos monoaurales se han utilizado al momento de caracterizar la respuesta del receptor auditivo en un ambiente natural de escucha binaural. Este supuesto, es probablemente equivocado.

El cerebro, tiene la capacidad de modular la respuesta coclear. Las fibras del haz olivococlear medial (MOC) se proyectan hasta las células ciliadas externas (CCE) (Fig. 1.1) cambiando su motilidad y por consiguiente, las características de la amplificación coclear (Guinan 2006; Guinan 2010). Es esta amplificación la que determina las características no lineales de la respuesta coclear. Las fibras del haz MOC pueden ser activadas de manera refleja por sonidos ipsilaterales 0 contralaterales. EI MOCR es, por tanto, probablemente activado de manera natural en la condición de escucha binaural, y modula las características de la respuesta coclear de manera dinámica. El propósito de la presente tesis es caracterizar la modulación eferente contralateral sobre la respuesta coclear humana.

En esta tesis se presentan los resultados de la activación del MOCR contralateral sobre estimaciones psicoacústicas de la respuesta coclear humana. Se presenta además un modelo computacional fenomenológico de enmascaramiento postestimulatorio con control eferente. El modelo se utiliza para analizar los resultados comportamentales obtenidos y extraer información respecto al efecto de la activación del MOCR sobre distintas propiedades de los filtros auditivos, en concreto, sobre la reducción de la ganancia y el grado de compresión y la sintonización coclear. En el modelo, se supone que la estimulación acústica contralateral activa el MOCR contralateral y que éste reduce la ganancia a intensidades bajas y medias. El modelo resulta fundamental para explicar algunos aspectos paradójicos de los resultados comportamentales obtenidos.

\section{Marco conceptual}

\section{El reflejo olivococlear}

En mamíferos, es posible identificar, de acuerdo a su origen, dos haces olivococleares con características especiales y distintivas. El haz olivococlear medial (MOC) y el haz olivococlear lateral (LOC) (Warr y Guinan 1979). Como se puede observar en la Fig. 1.1, las fibras del haz MOC se originan en la porción medial del complejo olivar superior (COS). Se ha observado en mamíferos inferiores que estas fibras mielinizadas contactan directamente con las CCEs de la cóclea ipsilateral y contralateral. No se conoce en humanos la proporción de fibras ipsi y contralaterales, sin embargo en monos Saimiri y en monos Patas la proporción de fibras ipsilaterales y contralaterales son similares (Guinan 2006). Las fibras del haz LOC son, por el contrario, predominantemente ipsilaterales y amielínicas. Tienen su origen en la zona más lateral del COS y contactan directamente con las fibras aferentes tipo I del ganglio auditivo en su porción cercana a la sinapsis con la célula ciliada interna (CCl).

No existe evidencia de que el haz LOC pueda ser activado de manera refleja por la 
estimulación auditiva. Por contra, el haz MOC puede ser activado por la estimulación auditiva ipsi o contralateral (Chambers et al. 2012; Robertson y Gummer 1985), conformando el reflejo olivococlear ipsi y contralateral, como se explica en la leyenda de la Fig. 1.1.

En mamíferos, se ha estudiado el efecto de la activación de los haces MOC y LOC, fundamentalmente a través de la estimulación eléctrica por electrodos ubicados a nivel del cuarto ventrículo. Dado que el haz MOC es mielinizado y el LOC no mielinizado, el haz MOC ha sido considerablemente más estudiado que el LOC. Estos estudios fisiológicos han evidenciado un efecto supresor sobre el receptor las fibras aferentes primarias del nervio auditivo producto de la activación de las fibras eferentes olivococleares en ausencia de ruido de fondo (Guinan y Gifford 1988b). Se ha observado también una disminución de la tasa de descarga espontánea de las fibras nerviosas (Guinan y Gifford 1988a). Sobre la cóclea, se ha encontrado una disminución en la amplitud y/o velocidad del desplazamiento de la membrana basilar al estimular el haz olivococlear medial MOC (Guinan y Cooper 2008; Murugasu y Russell 1996; Russell y Murugasu 1997), una disminución del potencial de acción compuesto y un incremento en el potencial microfónico coclear (Elgueda et al. 2011). El haz MOC ha sido activado de manera refleja mediante estímulos contralaterales y se ha observado un efecto supresor similar sobre las fibras del nervio auditivo (Warren y Liberman 1989a; Warren y Liberman 1989b) y la membrana basilar (Cooper y Guinan 2006).

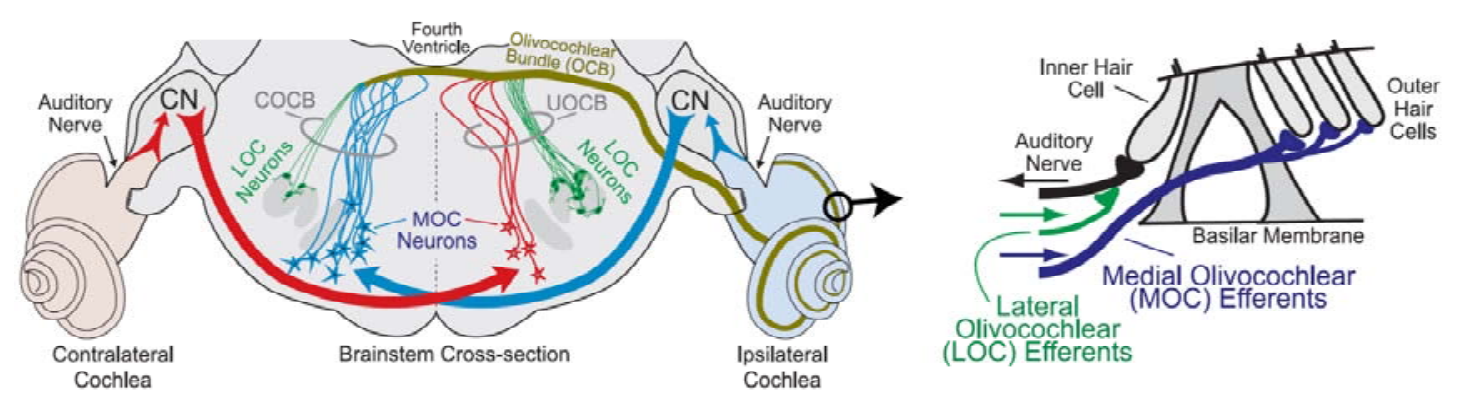

FIG. 1.1. Esquema del sistema olivococlear [adaptado de (Guinan 2006)]. Izquierda: corte transversal del tronco del encéfalo de gato. Se observan el haz LOC (verde) y el haz MOC (rojo o azul). La vía del reflejo olivococlear ipsi y contralateral para la cóclea derecha es mostrada en azul y rojo respectivamente. En el reflejo olivococlear contralateral, las fibras aferentes del nervio auditivo inervan interneuronas del núcleo coclear postero-ventral, axones de estas interneuronas cruzan ventralmente la línea media hasta llegar a la porción medial del COS contralateral, las neuronas del haz olivococlear medial viajan mediante el haz no cruzado hasta la cóclea. En el caso del reflejo olivococlear ipsilateral, las fibras del nervio auditivo inervan interneuronas del núcleo coclear postero-ventral, axones de estas interneuronas cruzan ventralmente la línea media hasta llegar a la porción medial del COS contralateral, las neuronas del haz olivococlear medial viajan mediante el haz cruzado hasta la cóclea contralateral, por tanto en este caso, las fibras del haz olivococlear cruzado son las que participan en el reflejo ipsilateral. Derecha: esquema del órgano de Corti que muestra las principales terminaciones del haz LOC con las dendritas de las fibras del nervio auditivo y del haz MOC con las CCEs. 
Diversos estudios han evidenciado que el haz MOC puede activarse de manera refleja por un ruido contralateral (Brown 1989; Chambers et al. 2012; Robertson y Gummer 1985). Asumiendo que un estímulo auditivo puede activar el MOCR contralateral, las investigaciones sobre la acción del MOCR contralateral sobre el receptor auditivo humano se han realizado fundamentalmente midiendo las otoemisiones acústicas (OAEs) en presencia y ausencia de estimulación acústica contralateral, habitualmente un ruido banda ancha. El efecto encontrado es principalmente una disminución de la amplitud de las OAEs transitorias (TrOAEs) (Berlin et al. 1993; Collet et al. 1990; van Zyl et al. 2009), de las OAEs de producto de distorsión (DPOAEs) (Atcherson et al. 2008; Chery-Croze et al. 1993; Lisowska et al. 2002; Sun 2008) y también de las OAEs de frecuencia de estimulación (SFOAEs) (Francis y Guinan 2010; Guinan et al. 2003; Lilaonitkul y Guinan 2009a; Lilaonitkul y Guinan 2009b; Souter 1995). Esto se conoce como supresión eferente de las OAEs.

Un inconveniente del estudio del efecto supresor del sistema olivococlear utilizando OAEs es que la información obtenida es poco precisa en cuanto al efecto sobre las propiedades del receptor auditivo. Investigaciones recientes sugieren que, si bien es posible obtener valiosa información con DPOAEs, la extrapolación de esta información a las propiedades del receptor auditivo no están exentas de problemas (Johannesen y Lopez-Poveda 2008).

\section{Medición de las propiedades del receptor auditivo}

Las CCEs confieren a la cóclea una respuesta no lineal que determina el grado de selectividad frecuencial de la respuesta mecánica coclear. La selectividad frecuencial nos permite, entre otras cosas, percibir parcialmente por separado los distintos componentes en frecuencia de un estímulo complejo (Evans 2001; Shera et al. 2002). Esta característica facilita la discriminación de algunos aspectos fundamentales de la voz humana como el tono y el timbre. Además de la selectividad frecuencial, la no linealidad otorgada por mecanismos activos cocleares a través de las CCEs confiere al receptor auditivo otras propiedades como la ganancia, que nos permite percibir estímulos de muy baja presión, del orden de 0.00002 Pa (Moore 2007). Sin embargo, también podemos percibir, distinguir y codificar un estímulo de hasta un millón de veces superior. Esta capacidad esta otorgada por otra propiedad de la no linealidad denominada compresión. Por tanto la ganancia y la compresión nos permiten percibir un rango amplio de presiones acústicas, vale decir nos otorga un rango dinámico amplio (Oxenham y Bacon 2003).

Como se mencionó previamente, existen diversas pruebas psicoacústicas que nos permiten obtener valiosa información respecto a la respuesta coclear humana. Por su utilidad, en esta tesis se han seleccionado las pruebas que nos permiten valorar el efecto del MOCR, activado por ruido contralateral, sobre algunas propiedades de la respuesta coclear humana como la sintonización, la ganancia y compresión a través de la medición de las curvas de sintonización psicoacústicas (PTCs) (Eustaquio-Martin y Lopez-Poveda 2011; Kidd y Feth 1981; Lopez-Poveda et al. 2007; Small 1959) y las curvas de enmascaramiento temporal (TMCs) (Lopez-Poveda y Alves-Pinto 2008; 
Lopez-Poveda et al. 2003; Lopez-Poveda et al. 2005; Nelson et al. 2001; Plack et al. 2004).

\section{PTCs y TMCs}

Para evaluar el efecto del ruido contralateral sobre las propiedades del receptor auditivo se utilizó la técnica de enmascaramiento post-estimulatorio. Esta prueba consiste en detectar un tono puro breve, denominado sonda o señal, precedido de un tono puro más prolongado, denominado máscara. Se midió la intensidad umbral de la máscara necesaria para enmascarar efectivamente al tono sonda, para distintas frecuencias de máscara (PTC) o para distintos intervalos de tiempo máscara-sonda (TMC). Ambas técnicas aportan valiosa información respecto a distintas propiedades del receptor auditivo. Las PTCs representan una aproximación comportamental a las curvas de sintonización coclear (Evans 2001; Lopez-Poveda y Eustaquio-Martin 2013; Shera et al. 2002) y la pendiente de las TMCs refleja el efecto combinado de la tasa de recuperación post-coclear y la compresión (Lopez-Poveda et al. 2003; Nelson et al. 2001).

Se utilizó la técnica de enmascaramiento post-estimulatorio por las ventajas de esta técnica que permite de obtener una aproximación a las propiedades de la respuesta del receptor auditivo, minimizando la ocurrencia de "latidos auditivos" (beats) y supresión, y que pueden dificultar la interpretación de los resultados (Kluk y Moore 2004).

Como tono sonda, se empleó un tono puro de frecuencia fija y de baja intensidad a fin de estimular una pequeña región coclear; es decir, evitando la dispersión de energía de la sonda a otras regiones cocleares diferentes de la región de la membrana basilar de interés. De esta manera se puede delimitar mejor la región coclear estudiada. Como máscara se utilizó un tono puro de larga duración. En estas condiciones, se asume que el umbral de la máscara depende de la excitación relativa de la máscara y del tono sonda en la región coclear activada por el tono sonda. Una PTC es la representación gráfica del umbral de máscara en función de la frecuencia de máscara; una TMC es la representación del umbral de máscara en función del intervalo temporal máscara-sonda. Al ser el tono sonda fijo en frecuencia e intensidad, se asume que todas las máscaras en cualquier PTC o TMC producen la misma excitación en la región coclear excitada por el tono sonda. Es decir, tanto las PTCs como las TMCs representan curvas de isorespuesta (Eustaquio-Martin y LopezPoveda 2011; Lopez-Poveda et al. 2007; Nelson et al. 2001).

Para estudiar el efecto del MOCR sobre las propiedades del receptor auditivo para una región apical y basal, se estudió el efecto de la estimulación acústica contralateral sobre las PTCs y las TMCs obtenidas con frecuencias de sonda de $500 \mathrm{y}$ $4000 \mathrm{~Hz}$, respectivamente.

En este trabajo se presupone que no es posible evaluar la magnitud y dirección del efecto de la activación del MOCR contralateral sobre la respuesta coclear 
directamente a partir de las PTCs y TMCs. Esto es particularmente evidente en bajas frecuencias, donde la compresión y los mecanismos cocleares activos ocurren para un rango de frecuencias de estimulación comparativamente más anchos que para altas frecuencias (Lopez-Poveda et al. 2003; Plack y Drga 2003; Rhode y Cooper 1996). Por esta razón, aquí desarrollamos y empleamos un modelo computacional fenomenológico y bioinspirado de enmascaramiento post-estimulatorio con control eferente para explicar los efectos de la estimulación contralateral sobre las PTCs (Capítulo 5).

\section{El ruido como evocador del MOCR}

Las neuronas del haz MOC pueden activarse por estímulos acústicos ipsi y contralaterales (Brown 1989; Chambers et al. 2012; Robertson y Gummer 1985), desencadenando así el MOCR. Estudios previos han demostrado que cuando se emplea ruido contralateral como evocador del MOCR, el ancho de banda del ruido contralateral es un factor importante en la magnitud del MOCR, observándose que el efecto sobre las OAEs es mayor cuanto mayor es el anchos de banda del ruido (Lisowska et al. 2002; Maison et al. 2000; Velenovsky y Glattke 2002). Por esta razón, en esta tesis se eligió el ruido blanco contralateral (CWN) como estímulo evocador del MOCR contralateral.

La intensidad del ruido contralateral es otro parámetro importante a considerar. Se ha observado que a mayor intensidad de ruido, mayor es su efecto supresor sobre las OAEs (Hood et al. 1996), con un umbral cercano a $40 \mathrm{~dB}$ SL en sujetos auditivamente sanos (Maison et al. 1997). Considerando estos factores, en este trabajo, se empleó ruido blanco con una intensidad de $60 \mathrm{~dB}$ SPL, suficientemente alta para desencadenar el MOCR contralateral pero insuficiente para desencadenar en reflejo del oído medio (MEMR) de acuerdo a los resultados obtenidos en sujetos normoyentes (Guinan et al. 2003; Lilaonitkul y Guinan 2009a; Lilaonitkul y Guinan 2009b). En esta tesis, se presenta un experimento control (Capítulo 2 y 3) orientado a demostrar que el ruido blanco utilizado no activa el MEMR por sí solo, ni en combinación con los estímulos tonales utilizados en la medición de las PTCs y las TMCs.

Ante la posibilidad de que exista una diferencia en la magnitud del MOCR entre ambos oídos, las medidas se realizaron en el oído derecho pues se ha encontrado una mayor inhibición en el oído derecho cuando se presenta un ruido contralateral (ventaja del oído izquierdo). Esto se fundamentaría en una asimetría en las vías olivococleares ipsi y contralaterales entre el lado derecho y el lado izquierdo y concuerda con la asimetría en otras regiones del cerebro auditivo (Atcherson et al. 2008; Philibert et al. 1998).

\section{Hipótesis}

La hipótesis general es que los sonidos contralaterales activan el MOCR y, por tanto, modifican las características de la respuesta coclear humana. El principal efecto 
esperado es una reducción de la ganancia coclear.

Las hipótesis concretas son:

1. La estimulación acústica contralateral incrementa el umbral absoluto de detección de tonos puros

2. La estimulación acústica contralateral modifica las características de los filtros auditivos humanos y sus curvas de sintonización psicoacústicas. Es probable que el efecto dependa de la intensidad en la que se realizan las mediciones.

3. Los sonidos contralaterales modifican las curvas cocleares de entrada/salida estimadas por métodos psicoacústicos. Presumiblemente muestran un rango dinámico más estrecho y una linealización de la función entrada/salida

4. Los efectos de la estimulación acústica contralateral sobre las pruebas psicoacústicas pueden explicarse y simularse mediante un banco de filtros nolineales con un control de la ganancia.

\section{Objetivos}

El objetivo general de esta tesis es comprobar si las características de la respuesta coclear humana (inferidas mediante métodos psicoacústicos) pueden ser moduladas por la presencia de estímulos acústicos contralaterales. Asimismo, se pretende conocer cuál es la dirección del potencial cambio sobre las propiedades no lineales de la respuesta coclear. El desarrollo de este objetivo, implica llevar a cabo los siguientes objetivos específicos:

1. Caracterizar los efectos de los sonidos contralateral continuos, que presumiblemente evocan el MOCR, sobre el umbral absoluto de detección de tonos puros y la integración temporal.

2. Caracterizar los efectos de los sonidos contralaterales continuos, que presumiblemente evocan el MOCR, sobre las PTCs.

3. Caracterizar los efectos de los sonidos contralaterales continuos, que presumiblemente evocan el MOCR, sobre la tasa de recuperación del enmascaramiento post-estimulatorio y sobre las curvas cocleares de entrada salida (IOCs) inferidas mediante métodos psicoacústicos.

4. Analizar los resultados experimentales con un modelo computacional de la respuesta coclear humana con modulación eferente, diseñado para este fin, que permita obtener información cualitativa y cuantitativa sobre el efecto de la estimulación acústica contralateral sobre la respuesta coclear humana.

\section{Contribuciones originales}

Esta tesis aporta evidencia de que en una situación de escucha binaural, nuestros oídos están conectados entre sí, y, por tanto, la estimulación percibida por un oído puede condicionar la sensibilidad y el funcionamiento del oído contralateral. Esta conexión estaría mediada por el MOCR contralateral. Aquí se presentan resultados experimentales novedosos entre los que cabe destacar: 
1. Se evalúa el efecto del CWN sobre los umbrales absolutos de detección de tonos puros de diferente duración. Se demuestra un incremento del umbral absoluto mayor para una frecuencia apical $(500 \mathrm{~Hz})$ que para una frecuencia basal (4000 $\mathrm{Hz}$.

2. Se demuestra que el $\mathrm{CWN}$ no tiene afecta la componente post-mecánica de la tasa de recuperación del enmascaramiento post-estimulatorio.

3. Se evalúa el efecto del CWN sobre la función de entrada-salida del receptor auditivo humano, observándose una linealización de la respuesta auditiva. El efecto del CWN es mayor para la región apical $(500 \mathrm{~Hz})$ que para la basal (4000 $\mathrm{Hz}$ ).

4. Bajo la evidencia fisiológica de que el efecto del MOCR sobre el receptor auditivo es dependiente de la frecuencia y la intensidad, aquí se evalúa el efecto del CWN sobre las PTCs medidas a nivel umbral y supra-umbral. Los resultados experimentales muestran una disminución del nivel de máscara, que varía en función del nivel sonoro y de la frecuencia de máscara. Estos resultados son compatibles con una reducción en la ganancia, mayor en la región apical que en la basal.

5. Se presenta un modelo computacional fenomenológico de enmascaramiento post-estimulatorio con control eferente. Este modelo permite analizar los datos psicoacústicos obtenidos, así como extraer información cualitativa y cuantitativa sobre el efecto de la estimulación acústica contralateral sobre las propiedades no lineales del receptor auditivo humano. El modelo reproduce de manera adecuada los resultados experimentales, y el análisis de los resultados experimentales utilizando el modelo sugieren que el CWN actúa reduciendo la ganancia coclear, y que esta reducción en mayor en el ápex que en la base.

6. Finalmente se propone un experimento novedoso dirigido a demostrar que uno de los potenciales beneficios del MOCR es la mejoría de la discriminación verbal en ambiente ruidoso.

\section{Estructura de la tesis}

Esta tesis está organizada de manera que cada capítulo contribuye a dar cumplimiento a alguno de los objetivos planteados. Cabe destacar que los Capítulos 2, 3 y 4 presentan resultados experimentales obtenidos utilizando, en algunos casos, los mismos sujetos y técnicas parecidas. Aun así, las pruebas y resultados descritos en cada capítulo se tomaron de forma independiente para alcanzar objetivos particulares. Por ello, y también para facilitar su lectura, los métodos se describen de forma independiente en cada capítulo, manteniendo la numeración de los sujetos entre capítulos.

En el Capítulo 2, se presentan resultados sobre el efecto del CWN sobre los umbrales absolutos de detección de tonos puros de $500 \mathrm{~Hz}$ y $4000 \mathrm{~Hz}$ de diferentes duraciones. El principal efecto observado consiste en un incremento del umbral del tono sonda. El efecto es mayor en la frecuencia de $500 \mathrm{~Hz}$. Se describe, además, un experimento control que evidencia que el CWN no desencadena el MEMR. En este 
capítulo se analiza y discute en torno a la posibilidad de que una reducción en la ganancia coclear sea la causa de la variación de los umbrales producto de la presencia de CWN.

En el Capítulo 3, se evalúa el efecto del CWN sobre la tasa de recuperación del enmascaramiento post-estimulatorio. Se describe, además, un experimento control que descarta que el CWN o el CWN mesclado con las máscaras ipsilaterales utilizadas en la prueba psicoacústica desencadene el MEMR. A partir de las TMCs medidas, se infieren las curvas de entrada-salida cocleares. El principal resultado consiste en una linealización de la curva de entrada-salida, producto del CWN. En este capítulo se discute además las posibles implicancias prácticas de este hallazgo.

El Capítulo 4 describe el efecto de un CWN sobre las PTCs. El principal efecto observado es una reducción en el umbral de las máscaras. Se analizan las diferencias observadas entre el efecto del CWN sobre las PTCs medidas a nivel umbral y las medidas a nivel supra-umbral $y$ se discute sobre el origen de los hallazgos observados.

En el Capítulo 5, se presenta un modelo computacional fenomenológico de enmascaramiento post-estimulatorio con control eferente. El modelo se utiliza para reproducir los resultados psicoacústicos observados en el Capítulo 4. Se demuestra que el modelo logra reproducir adecuadamente los resultados experimentales de manera cualitativa y cuantitativa, por lo que permite analizar el origen de las manifestaciones psicoacústicas del CWN sobre las pruebas de enmascaramiento post-estimulatorio.

En el Capítulo 6, se realiza una discusión general de los resultados obtenidos. Se integran los principales hallazgos de los Capítulos 2, 3, 4 y 5 . Se analizan estos resultados y su relación con la literatura existente y se discuten posibles implicaciones de los hallazgos. Se presentan además posibles desafíos futuros generados por los resultados experimentales obtenidos y se describe un experimento piloto diseñado para continuar con esta línea de investigación.

\section{Aspectos éticos}

Todos los procedimientos experimentales aquí descritos fueron aprobados por el Comité de Ética de Experimentación Humana de la Universidad de Salamanca.

\section{Unidades de medidas}

Todas las medidas se expresan en unidades del Sistema Internacional. 



\section{Capítulo 2}

\section{Efecto del MOCR contralateral sobre los umbrales absolutos de detección de tonos puros}

\section{Introducción}

Diversos estudios fisiológicos han demostrado una disminución de la ganancia coclear producto de la activación eléctrica del haz MOC (Guinan y Cooper 2008; Murugasu y Russell 1996; Russell y Murugasu 1997). En humanos, el correlato fisiológico de este fenómeno es el conocido efecto supresor del MOCR sobre las OAEs descrito en el capítulo anterior. Por otro lado, la estimulación acústica contralateral puede activar el MOCR (Brown 1989; Chambers et al. 2012; Robertson y Gummer 1985). En este capítulo, se presentan dos experimentos dirigidos a evaluar el posible efecto reductor de la ganancia coclear, y por tanto de la sensibilidad auditiva, por parte del MOCR activado por estimulación acústica contralateral.

El umbral absoluto de un tono puro depende de la duración del tono y del nivel de excitación que provoca sobre el receptor auditivo. En términos sencillos, se podría decir que el umbral auditivo disminuye conforme se incrementa la duración de este. La pendiente de esta disminución varía en función de la frecuencia (Watson y Gengel 1969). Dos teorías pueden explicar de manera satisfactoria este fenómeno. Una de ellas propone que el sistema auditivo integra energía en el tiempo y que el umbral absoluto de detección de un tono depende, por tanto, de un mínimo de energía que debe ser integrada. Al ser mayor la duración, se puede alcanzar el mencionado nivel umbral con una intensidad comparativamente más baja que con un estímulo de duración menor. Esta teoría se conoce como sumación o integración temporal (Heil y Neubauer 2001; Heil y Neubauer 2003; Heil et al. 2008; Meddis 2006). Una segunda teoría, señala que el cerebro realiza un muestreo aleatorio durante una ventana de 
tiempo que, en este caso, está determinada por la duración del estímulo. Si un estímulo tiene mayor duración, entonces tiene más posibilidades de ser detectado pues su ventana de muestreo es mayor. Esta teoría es conocida como "muestreo múltiple" (Viemeister y Wakefield 1991).

En cualquiera de estas dos teorías, el umbral auditivo dependería de la interacción de un fenómeno mecánico (que determina un nivel de excitación coclear) y de un fenómeno post-mecánico (de integración temporal o ventana de muestreo). Considerando que el haz MOC inerva a las CCEs y que este haz puede activarse de manera refleja por un ruido contralateral, es razonable pensar que la estimulación acústica contralateral podría cambiar el umbral de detección de un tono, afectando al fenómeno mecánico que lo desencadena sin afectar al componente postmecánico. Si se asume que el componente post-mecánico depende de la duración del estímulo (vale decir: a mayor duración, mayor ventana de integración temporal y/o mayor ventana de muestreo), es posible evaluar el efecto del MOCR contralateral sobre la sensibilidad coclear midiendo su efecto sobre un tono de duración y frecuencia fijas (condición en la que el componente post-mecánico no varía). Además, si se evalúa el efecto de la estimulación acústica contralateral sobre el umbral auditivo de un tono sonda en función de su duración, una presunta disminución en la ganancia generaría una elevación de los umbrales de la curva obtenida, pero no afectaría la pendiente, al menos cuando los niveles sonoros del tono se mantienen en la zona lineal de la respuesta coclear (Plack y Skeels 2007).

Aquí se plantea un experimento orientado a evidenciar un posible efecto del MOCR sobre los umbrales absolutos de detección de tonos puros por reducción de la ganancia coclear. Estudios previos han demostrado que el CWN es efectivo en activar el MOCR contralateral (Lilaonitkul y Guinan 2009a; Lilaonitkul y Guinan 2009b). Por tanto aquí se evalúa el efecto del CWN sobre el umbral absoluto de detección de tonos puros de diferente duración. Se emplearon tonos puros de $500 \mathrm{~Hz}$ y $4000 \mathrm{~Hz}$ con el fin de obtener información referente a las regiones apical y basal de la cóclea, respectivamente. Además, se realizó un experimento control con el objeto de verificar que el CWN utilizado no activa el MEMR.

\section{Materiales y métodos}

La tarea consiste en medir el umbral absoluto de detección de un tono puro en presencia y ausencia de CWN. En una primera prueba, se midió el umbral para tonos puros de frecuencia $500 \mathrm{~Hz}$ y $4000 \mathrm{~Hz}$, con una duración de 40 y 10 ms, respectivamente, y con rampas de entrada/salida de tipo coseno de 20 y $5 \mathrm{~ms}$ de duración, respectivamente (es decir, los tonos no tenían meseta). La duración para el tono de $500 \mathrm{~Hz}$ fue mayor a fin de evitar dispersión de energía a nivel de la membrana basilar que pudiera dificultar la interpretación de los resultados. En una segunda prueba, se midió el umbral absoluto de detección de tonos puros de $500 \mathrm{~Hz}$ y $4000 \mathrm{~Hz}$ en función de la duración de los tonos. Se emplearon duraciones entre 10 y $500 \mathrm{~ms}$. En esta segunda prueba, los tonos puros se presentaron con rampas de entrada/salida de $5 \mathrm{~ms}$ en todos los casos. En ambas pruebas, se empleó un CWN 
con un nivel sonoro estable de $60 \mathrm{~dB}$ SPL, nivel suficiente para activar el MOCR contralateral e insuficiente para desencadenar el MEMR (Lilaonitkul y Guinan 2009a; Lilaonitkul y Guinan 2009b). Se empleó un CWN con una duración de 1210 ms que comenzó 500 ms antes del inicio del tono (duración suficiente para evocar el MOCR).

\section{Sujetos}

En estas pruebas, participaron cinco sujetos voluntarios, sanos auditivamente. Dos mujeres (S1 y S4) y tres hombres (S2, S3, S5). La edad de los sujetos en años fue: 31 (S1), 31 (S2), 43 (S3), 27 (S4), y 25 (S5). Para comprobar su capacidad auditiva se les realizó una audiometría en ambos oídos, con anterioridad a su inclusión en el estudio. En la primera prueba, participaron los sujetos S1, S2, S3, S4, y S5; en la segunda prueba, participaron los sujetos S1, S2 y S4. Los sujetos no recibieron ningún tipo de retribución por su participación.

\section{Procedimiento para la medida del umbral absoluto}

Los umbrales absolutos se midieron utilizando el procedimiento adaptativo de doble alternativa y elección forzosa (2AFC). Se presentó una secuencia de dos estímulos sonoros a través de auriculares acompañados de dos estímulos luminosos en un monitor de ordenador: en uno de los dos estímulos se presentaba el tono sonda; el otro estímulo contenía silencio. Se instruyó al sujeto para indicar cuál de los dos estímulos contenía el tono sonda. Al sujeto se le informó si su respuesta fue acertada o no tras cada presentación (es decir, se le dio feedback) mediante información visual en la pantalla del ordenador. El intervalo temporal entre los dos estímulos fue de $500 \mathrm{~ms}$. El tono sonda se presentó en el primer o en el segundo estímulo de forma aleatoria. Durante la prueba, el nivel del tono varió de acuerdo a un procedimiento adaptativo de dos aciertos-baja y un fallo-sube, para estimar el punto del $71 \%$ de aciertos de la función psicométrica (Levitt 1971). Los cambios en el nivel sonoro del tono sonda fueron de 6 en $6 \mathrm{~dB}$ hasta el tercer cambio de dirección, a partir del cual los cambios fueron de 2 en $2 \mathrm{~dB}$. El umbral absoluto del tono se obtuvo promediando los niveles sonoros de los últimos 12 puntos de cambio. El registro se desechó cuando la desviación estándar de esos 12 puntos excedió de 6 dB. Se obtuvieron un mínimo de tres umbrales válidos para cada condición. El promedio de estos tres valores representa el umbral promedio final para cada duración del tono. Cuando la desviación estándar de los tres valores superó los $6 \mathrm{~dB}$, se obtuvieron nuevas mediciones y se agregaron al promedio. En algunas condiciones, no se logró obtener un mínimo de tres repeticiones validas (menos de 6 $\mathrm{dB}$ de desviación estándar en cada medición y menos de $6 \mathrm{~dB}$ de desviación estándar entre las mediciones). Estos puntos no se consideraron válidos y fueron descartados.

\section{Prueba del reflejo del oído medio}

Los efectos del MEMR podrían confundirse con los del MOCR. Se realizó una prueba control de contracción del MEM de (Lilaonitkul y Guinan 2009a) a fin de confirmar que el CWN no activó el MEMR durante la medición del umbral absoluto de los tonos sonda. Cuando se presenta un tono puro en el conducto auditivo externo (CAE) de 
un sujeto, el nivel sonoro del tono en el canal auditivo depende de la impedancia del oído medio y por tanto de la activación del MEMR. El test consiste en medir el nivel sonoro de un tono sonda de distintas frecuencias en presencia y en ausencia de CWN. Un potencial factor de confusión sobre el nivel de presión sonora del tono medido en el canal auditivo es la presencia de una SFOAE generada por el tono sonda en el interior del oído. Para evitar este factor de confusión, se presentó un tono supresor de frecuencia $110 \mathrm{~Hz}$ sobre la frecuencia el tono de sonda y de intensidad $15 \mathrm{~dB}$ sobre el tono de sonda para suprimir la contribución de la SFOAE [véase (Lilaonitkul y Guinan 2009a)]. Se emplearon tonos de sonda entre 396 y 4000 $\mathrm{Hz}$ para cubrir gran parte del espectro de frecuencia estudiado en las pruebas psicoacústicas. El test se realizó usando un tono de baja intensidad (40 dB SPL). Las mediciones se realizaron usando el equipamiento IHS Smart System (con la versión de software SMARTOAE 4.52) equipada con un micrófono sonda Etymotic ER-10D. Para cada sujeto y condición, se obtuvieron tres medidas y se promediaron. Todas las medidas se realizaron en una única sesión y se obtuvieron de manera alternada en presencia y en ausencia de CWN, en intervalos de tiempo de aproximadamente 10 ms. Durante la medición los sujetos estuvieron cómodamente sentados en una cabina sonoamortiguada de doble pared y se les pidió que permanecieran lo más quietos posible.

\section{Resultados}

\section{El reflejo del oído medio}

La Fig. 2.1 evidencia que el CWN utilizado (60 dB SPL) no cambia el nivel de $40 \mathrm{~dB}$ SPL del tono de sonda entorno a la frecuencia de $500 \mathrm{~Hz}$ ni a la de $4000 \mathrm{~Hz}$ (destacadas por las áreas sombreadas en la figura). Se puede concluir, por tanto, que el CWN empleado no activa el MEMR y que cualquier efecto del CWN sobre los umbrales absolutos de detección tonal no se deben al MEMR. 


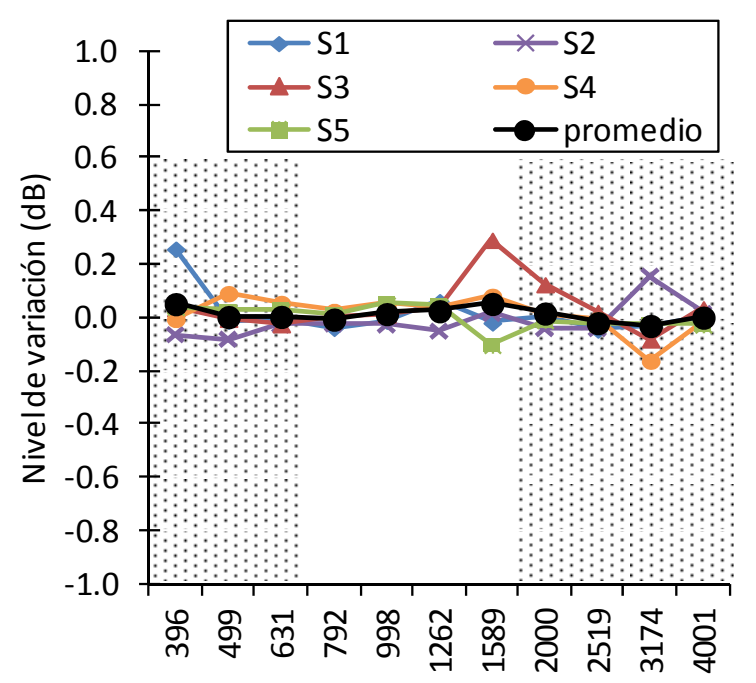

Frecuencia del tono sonda( $\mathrm{Hz})$
Figura 2.1. Variación de la admitancia de un tono sonda medido en el canal auditivo producto del CWN. Cada curva ilustra los resultados de un sujeto o el promedio. El cambio se expresa como el nivel medido en el CAE sin CWN menos el nivel medido con CWN. Un valor negativo indica que el CWN incrementa la impedancia del oído medio, presumiblemente por activación del reflejo MEM. Las áreas sombreadas ilustran los rangos de frecuencias utilizadas en las mediciones.

\section{El efecto del CWN sobre los umbrales absolutos de detección de tonos puros}

La Fig. 2.2 ilustra el efecto del CWN sobre los umbrales absolutos para tonos puros de 500 y $4000 \mathrm{~Hz}$ de 40 y 10 ms de duración, respectivamente (prueba 1). En ambos casos, se observa un leve incremento del umbral en presencia de CWN. En promedio, el incremento es levemente mayor en $500 \mathrm{~Hz}$ que en $4000 \mathrm{~Hz}(2.2$ y $1 \mathrm{~dB}$, respectivamente). Sin embargo, este incremento no es significativo en ninguna de las dos frecuencias aunque en $500 \mathrm{~Hz}$ está muy cerca de serlo $(p=0.059$, prueba- $t$ pareada de una cola).

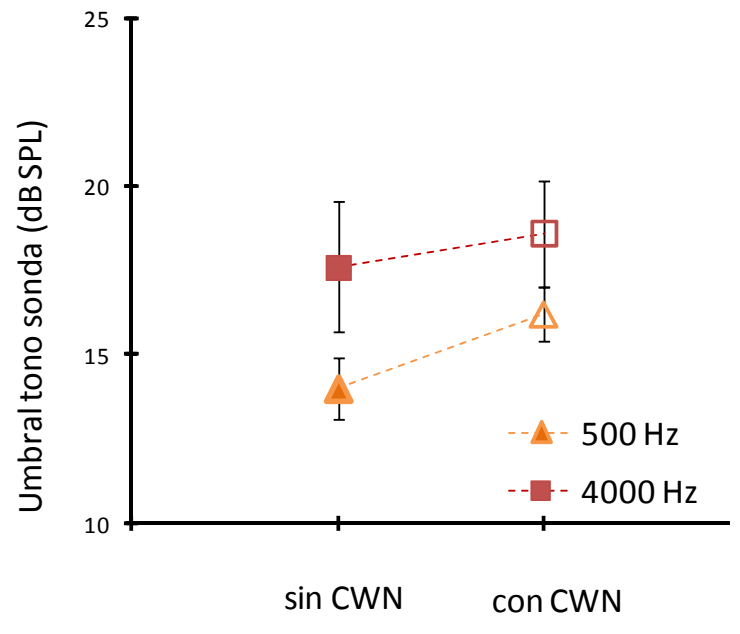

Figura 2.2. Efecto del CWN sobre el umbral absoluto de detección de tonos puros de $500 \mathrm{~Hz}$ y $4000 \mathrm{~Hz}$ de 40 y 10 ms de duración, respectivamente. Las barras de error ilustran una desviación estándar.

La Fig. 2.3 muestra el efecto del CWN sobre los umbrales absolutos de detección de tonos puros de distinta duración. El efecto principal es una elevación del umbral 
absoluto. A simple vista puede observarse que esta elevación es mayor en $500 \mathrm{~Hz}$ que en $4000 \mathrm{~Hz}$. Para realizar un análisis cuantitativo, se ajustó una función logarítmica de tipo $\mathrm{y}=a \ln (\mathrm{x})+b$ por el método de mínimos cuadrados a las series de datos individuales (resultados no mostrados) y a la serie promedio (líneas continuas en la Fig. 2.3). No se observaron diferencias estadísticamente significativas en la pendiente de las funciones ajustadas a los datos obtenidos con y $\sin C W N$ en ninguna de las dos frecuencias. Es decir, como se puede observar en la Fig. 2.3, el CWN desplazó la curva hacia niveles umbrales mayores de manera similar para todas las duraciones de tono sonda, tanto en la frecuencia de $500 \mathrm{~Hz}$ como de $4000 \mathrm{~Hz}$. En otras palabras, el CWN elevó el umbral absoluto de forma idéntica independientemente de la duración del tono.

La magnitud del incremento del umbral absoluto se estimó a partir del parámetro $b$ del ajuste. El promedio de las diferencias individuales en el valor de este parámetro fue de 3.45 y $0.07 \mathrm{~dB}$ en 500 y $4000 \mathrm{~Hz}$, respectivamente. El incremento en $b$ estimado a partir del ajuste a los datos promedio resulto ser de 1.79 y $0.55 \mathrm{~dB}$ a 500 $\mathrm{Hz}$ y $4000 \mathrm{~Hz}$, respectivamente. A pesar de la clara tendencia, ninguno de estos incrementos resultó estadísticamente significativo. Dicho esto, sin embargo, el efecto del CWN resultó significativo al promediar los umbrales medidos para todas las duraciones, tanto en la frecuencia de $500 \mathrm{~Hz}$ ( $p=0.00012$, prueba-t pareada de una cola) como en $4000 \mathrm{~Hz}$ ( $p=0.000023$, prueba-t pareada de una cola). Además, como muestra la Fig. 2.3, existen varias duraciones en las que la diferencia entre los umbrales obtenidos con y $\sin \mathrm{CWN}$ es estadísticamente significativa, tanto en 500 como en $4000 \mathrm{~Hz}$. 


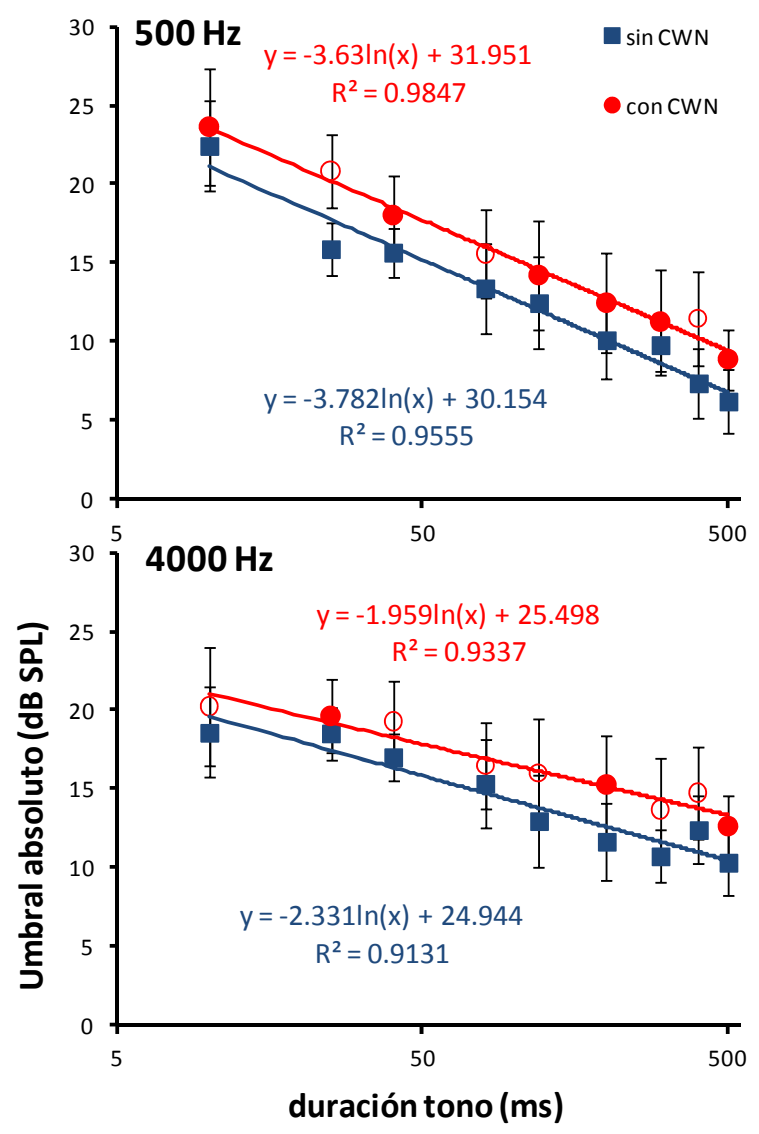

Figura 2.3. Efecto del CWN sobre el umbral absoluto de detección de tonos puros de diferente duración. El panel superior e inferior muestra los resultados promedios para la frecuencia de $500 \mathrm{~Hz}$ y $4000 \mathrm{~Hz}$ respectivamente. Los símbolos representan los valores promedios en ausencia y presencia de CWN como se indica en la leyenda del panel superior. Las líneas representan funciones logarítmicas ajustadas por mínimos cuadrados a los datos. Las ecuaciones de cada panel representan la función de ajuste para cada curva de acuerdo al color que representan. Las barras de error ilustran una desviación estándar. Los símbolos vacíos indican las frecuencias en que se observa una diferencia estadísticamente significativa ( $p<0.05$, prueba- $t$ pareado de una cola).

\section{Discusión}

Los resultados (Fig. 2.2 y 2.3 ) muestran que el CWN aumenta el umbral absoluto de detección de tonos puros de 500 y $4000 \mathrm{~Hz}$ independientemente de la duración del tono. La magnitud del incremento es mayor en $500 \mathrm{~Hz}$ que en $4000 \mathrm{~Hz}$. Considerando que el experimento control de la activación del MEMR (Fig. 2.1) muestra que este reflejo no se activa para el rango de frecuencias estudiadas, es posible concluir que el efecto del CWN ocurre por la activación del MOCR contralateral.

Al comparar el umbral de un tono de sonda en presencia y en ausencia de CWN, parece lógico pensar que la ventana temporal de análisis (ventana de integración o de muestreo) será la misma para tonos de idéntica duración. Por tanto, cualquier potencial variación en el umbral respondería a una variación en el nivel de excitación coclear evocada por el tono puro. Esta idea es reforzada por los presentes resultados que demuestran que la pendiente de variación del umbral absoluto con la duración del tono es muy similar en presencia y en ausencia de CWN (Fig. 2.3). Esto sugiere que el CWN no tiene un efecto sobre la ventana temporal de análisis, por tanto no tendría un efecto sobre fenómenos post-mecánicos que expliquen la detección del tono sonda por parte del sujeto. Considerando lo expuesto arriba es posible sugerir que: $i)$ el CWN reduce la ganancia del receptor auditivo; ii) la vía de acción se debe 
probablemente a la activación del MOCR. Estos conceptos son ampliamente compatibles con la literatura científica descritos en el Capítulo 1.

Es importante destacar que el número de sujetos evaluados es reducido. Esto podría explicar la ausencia de diferencias significativas entre los niveles de las curvas presentadas en la Fig. 2.3. Asimismo es posible pensar que incrementando el número de sujetos las diferencias estadísticamente significativas entre los umbrales del tono sonda se extienda a todas las duraciones. Por lo tanto, se hace necesario en un futuro, realizar los experimentos presentados en este capítulo a una muestra mayor de sujetos.

\section{Conclusiones}

1. Un CWN continuo de $60 \mathrm{~dB}$ SPL aumenta el umbral absoluto de detección de tonos puros de 500 y $4000 \mathrm{~Hz}$.

2. El incremento es mayor en la frecuencia de $500 \mathrm{~Hz}$ que en la de $4000 \mathrm{~Hz}$, aunque no es estadísticamente significativo.

3. El incremento del umbral absoluto es independiente de la duración del tono.

4. El incremento del umbral del tono sonda probablemente se debe a una reducción de la ganancia coclear por activación del MOCR. 


\section{Capítulo 3}

\section{Efecto del MOCR contralateral sobre la tasa de recuperación del enmascaramiento post-estimulatorio}

\section{Introducción}

Unas de las propiedades de la respuesta coclear sana es que presenta compresión. Esta característica le permite al sistema auditivo percibir y codificar de manera adecuada un rango muy amplio de intensidades acústicas. Diversos estudios fisiológicos en mamíferos han estudiado el efecto de la activación del haz olivococlear sobre la curva de entrada/salida (IOC) de la cóclea (Cooper y Guinan 2006; Dolan et al. 1997; Guinan y Cooper 2008; Murugasu y Russell 1996; Russell y Murugasu 1997) y sobre las fibras del nervio auditivo (Guinan y Gifford 1988a; Guinan y Gifford 1988b). Estos estudios han evidenciado un efecto de reducción de la ganancia coclear cuya magnitud depende del nivel sonoro: la reducción de ganancia es mayor a niveles sonoros bajos que a niveles sonoros altos. Además, se ha observado que en una situación de ambiente ruidoso, las fibras del nervio auditivo reducen su rango dinámico incrementando su umbral y disminuyendo su umbral de saturación. Sin embargo, la activación del sistema olivococlear restituye el rango dinámico de la respuesta neuronal (Kawase et al. 1993; Winslow y Sachs 1987). Este fenómeno se conoce como "efecto desenmascarante" del reflejo olivococlear y facilitaría la detección estímulos acústicos transitorios en presencia de ruido de fondo.

Existen diversas técnicas conductuales que permiten inferir de forma aproximada el grado de compresión coclear, o periférica, en humanos. La más usada es conocida como la técnica de las "curvas de enmascaramiento temporal", o técnica TMC (Nelson et al. 2001). Consiste en la medición, utilizando la técnica de enmascaramiento post-estimulatorio, del nivel sonoro umbral para que un tono puro 
(denominado máscara) enmascare a un tono puro breve (denominado sonda o señal) que se presenta seguido de la máscara. La representación gráfica del nivel umbral de la máscara en función del intervalo temporal de separación entre la máscara y la sonda se denomina TMC. La pendiente de una TMC representa, por tanto, la tasa de recuperación del enmascaramiento post-estimulatorio.

En esta técnica, se emplean sondas breves y cuyo nivel sonoro está fijo solo unos pocos decibelios por encima del umbral absoluto de detección de la sonda. Se supone que el umbral de enmascaramiento ocurre cuando el cociente entre la excitación que producen la máscara y la señal en la región coclear sintonizada a la frecuencia de la señal excede un cierto valor crítico, diferente para cada sujeto y región de frecuencia (Oxenham y Moore 1994). El nivel umbral de la máscara aumenta a medida que aumenta el intervalo temporal máscara-sonda. Así, la pendiente de la TMC refleja simultáneamente dos contribuciones: (1) el incremento de la excitación coclear (mecánica) de la máscara en la región coclear sintonizada a la frecuencia de la sonda y, por tanto, la compresión coclear a la que está sujeta la máscara; y (2) la tasa de recuperación post-mecánica del enmascaramiento postestimulatorio (Nelson et al. 2001; Oxenham y Moore 1994). Las regiones basales de la cóclea responden de forma lineal (sin compresión) frente a estímulos de muy baja frecuencia (Robles y Ruggero 2001; Ruggero et al. 1997). Por tanto, la TMC obtenida con una frecuencia de sonda $\left(f_{p}\right)$ alta (digamos $4000 \mathrm{~Hz}$ ) y una frecuencia de máscara $\left(f_{m}\right)$ comparativamente baja (digamos $1600 \mathrm{~Hz}$ ) no estaría afectada por compresión coclear y reflejaría únicamente la tasa de recuperación post-coclear del enmascaramiento post-estimulatorio. A la TMC obtenida en esta condición se le denomina TMC de referencia lineal. Suponiendo que la tasa de recuperación postmecánica del enmascaramiento post-estimulatorio es independiente del nivel sonoro, de la frecuencia de sonda (Lopez-Poveda y Alves-Pinto 2008; Lopez-Poveda et al. 2003), y de la frecuencia de la máscara, es posible inferir el grado de compresión coclear comparando la pendiente de cualquier TMC con la pendiente de la TMC de referencia lineal. De hecho, se puede inferir de forma aproximada la curva de entrada/salida (IOC) coclear, y por tanto el grado de compresión que afectaría a la máscara en la región coclear de la sonda, representando gráficamente los niveles sonoros de la TMC de referencia lineal frente a los niveles sonoros de cualquier otra TMC emparejados por intervalos máscara-sonda (Nelson et al. 2001).

El estudio de la tasa de recuperación del enmascaramiento post-estimulatorio permite, por lo tanto, inferir la función de entrada-salida del receptor auditivo y la compresión coclear, que no pueden ser obtenidas con técnicas fisiológicas directas ya que estas últimas son invasivas. Diversos estudios han evidenciado un efecto del MOCR ipsilateral sobre la tasa de recuperación del enmascaramiento postestimulatorio; efecto probablemente mediado por una reducción de la ganancia coclear (Jennings y Strickland 2012a; Jennings y Strickland 2012b; Jennings et al. 2009; Krull y Strickland 2008; Roverud y Strickland 2010). No existen, sin embargo, estudios acerca del efecto del MOCR contralateral sobre la tasa de recuperación del enmascaramiento post-estimulatorio. 
3. Efecto del MOCR contralateral sobre la tasa de recuperación del enmascaramiento postestimulatorio

Considerando que 1) las fibras eferentes del haz MOC proyectan hacia las CCEs y su activación cambia la respuesta coclear, y 2) que las fibras del haz MOC pueden ser activadas por estimulación acústica contralateral, es posible suponer que el CWN cambiará la tasa de recuperación del enmascaramiento post-estimulatorio afectando al componente de compresión (mecánico) pero no a la tasa de recuperación postmecánica del enmascaramiento post-estimulatorio.

En el presente capítulo, se investiga el efecto del CWN sobre la tasa de recuperación del enmascaramiento post-estimulatorio y la compresión para una región apical y una basal mediante la medición de TMCs con sondas de $500 \mathrm{~Hz}$ y de $4000 \mathrm{~Hz}$, respectivamente, en presencia y ausencia de CWN. Además, se evalúa el efecto del CWN sobre la tasa de recuperación post-mecánica comparando la pendiente de una TMC de referencia lineal obtenida en presencia y ausencia de CWN. Se realizó, además, un experimento control para verificar que el CWN no activa el MEMR ni por sí solo ni en combinación con las máscaras utilizadas para medir las TMCs.

\section{Materiales y métodos}

\section{Estímulos y parámetros}

Como sugieren los resultados del Capítulo 2, el CWN podría disminuir la ganancia coclear. Por tanto, si se utilizara un tono sonda con idéntico nivel sonoro (en dB SPL) en las condiciones con y $\sin \mathrm{CWN}$, la excitación coclear provocada por la sonda sería menor en la primera condición. Para evitar esta situación y con el fin de realizar mediciones en condiciones de igual excitación, primero se midió para cada sujeto el umbral de detección de la sonda en presencia y en ausencia de CWN y, después, al medir las TMCs, se utilizó un nivel de la sonda $10 \mathrm{~dB}$ por encima del umbral correspondiente. Con este procedimiento, la potencial reducción de ganancia coclear causada por el CWN se compensa al emplear una sonda con un nivel mayor nivel sonoro.

La Fig. 3.1 resume los estímulos utilizados y sus parámetros. Se utilizó un CWN fijo de 60 dB SPL. El ruido comenzó 500 ms antes del inicio de la máscara y su duración fue de 1210 ms. Las frecuencias de la sonda $\left(f_{P}\right)$ fueron $500 \mathrm{~Hz}$ y $4000 \mathrm{~Hz}$. Se utilizaron frecuencias de máscara de $0.5,0.7,0.9,1.0,1.05$ and $1.1 \times f_{p}$. Se obtuvieron TMCs empleando intervalos sonda-máscara (definidos entre el final de la sonda y el inicio de la máscara) entre 5 y $100 \mathrm{~ms}$, con pasos de $5 \mathrm{~ms}$, más un intervalo inicial de $2 \mathrm{~ms}$. La duración del tono sonda fue de $10 \mathrm{~ms}$ para la sonda de $4000 \mathrm{~Hz}$ y de $40 \mathrm{~ms}$ para la de $500 \mathrm{~Hz}$ con rampas de tipo coseno de ataque/soltura de 5 y 20 ms de duración, respectivamente. Se empleó una duración mayor para la sonda de $500 \mathrm{~Hz}$ a fin de minimizar los efectos de "escucha fuera de frecuencia" (off-frequency listening) sobre la detección de la sonda (Patterson y Nimmo-Smith 1980). La duración de la máscara fue de 200 ms, incluyendo rampas de ataque/soltura de 5 ms de duración. 

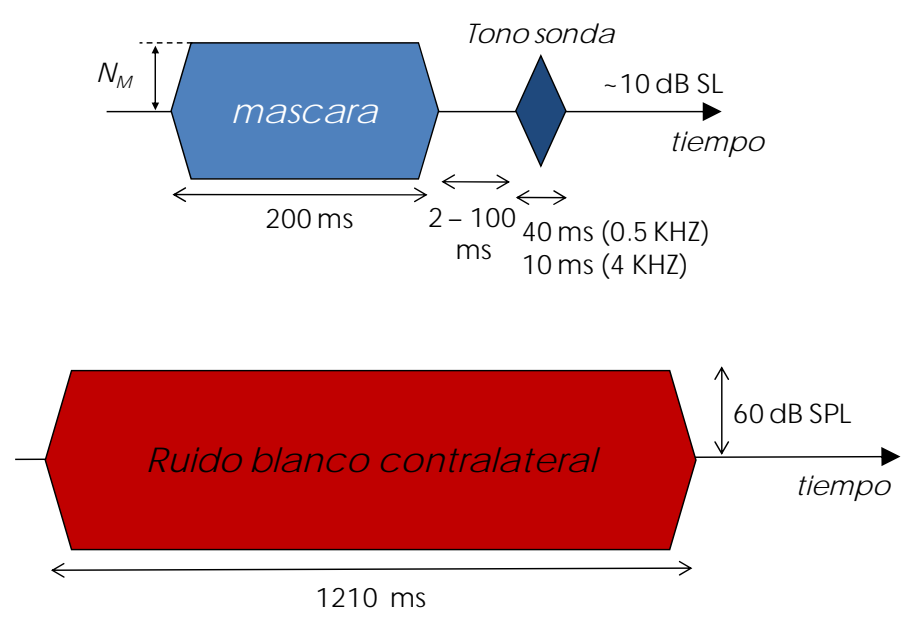

Figura 3.1. Representación esquemática de los parámetros de estimulación utilizados en la medición de las TMCs. Obsérvese que los colores de la ilustración no siguen la convención habitual. Es decir, el ruido contralateral (ilustrado en rojo) se presentó siempre en el oído izquierdo mientras que la TMC se midió siempre en el oído derecho.

La TMC de referencia lineal se midió empleando una sonda de $4000 \mathrm{~Hz}$ y una máscara de $1600 \mathrm{~Hz}$ (Lopez-Poveda y Alves-Pinto 2008). Esta referencia lineal se midió tanto en presencia como en ausencia de CWN, para evaluar el efecto del CWN sobre la tasa de recuperación post-mecánica del enmascaramiento postestimulatorio y también para inferir las IOC psicoacústicas.

Los estímulos fueron generados digitalmente (frecuencia de muestreo de $44100 \mathrm{~Hz}$ ) mediante la aplicación Audiolab, diseñada en entorno Matlab por la Unidad de Audición Computacional y Psicoacústica, del Instituto de Neurociencias de Castilla y León. Los estímulos se reprodujeron a través de una tarjeta de sonido RME Fireface 400 y se presentaron a los sujetos por medio de los auriculares de inserción Etymotic ER-2, de atenuación inter-aural nominal de 70+ dB, que fueron previamente calibrados utilizando un sonómetro unido a un acoplador de Zwislocki DB-100. Las pruebas se realizaron en una cabina sonoamortiguada de doble pared.

\section{Sujetos}

En estos experimentos, participaron los mismos cinco voluntarios normoyentes que participaron en los experimentos descritos en el Capítulo 2, pero todas las mediciones se realizaron de forma independiente. Todas las mediciones se realizaron en el oído derecho.

\section{Procedimiento para la medida de las TMCs}

Los umbrales de las máscaras se obtuvieron empleando un procedimiento de 2AFC. Se presentó una secuencia con dos estímulos: uno de ellos presentaba la máscara 
3. Efecto del MOCR contralateral sobre la tasa de recuperación del enmascaramiento postestimulatorio

seguida del tono sonda; el otro sólo contenía la máscara. El intervalo temporal entre los dos estímulos fue de $500 \mathrm{~ms}$. El tono sonda se presentó en el primer o segundo estímulo de forma aleatoria y se pidió al sujeto que indicara cuál de los dos estímulos contenía el tono sonda. El nivel de la máscara cambió durante la prueba de acuerdo a un procedimiento adaptativo. Es decir, el nivel sonoro de la máscara subió tras dos aciertos consecutivos del sujeto y bajó tras un fallo. De esta forma, se obtuvo el umbral de enmascaramiento como el nivel sonoro de la máscara al cual el sujeto percibe la sonda de forma correcta el $71 \%$ de las ocasiones (Levitt 1971). Los cambios en el nivel de la máscara fueron de 6 en $6 \mathrm{~dB}$ hasta el tercer cambio de dirección, a partir del cual los cambios fueron de 2 en $2 \mathrm{~dB}$. El umbral de enmascaramiento se obtuvo como el promedio del nivel de la máscara en los últimos 12 cambios. El dato resultante se desechó cuando la desviación estándar de esos 12 valores fue mayor a $6 \mathrm{~dB}$. Se obtuvieron un mínimo de tres umbrales válidos en cada condición. El promedio de estos tres valores representa el umbral promedio final para cada frecuencia de máscara. Cuando la desviación estándar de los tres valores superó los $6 \mathrm{~dB}$, se obtuvo una o varias nuevas medidas y se agregaron al promedio. En los casos en que no se logró obtener un mínimo de tres medidas validas (con menos de $6 \mathrm{~dB}$ de desviación estándar en cada medición y menos de $6 \mathrm{~dB}$ de desviación estándar entre las mediciones), los se consideraron inválidos y se descartaron. Cada una de las TMCs se obtuvo en presencia y en ausencia de CWN. A efectos del cálculo de las TMCs promedio de todos los sujetos, solo se incluyeron como válidos aquellos puntos que pudieron medirse en las dos condiciones para un mismo sujeto.

\section{Umbrales del tono sonda}

Los umbrales de los tonos sonda se midieron usando los procedimientos y equipamiento descritos en el Capítulo 2. Los valores obtenidos en presencia y ausencia de CWN se muestran en la Tabla 3.1.

Tabla 3.1. Umbrales individuales de los tonos sonda (en dB SPL). Obsérvese que para algunos sujetos, el umbral es idéntico con y $\sin C W N$. Obsérvese que estos valores son los representados en la Fig. 2.2 .

\begin{tabular}{|l|c|c|c|c|}
\hline & \multicolumn{2}{|c|}{$500 \mathrm{~Hz}$} & \multicolumn{2}{c|}{$4000 \mathrm{~Hz}$} \\
\hline & Sin CWN & Con CWN & Sin CWN & Con CWN \\
\hline S1 & 16 & 18 & 17 & 17 \\
\hline S2 & 14 & 14 & 23 & 23 \\
\hline S3 & 16 & 16 & 21 & 21 \\
\hline S4 & 12 & 18 & 14 & 18 \\
\hline S5 & 12 & 15 & 13 & 14 \\
\hline
\end{tabular}

\section{Ajuste de las TMCs}

Para facilitar el análisis de las TMCs, se ajustó una función doble exponencial a la 
TMC de referencia lineal y esta misma función más una doble Boltzmann a cualquier otra TMCs. El ajuste se realizó usando un procedimiento de mínimos cuadrados. La justificación y los detalles relativos al uso de estas funciones pueden encontrarse en (Johannesen y Lopez-Poveda 2008; Johannesen y Lopez-Poveda 2010). Los valores predichos por las funciones resultantes se emplearon en lugar de los datos experimentales en el análisis subsiguiente.

\section{Obtención de las IOC psicoacústicas a partir de las TMCs}

Las IOC psicoacústicas se infirieron representando gráficamente los umbrales de la TMC de referencia lineal en función de los umbrales de cualquier otra TMC emparejados por intervalos máscara-sonda (Nelson et al. 2001). Con el fin de estimar la IOC en el mayor rango de niveles de entrada posibles, en caso necesario los umbrales de la referencia lineal se extrapolaron a intervalos máscara-sonda más largos de los obtenidos experimentalmente (Lopez-Poveda et al. 2003). Se utilizó la misma referencia lineal para inferir las IOC psicoacústicas a las frecuencias de 500 y $4000 \mathrm{~Hz}$ (Lopez-Poveda et al. 2003).

Para cada una de las $\mathrm{IOC}$ resultantes se intentó obtener el umbral de compresión, el umbral de retorno a la linealidad, el grado de máxima compresión y la compresión media. El umbral de compresión y el de retorno a linealidad se definieron arbitrariamente como los niveles sonoros de entrada a los que la pendiente de la IOC se hizo igual a $0.6 \mathrm{~dB} / \mathrm{dB}$, siendo el umbral de compresión el menor de ambos niveles. El grado de máxima compresión se definió como el mínimo de la pendiente de la IOC (en $\mathrm{dB} / \mathrm{dB}$ ). El grado de compresión promedio se definió como el promedio la pendiente de la $I O C$ en el rango de niveles de entrada entre el umbral de compresión y el de retorno a la linealidad. En algunos casos, la pendiente de la IOC fue siempre menor que $0.6 \mathrm{~dB} / \mathrm{dB}$ en todo el rango de niveles de entrada disponibles. En estos casos, la compresión promedio se obtuvo promediando la pendiente de la IOC en todos los niveles de entrada disponibles. Estos parámetros y definiciones son típicos de este tipo de estudios (Johannesen y Lopez-Poveda 2008; Johannesen y Lopez-Poveda 2010; Lopez-Poveda y Johannesen 2010; Lopez-Poveda y Johannesen 2012). Cabe destacar, sin embargo, que, en algunos casos, fue imposible obtener todos estos parámetros para una misma IOC.

\section{Prueba del efecto del CWN sobre la tasa de recuperación post-mecánica del enmascaramiento post-estimulatorio}

Una suposición implícita en la obtención y el análisis de las IOCs es que el CWN no afecta a la tasa de recuperación post-mecánica del enmascaramiento postestimulatorio. Esta suposición se comprobó experimentalmente comparando la pendiente de una misma TMC de referencia lineal obtenida en presencia y en ausencia de CWN (que no están afectadas por la compresión). Los procedimientos y equipamiento utilizados para obtener y analizar estas TMCs fueron idénticos a los empleados para obtener las otras TMCs. 
3. Efecto del MOCR contralateral sobre la tasa de recuperación del enmascaramiento postestimulatorio

\section{Prueba del reflejo del oído medio}

Los sujetos que participan en los experimentos de este capítulo son los mismos que los que participaron en los experimentos descritos en el Capítulo 2. Es por esto que como se muestra en la Fig. 2.1, es posible descartar que el CWN active el MEMR. Sin embargo, podría ocurrir que las máscaras involucradas en las mediciones de las TMCs con niveles superiores a los $65 \mathrm{~dB}$ activaran el MEMR, tanto en presencia como en ausencia de CWN. En sí mismo, esto no supondría un problema, ya que aquí interesa el efecto diferencial del CWN. Resulta importante saber, sin embargo, si la magnitud del MEMR evocado por la máscara ipsilateral en combinación con el CWN es mayor que el evocado por la máscara sola. Para evaluar esta posibilidad, la prueba de control del MEMR detallada en el Capítulo 2 se realizó de nuevo empleando tonos de sonda de distinta intensidad hasta $80 \mathrm{~dB} S P L$, que es nivel más alto que el quipo utilizado puede generar sin presentar una distorsión significativa. En este caso, se utilizó un tono supresor de $80 \mathrm{~dB}$ SPL. El equipo y las condiciones de medición fueron idénticos a los descritos en el Capítulo 2.
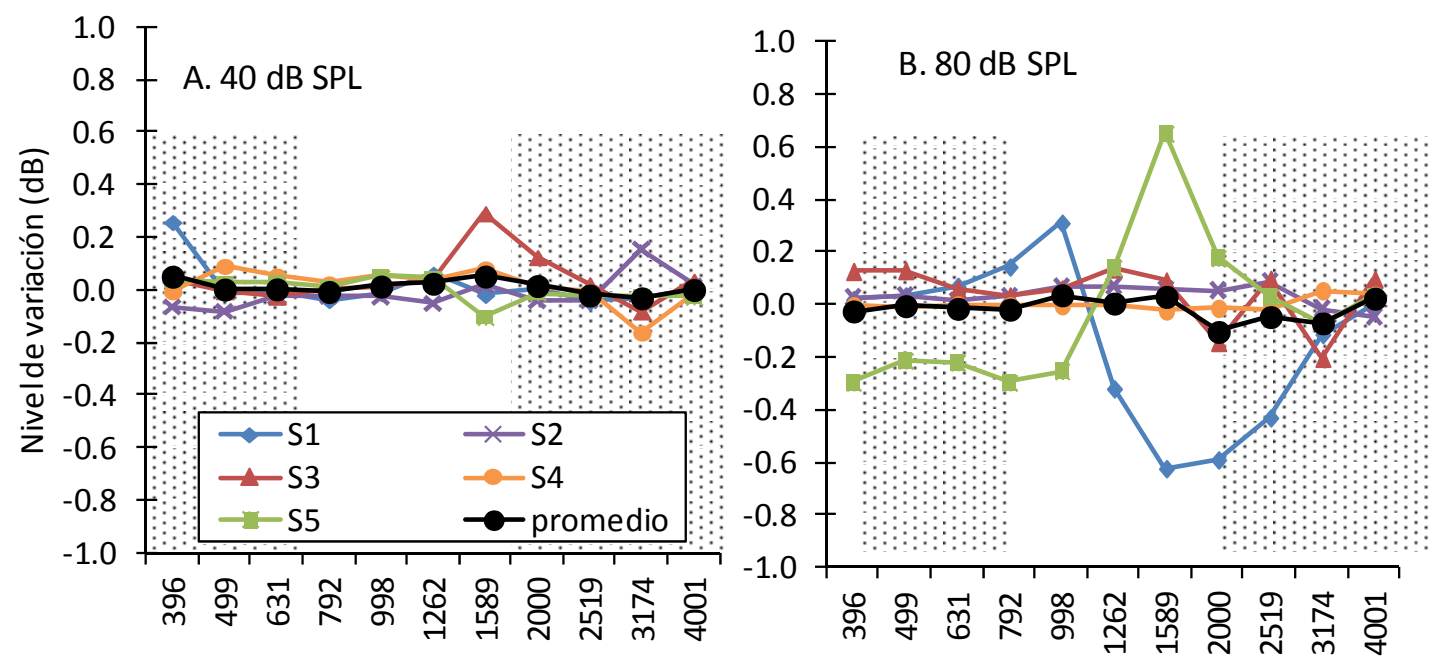

Frecuencia del tono sonda( $\mathrm{Hz})$

Figura 3.2. Variación de la admitancia de un tono sonda medido en el canal auditivo producto del CWN. Cada curva representa a un sujeto o al promedio. La variación se expresa como el nivel sonoro del tono medido en el CAE sin CWN menos el nivel medido con CWN. Un valor negativo indica que el CWN incrementa la impedancia del oído medio, presumiblemente por activación del MEMR. El área sombreada ilustra el rango de frecuencias de máscara utilizadas al medir las TMCs. A. Para un tono de sonda de $40 \mathrm{~dB}$ SPL. Esta figura es una reproducción de la Fig. 2.1. B. Para un tono sonda de $80 \mathrm{~dB}$ SPL. 


\section{Resultados}

\section{Control del reflejo del oído medio}

Si el CWN activase de manera significativa en MEMR, esto podría interferir en la interpretación de los resultados pues los efectos del MEMR se pueden confundir con los del MOCR. El objetivo de este experimento control fue descartar esta posibilidad. La Fig. 3.2A (reproducida de la Fig. 2.1) demuestra que el CWN (de $60 \mathrm{~dB}$ SPL) en combinación con tonos de $40 \mathrm{~dB}$ SPL no altera la admitancia del oído medio en el rango de frecuencias involucradas en la obtención de las TMCs (destacadas por las áreas sombreadas). Por lo tanto, el CWN en combinación con tonos de baja intensidad no activa el MEMR. La Fig. 3.2B muestra los resultados correspondientes empleando tonos de $80 \mathrm{~dB} S P L$, vale decir, tonos que podrían activar el reflejo MEM por sí solos o en combinación con el CWN. En este último caso, el CWN posiblemente activa el MEMR en los sujetos S1 y S5. Sin embargo, la magnitud de este efecto es muy pequeña $(<1 \mathrm{~dB}$ ) y ocurre en un rango de frecuencias (entre 1000 $\mathrm{Hz}$ y $2000 \mathrm{~Hz}$ ) que esta fuera del rango de interés en el presente estudio. Esto demuestra que los resultados que se presentan a continuación no están afectados por el MEMR.

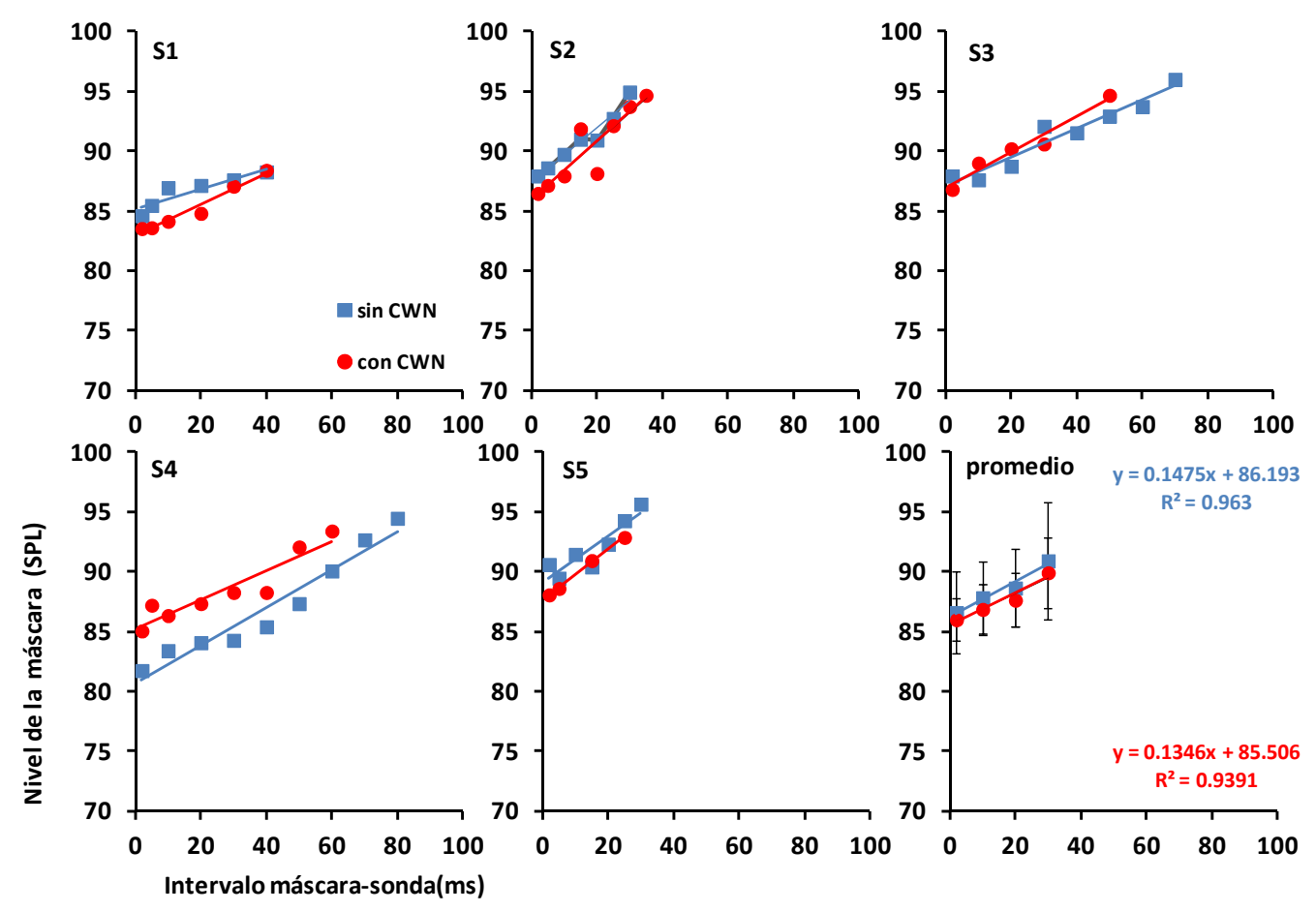

Figura 3.3. Tasa de recuperación post-mecánica del enmascaramiento post-estimulatorio con y $\sin$ CWN. La frecuencias del tono sonda y de la máscara fueron de $4000 \mathrm{~Hz}$ y $1600 \mathrm{~Hz}$, respectivamente. Cada panel ilustra los resultados de un sujeto o el promedio entre sujetos, tal y como se indica en el extremo superior izquierdo del panel. Las líneas representan funciones lineales ajustadas a los datos por el método de mínimos cuadrados. 
3. Efecto del MOCR contralateral sobre la tasa de recuperación del enmascaramiento postestimulatorio

\section{Efecto del CWN sobre la tasa de recuperación post-mecánica del enmascaramiento post-estimulatorio.}

La Fig. 3.3 muestra el efecto del CWN sobre la TMC de referencia lineal. Cuando se ajusta una línea recta a los datos, la pendiente de las líneas ajustadas a los datos obtenidos con y sin CWN para los 5 sujetos es prácticamente idéntica ( 0.13 and 0.14 $\mathrm{dB} / \mathrm{ms}$, respectivamente). Esta diferencia no es estadísticamente significativa ( $p=$ $0.16, N=5$, prueba $t$ pareada de una cola). Esto sugiere que el CWN no tiene un efecto sobre la tasa de recuperación post-coclear del enmascaramiento postestimulatorio y, por lo tanto, que cualquier efecto del CWN sobre las otras TMCs se deberá probablemente a que el CWN modifica la cantidad de compresión. Considerando que las fibras eferentes del haz LOC inervan a fibras aferentes del nervio auditivo, si el CWN activase las fibras LOC, el CWN podría cambiar la tasa de recuperación post-coclear del enmascaramiento post-estimulatorio. El presente resultado sugiere, por tanto, que cualquier efecto del CWN sobre las TMCs será el resultado de la activación de las fibras del haz MOC.

\section{Efecto del CWN sobre las TMCs}

Las Figs. 3.4 y 3.5 ilustran las TMCs obtenidas en presencia (círculos rojos) y en ausencia (cuadrados azules) de CWN, para sondas de 4000 y $500 \mathrm{~Hz}$, respectivamente. Cada columna muestra los resultados para un sujeto distinto y cada panel de una misma columna muestra las TMCs para una frecuencia de máscara diferente, tal y como se indica en la esquina superior izquierda del panel de la primera columna.

Un resultado que destaca es que, en consistencia con los efectos del CWN sobre el umbral auditivo (Capítulo 2), el efecto del CWN es más evidente en $500 \mathrm{~Hz}$ (Fig. 3.5) que en $4000 \mathrm{~Hz}$ (Fig. 3.4). También se observa a primera vista que la magnitud del efecto varía en función de la frecuencia de máscara y del intervalo máscara-sonda.

En $500 \mathrm{~Hz}$, se observa un resultado interesante. Como se puede observar en la Fig. 3.5, la dirección del efecto del CWN varía entre los sujetos, pudiendo distinguirse dos grupos: para los sujetos S1, S2 y S3, el CWN disminuye el umbral de la máscara; para los sujetos $\mathrm{S} 4$ y S5, por el contrario, el umbral de la máscara aumenta con el CWN. Esta inconsistencia en los resultados podría deberse a la distinta condición de excitación en la que fueron medidas las TMCs en presencia y ausencia de CWN. Es importante insistir en que se intentó medir las TMCs en condiciones de igual excitación del tono sonda. Es decir, el nivel de tono sonda en dB SPL fue diferente con y $\sin C W N$ e igual a $10 \mathrm{~dB}$ sobre el umbral del tono medido en cada caso. Sin embargo, la Tabla 3.1 muestra que el umbral del tono sonda fue prácticamente idéntico en presencia y en ausencia del CWN para los sujetos S1, S2 y S3. Esto se debe probablemente a que la reducción de la ganancia coclear inducida por el CWN fue pequeña e inferior a $2 \mathrm{~dB}$, que es la menor variación que puede ser captado por el método adaptativo utilizado. Por lo tanto, en estos sujetos se utilizó prácticamente un mismo nivel SPL para el tono sonda en presencia y en ausencia de CWN. 
Asumiendo que el CWN disminuye levemente la ganancia para $500 \mathrm{~Hz}$ (véase el Capítulo 2), el nivel de excitación causado por la sonda pudo ser menor en la condición con CWN que en la condición sin CWN en estos sujetos. En otras palabras, es posible e incluso probable, que para este grupo de sujetos las TMCs se hayan medido de forma efectiva en condiciones de igual nivel SPL (iso-SPL) y distinto nivel de excitación, a pesar de nuestros intentos por conseguir un mismo nivel de excitación. Lo contrario ocurriría con los sujetos S4 y S5, para quienes la disminución del umbral del tono sonda fue más evidente por lo que se pudo realizar la corrección de niveles sonoros de forma más eficaz a fin de obtener las TMCs en condiciones de igual nivel de excitación del tono sonda. En la sección de discusión de este capítulo se analiza con más detalle este resultado y se pone en evidencia que aunque aparentemente distintos, el patrón de los resultados para ambos grupos de sujetos es en realidad compatibles con un mismo efecto: el CWN reduce la ganancia coclear, tal y como ya se ha sugerido en el Capítulo 2.

\section{Efecto del CWN sobre las IOC psicoacústicas}

Con el objetivo de evaluar el efecto del CWN sobre la no linealidad de la respuesta periférica, se infirieron las IOCs a partir de las TMCs. Las IOCs resultantes para $4000 \mathrm{y}$ $500 \mathrm{~Hz}$ se muestran en la Fig. 3.6 y 3.7, respectivamente. Como era de esperar, al no inducir el CWN cambios importantes en las TMCs de $4000 \mathrm{~Hz}$ (Fig. 3.4) ni en la TMCs de referencia lineal (Fig. 3.3), las IOCs correspondientes son prácticamente idénticas en presencia y ausencia de CWN (Fig. 3.6). De hecho, un análisis cuantitativo de los parámetros de no linealidad obtenidos a partir de dichas curvas confirmó la ausencia de diferencias significativas (resultados no mostrados).

En $500 \mathrm{~Hz}$, por el contrario, el CWN sí causó un efecto evidente sobre las IOCs, como puede observarse en la Fig. 3.7. La Tabla 3.2 muestra los valores que pudieron obtenerse (para cada sujeto y cada frecuencia) del umbral de compresión, el umbral de retorno a la linealidad, la pendiente mínima y la pendiente media obtenidos en presencia y en ausencia de CWN, para esta frecuencia de $500 \mathrm{~Hz}$. Obsérvese que cuanto mayor es la pendiente de la IOC, menor es el grado de compresión. Una dificultad encontrada al momento de analizar las IOCs es que en algunos casos no fue posible obtener los umbrales de compresión y/o de retorno a la linealidad por encontrarse estos umbrales fuera del rango de intensidades de entrada que pudieron medirse. Los casos en cuestión se muestran como celdas vacías en la Tabla 3.2. A diferencia, sí fue posible obtener la pendiente mínima y la pendiente media en la mayoría de los casos. En la Tabla 3.2, los valores precedidos con el símbolo ' $<$ ' o '>' corresponden a los niveles sonoros de entrada mínimo y máximo, respectivamente, que pudieron medirse en la IOC correspondiente; valores que se encontraban en la zona de compresión. No representan, por tanto, valores umbrales. Los precedidos por el símbolo ' $<$ ' indican que el umbral de compresión estaba por debajo del valor mostrado y los precedidos por ' $>$ ' indican que el umbral de retorno a la linealidad estaba por encima del valor indicado. Así, al compararlos con su contrapartida (mismo sujeto, misma frecuencia, pero diferente condición) entregan información cualitativa del efecto del CWN sobre el umbral de compresión o de retorno a la 
3. Efecto del MOCR contralateral sobre la tasa de recuperación del enmascaramiento postestimulatorio

linealidad. Por ejemplo, no fue posible obtener el umbral de compresión para S4 en a $250 \mathrm{~Hz}$. Sin embargo, se observó que el mínimo nivel sonoro de entrada medido fue $67.7 \mathrm{~dB}$ SPL y que a ese nivel sonoro todavía había compresión. Por tanto, es muy probable que el verdadero umbral de compresión (que no se pudo obtener con esta técnica) fuese $<67.7 \mathrm{~dB} S \mathrm{SL}$, valor que es inferior al umbral de compresión obtenido con CWN (80.1 dB). Es decir, en este caso, pese a no obtener el verdadero umbral de compresión para las dos condiciones, sí es posible señalar que el CWN incrementó el umbral de compresión.

Los resultados de la Tabla 3.2 reflejan una clara tendencia a un incremento en el umbral de compresión en la condición con CWN en todas las frecuencias. También se observa una tendencia a una disminución del umbral de retorno a la linealidad con CWN. Estos resultados (incremento del umbral de compresión y disminución del umbral de retorno a la linealidad) son compatibles con una disminución del rango de niveles sonoros en el cual la IOC está sujeta a compresión. Vale decir, el CWN produce una reducción del rango dinámico de la compresión.

La Tabla 3.2 muestra además una marcada tendencia a una disminución de la pendiente mínima y de la pendiente media producto del CWN. Este efecto ocurre para todas las frecuencias. Para 350, 450 y $500 \mathrm{~Hz}$, fue posible obtener estas variables para los cinco sujetos, tanto en presencia como en ausencia de CWN. En estos casos, las diferencia entre la pendiente mínima fue estadísticamente significativa en las tres frecuencias ( $p<0.005$, prueba $t$ pareada de una cola, $N=5)$. La diferencia en la pendiente media fue significativa a $450 \mathrm{~Hz}(p<0.005$, prueba $t$ pareada de una cola, $N=5$ ). En general, estos resultados sugieren que el $C W N$ tiende a aumentar la pendiente de las IOCs, es decir, a reducir el grado de compresión.

En resumen, el CWN en general incrementa el umbral de compresión, reduce el umbral de retorno a la linealidad, y reduce la compresión máxima y la compresión media (i.e., incrementa la pendiente de la IOC). Se puede concluir, por tanto, que el CWN provoca, en general, una linealización de la IOC como se puede observar en la Fig. 3.8 


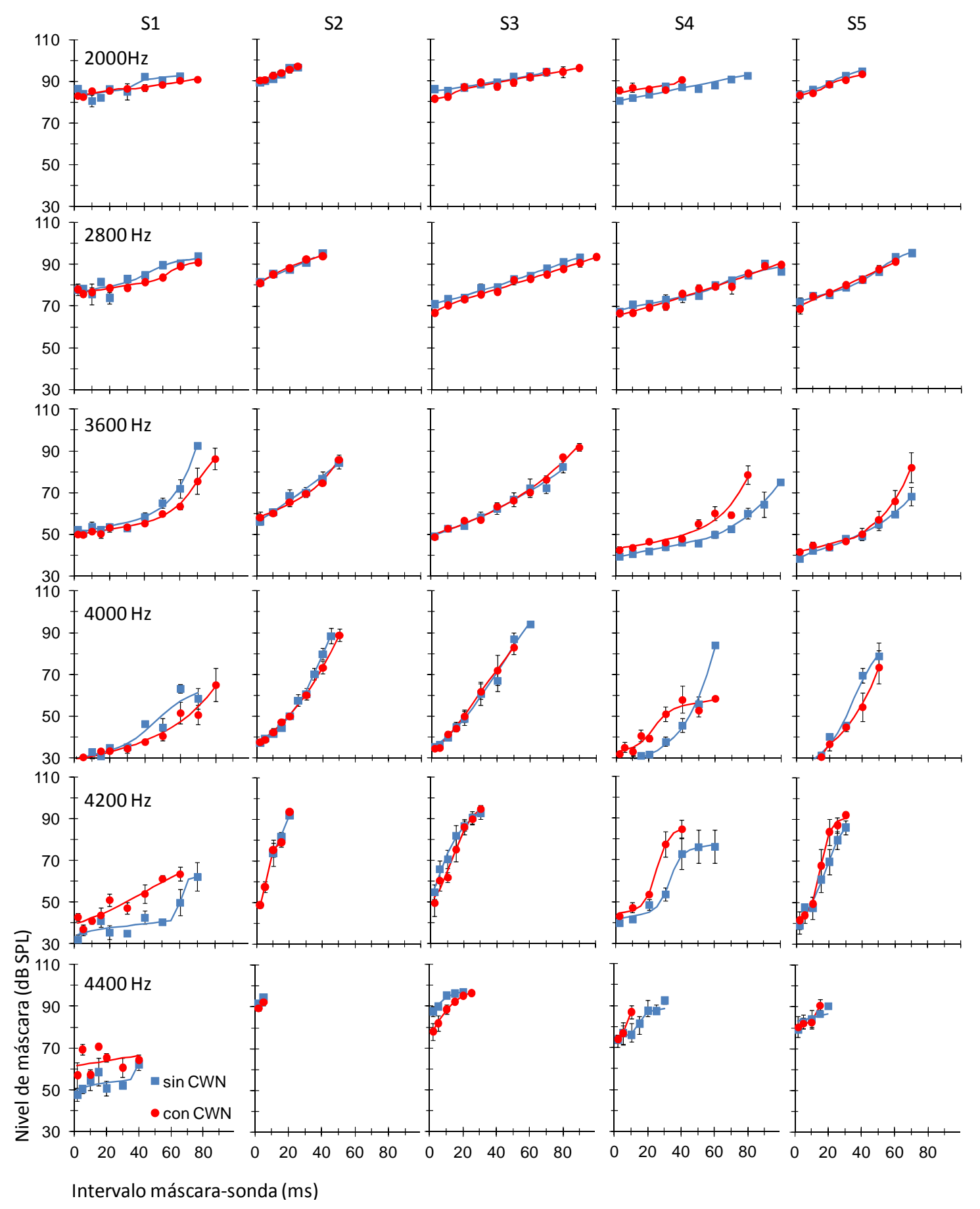

Figura 3.4. Efecto del CWN sobre las TMCs para un tono sonda de $4000 \mathrm{~Hz}$. Cada columna muestra las TMCs para un mismo un sujeto y cada panel las TMCs para una misma frecuencia de máscara, tal y como se indica en la esquina superior izquierda de la primera columna. Los símbolos rojos y azules ilustran las TMCs medidas en presencia y en ausencia de CWN, respectivamente. Las barras de error ilustran una desviación estándar. Las líneas continuas ilustran las funciones matemáticas ajustadas a los datos (véase las sección de Ajuste de las TMCs). 
3. Efecto del MOCR contralateral sobre la tasa de recuperación del enmascaramiento postestimulatorio

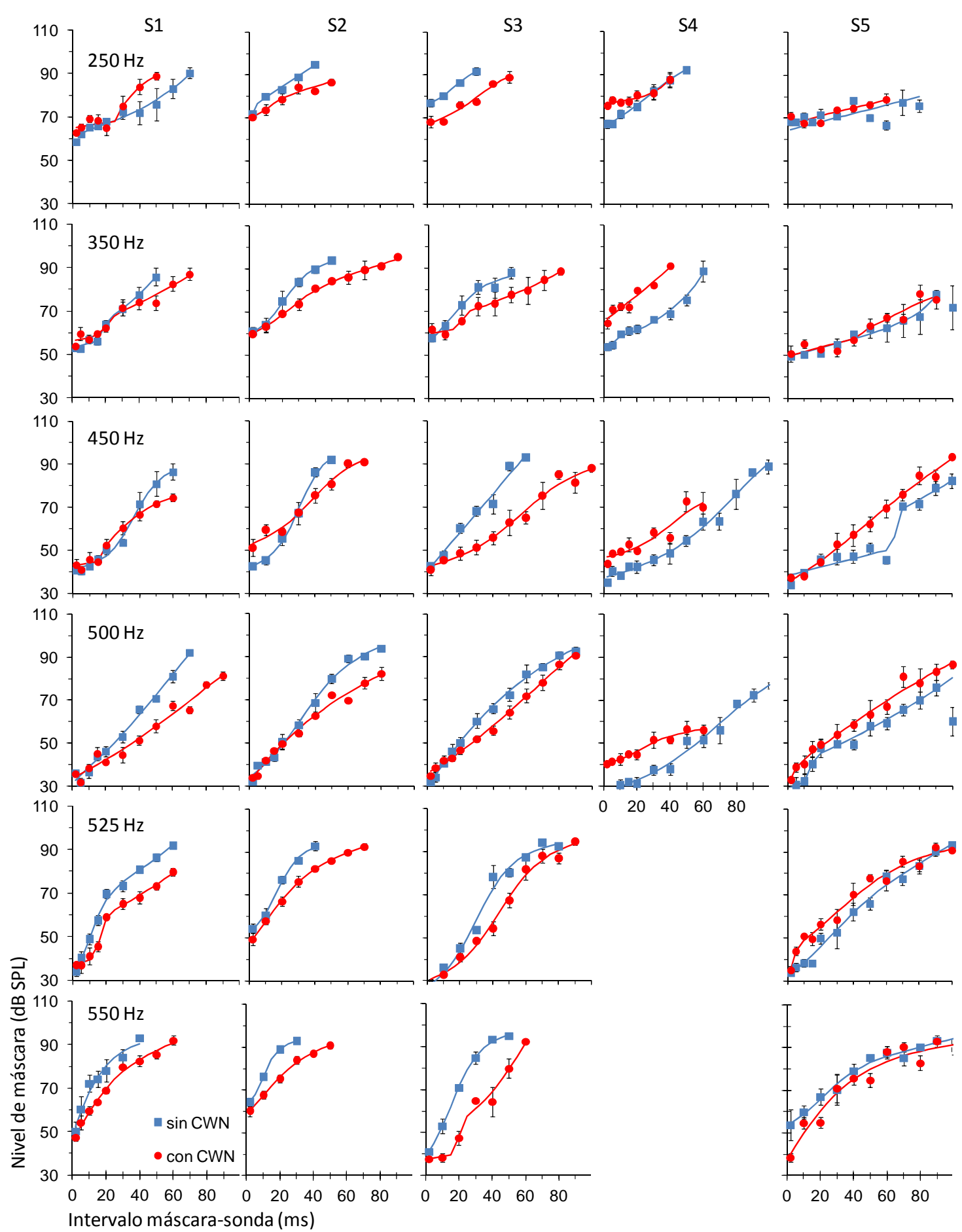

Figura 3.5. Igual que la Fig. 3.4 pero para un tono de sonda de $500 \mathrm{~Hz}$. Las TMCs de S4 para frecuencias de máscara de 525 y $550 \mathrm{~Hz}$ no se midieron por no disponibilidad del sujeto. 
S1

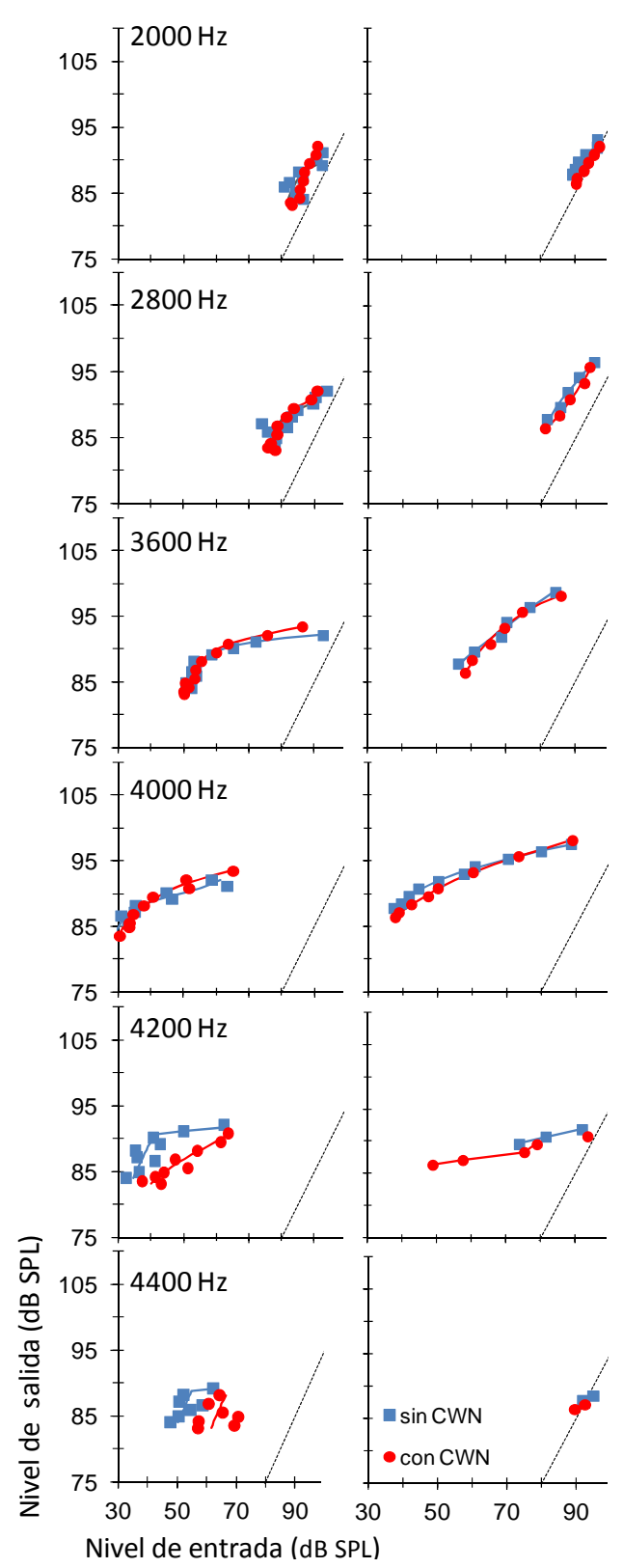

S3

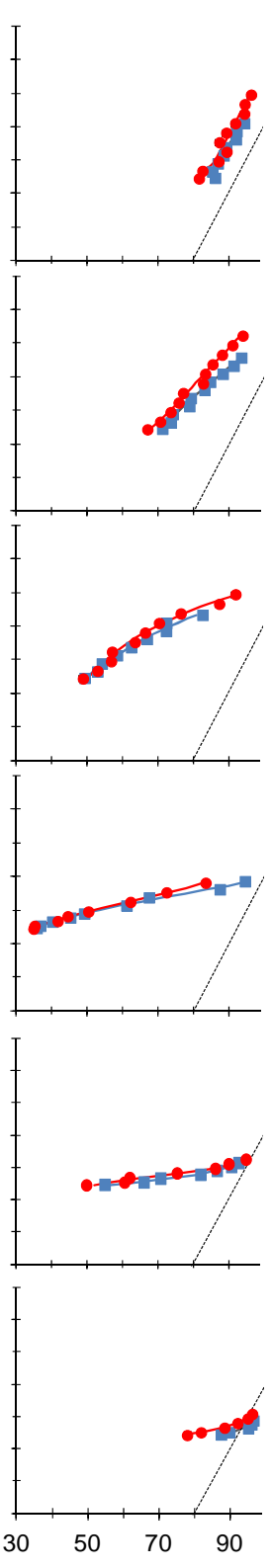

S4

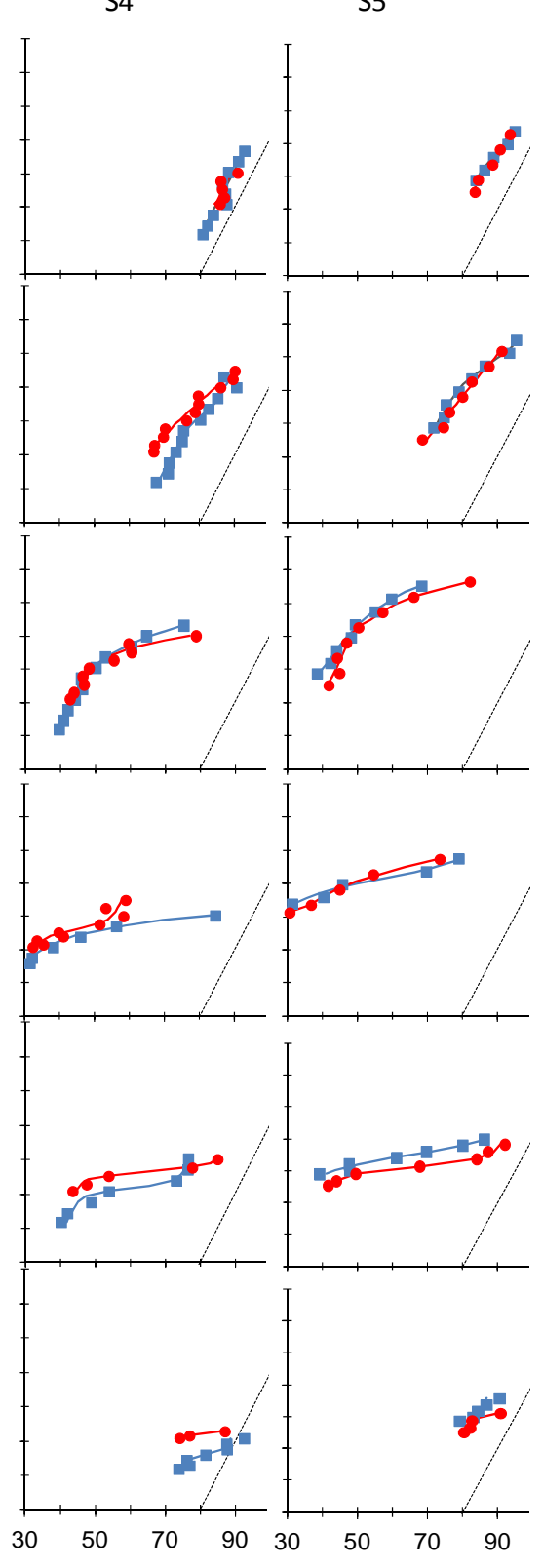


3. Efecto del MOCR contralateral sobre la tasa de recuperación del enmascaramiento postestimulatorio

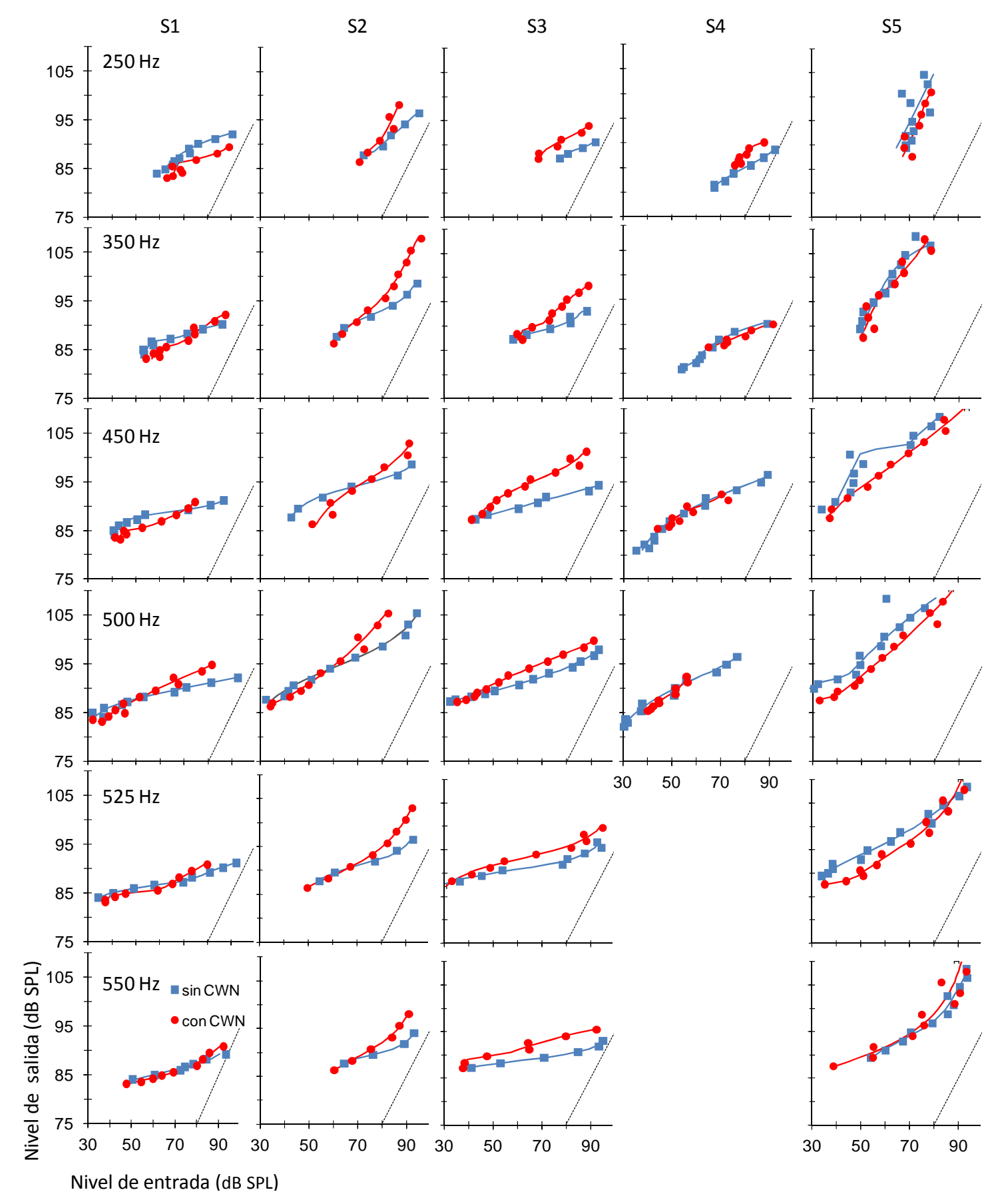

Figura 3.7. Igual que la Fig. 3.6 pero para una frecuencia de sonda de $500 \mathrm{~Hz}$. La ausencia de IOCs para S4 para frecuencias de máscara de 525 y $550 \mathrm{~Hz}$ se debe a que las correspondientes TMCs no se midieron por indisponibilidad del sujeto. 
Tabla 3.2. Efecto del CWN sobre el umbral de compresión (dB SPL), el umbral de retorno a la linealidad ( $d B S P L)$, la mínima pendiente de la $I O C(d B / d B)$ y la pendiente media $(d B / d B)$. Obsérvese que cuanto mayor es la pendiente, menor es la compresión. Las celdas vacías ilustran valores que no pudieron obtenerse por estar fuera del rango de niveles sonoros de entrada. d.i.: ilustran valores que no pudieron obtenerse por no disponer de suficientes puntos para ajustar la TMCs con las funciones matemáticas elegidas (véase la sección de Métodos). n.m.: no disponible porque la TMC correspondiente no se midió. n.a.: no aplicable porque la IOC correspondiente es recta con pendiente constante.

\begin{tabular}{|c|c|c|c|c|c|c|c|c|}
\hline & \multicolumn{2}{|c|}{ Umbral compresión } & \multicolumn{2}{|c|}{ Retorno linealidad } & \multicolumn{2}{|c|}{ Pendiente mínima } & \multicolumn{2}{|c|}{ Pendiente media } \\
\hline & $\sin C W N$ & con CWN & $\sin C W N$ & $\operatorname{con} C W N$ & $\sin C W N$ & con CWN & $\sin C W N$ & con CWN \\
\hline \multicolumn{9}{|c|}{$250 \mathrm{~Hz}$} \\
\hline S1 & 62.8 & 67.3 & 89.4 & 88.5 & 0.05 & 0.12 & 0.15 & 0.29 \\
\hline S2 & & 71.9 & $>94.6$ & 78.8 & 0.34 & 0.40 & 0.42 & 0.48 \\
\hline S3 & d.i. & 69.3 & d.i. & & d.i. & 0.22 & d.i. & 0.31 \\
\hline S4 & $<67.7$ & 80.1 & & & 0.26 & 0.14 & 0.32 & 0.35 \\
\hline S5 & n.a. & n.a. & n.a. & n.a. & 1.00 & 1.00 & 1.00 & 1.00 \\
\hline \multicolumn{9}{|c|}{$350 \mathrm{~Hz}$} \\
\hline S1 & 52.5 & & & & 0.04 & 0.29 & 0.13 & 0.29 \\
\hline S2 & $<60.4$ & 61.5 & 91.0 & 81.3 & 0.21 & 0.39 & 0.34 & 0.47 \\
\hline S3 & $<57.6$ & 59.6 & 86.0 & $>88.2$ & 0.13 & 0.35 & 0.25 & 0.38 \\
\hline S4 & 57.9 & & & & 0.13 & 0.20 & 0.33 & 0.22 \\
\hline S5 & n.a. & 61.3 & n.a. & 74.1 & 0.64 & 0.45 & 0.64 & 0.50 \\
\hline \multicolumn{9}{|c|}{$450 \mathrm{~Hz}$} \\
\hline S1 & 42.5 & 41.8 & 86.6 & 73.0 & 0.03 & 0.14 & 0.11 & 0.28 \\
\hline S2 & 44.1 & 56.3 & $>92.8$ & 89.8 & 0.13 & 0.30 & 0.26 & 0.41 \\
\hline S3 & $<42.2$ & 45.0 & & & 0.13 & 0.19 & 0.13 & 0.31 \\
\hline S4 & 40.6 & 49.0 & & & 0.20 & 0.21 & 0.31 & 0.32 \\
\hline S5 & & & 73 & $>92.2$ & 0.02 & 0.30 & 0.26 & 0.37 \\
\hline \multicolumn{9}{|c|}{$500 \mathrm{~Hz}$} \\
\hline S1 & & & & & 0.04 & 0.22 & 0.08 & 0.26 \\
\hline S2 & & & 92.3 & 77.1 & 0.21 & 0.26 & 0.32 & 0.40 \\
\hline S3 & & & & & 0.09 & 0.18 & 0.20 & 0.23 \\
\hline S4 & 29.2 & 41.6 & 77.3 & 53.2 & 0.23 & 0.30 & 0.33 & 0.41 \\
\hline S5 & & & 58.4 & $>87.2$ & 0.18 & 0.20 & 0.36 & 0.24 \\
\hline \multicolumn{9}{|c|}{$525 \mathrm{~Hz}$} \\
\hline S1 & $<33.9$ & 38.5 & & & 0.04 & 0.04 & 0.08 & 0.21 \\
\hline S2 & & & 91.1 & 85.2 & 0.15 & 0.24 & 0.27 & 0.34 \\
\hline S3 & $<28.5$ & 31.0 & 92.8 & $>93.7$ & 0.08 & 0.11 & 0.20 & 0.25 \\
\hline S4 & n.m. & n.m. & n.m. & n.m. & n.m. & n.m. & n.m. & n.m. \\
\hline S5 & & & 93.0 & 83.5 & 0.26 & 0.20 & 0.34 & 0.36 \\
\hline \multicolumn{9}{|c|}{$550 \mathrm{~Hz}$} \\
\hline S1 & & & & & 0.06 & 0.09 & 0.09 & 0.24 \\
\hline S2 & d.i. & & d.i. & 86.8 & d.i. & 0.26 & d.i. & 0.36 \\
\hline S3 & & & & & 0.06 & 0.10 & 0.16 & 0.16 \\
\hline S4 & n.m. & n.m. & n.m. & n.m. & n.m. & n.m. & n.m. & n.m. \\
\hline S5 & & & 83.2 & 80.4 & 0.26 & 0.17 & 0.36 & 0.32 \\
\hline
\end{tabular}


3. Efecto del MOCR contralateral sobre la tasa de recuperación del enmascaramiento postestimulatorio

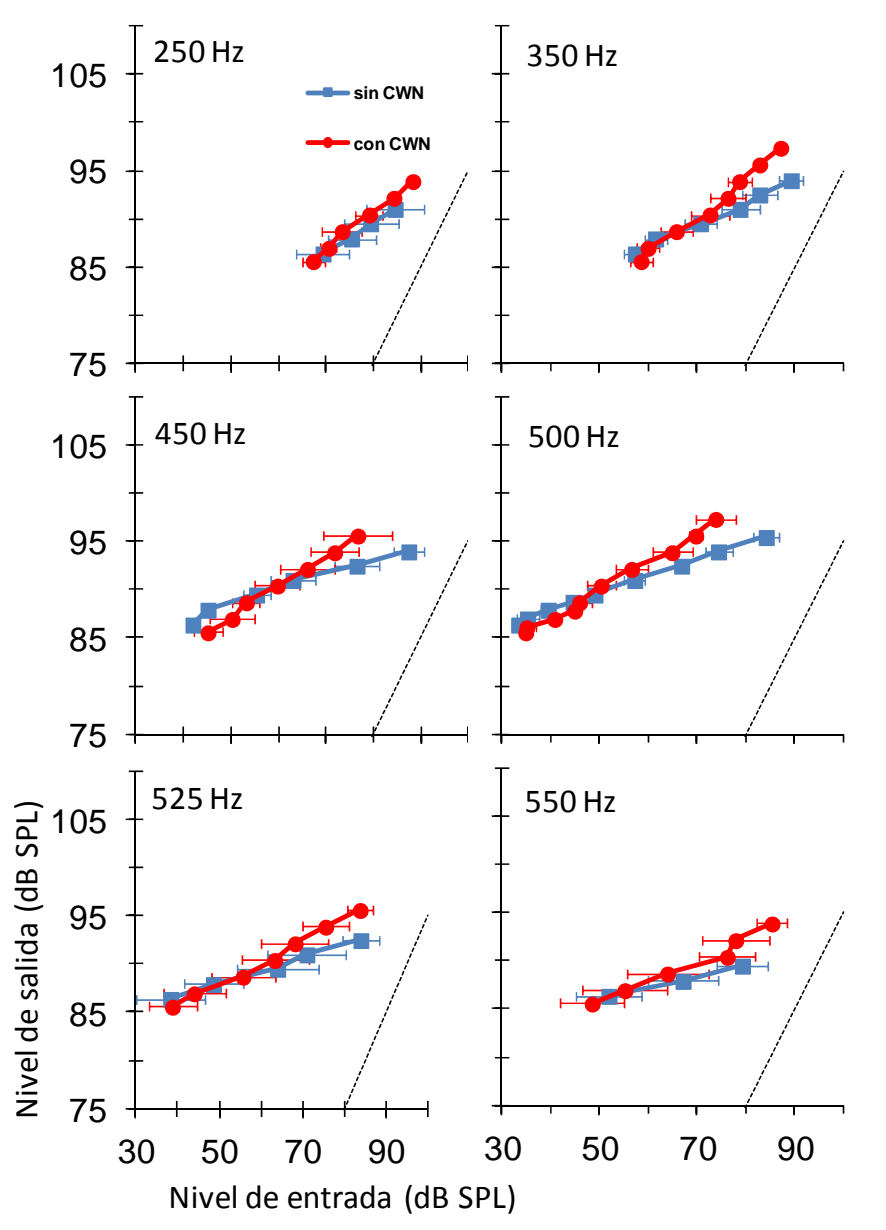

Figura 3.8. Efecto del CWN sobre las IOCs para la sonda de $500 \mathrm{~Hz}$. Se muestran las IOCs promedio de los tres sujetos (S1, S2 y S3) en los que las TMCs se tomaron utilizando sondas con prácticamente idénticos niveles SPL en presencia y en ausencia de CWN. Cada panel muestra las IOCs para un frecuencia de máscara, tal y como se indica en la esquina superior izquierda de cada panel. Los símbolos rojos y azules ilustran las IOCs inferidas a partir de las TMCs medidas en presencia y en ausencia de CWN, respectivamente. Solo se promediaron aquellos puntos en los que se tenían datos para los tres sujetos. Las líneas punteadas ilustran un comportamiento lineal (i.e., con pendiente de $1 \mathrm{~dB} / \mathrm{dB}$ ). Las barras de error horizontales ilustran el error estándar en los niveles de entrada.

\section{Discusión}

EI CWN no alteró significativamente la pendiente de la TMC de referencia lineal. Bajo el supuesto de que esta referencia lineal no está afectada por la compresión, este resultado sugiere que: $i$ ) la estimulación acústica contralateral no altera la tasa de recuperación neural; y ii) este resultado combinado con el hecho de que el CWN sí tiene un efecto sobre otras TMCs obtenidas con frecuencias de máscara más cercanas a la frecuencia de sonda (sobre todo a $500 \mathrm{~Hz}$, Fig. 3.5), sugiere que el efecto del CWN sobre estas otras TMCs, se debe a que el CWN modifica el grado de 
compresión periférica, probablemente por activación del MOCR.

El CWN, y presumiblemente también el MOCR, tiene un mayor efecto sobre las TMCs de $500 \mathrm{~Hz}$ que sobre las de $4000 \mathrm{~Hz}$. Este resultado es, por tanto, consistente con el mayor efecto del CWN sobre el umbral absoluto de detección de tonos puros de baja frecuencia descrito en el Capítulo 2.

El CWN y, por tanto, el MOCR, parece tener un efecto diferente sobre el umbral de las máscaras de las TMCs para unos sujetos que para otros. En este sentido, es posible diferenciar dos grupos de sujetos. En uno de los grupos (sujetos S1, S2 y S3), el CWN reduce, en general, el umbral de la máscara. En el otro grupo (sujetos S4 y S5), el CWN produce, en general, el efecto opuesto; es decir, eleva el umbral de la máscara. Probablemente, esta incongruencia es solo aparente. Ambos patrones podrían deberse a que, en realidad, el CWN reduce la ganancia coclear y, por tanto, la excitación coclear evocada por la sonda, pero el nivel de excitación lograda por el tono sonda en presencia y ausencia de CWN fue distinto en ambos grupos a pesar de nuestro intento por conseguir un mismo nivel de excitación.

La Fig. 3.9 sirve para ilustrar esta explicación. La Fig. 3.9 muestra IOCs cocleares esquemáticas para una frecuencia de $500 \mathrm{~Hz}$ en presencia (línea roja punteada) y en ausencia (línea azul continua) de CWN. Las curvas están basadas en el modelo de enmascaramiento post-estimulatorio con atenuación eferente descrito en el Capítulo 5 , que concuerda cualitativamente con lo observado en experimentos fisiológicos (Aguilar et al. 2013; Lopez-Poveda et al. 2013). La Fig. 3.9A ilustra lo que ocurriría cuando se utiliza un tono sonda con idéntico nivel SPL en presencia y en ausencia de CWN, como ha ocurrido en el primer grupo de sujetos (S1, S2 y S3, excepto S1 a 500 $\mathrm{Hz}$; Tabla 3.1). En este caso, el CWN disminuye el nivel de excitación del tono sonda levemente, disminución que probablemente no pudo detectarse por nuestro método adaptativo. Asumiendo que el enmascaramiento se produce cuando se sobrepasa una cierta relación de excitación máscara/sonda y que esta relación es constante y no varía producto de la activación del MOCR, entonces al disminuir el nivel de excitación del tono sonda, el nivel de excitación necesario que debe provocar la máscara disminuirá proporcionalmente. Es decir, a igual SPL de sonda, se requerirá un menor nivel de máscara en presencia del $C W N$, que es lo que ocurre para los sujetos S1, S2 y S3.

La Fig. 3.9B ilustra lo que ocurriría cuando se incrementa el nivel SPL del tono sonda con el objetivo de obtener una igual excitación del tono sonda en presencia y en ausencia de CWN. Al igual que en el caso anterior, en este caso el CWN también disminuye el nivel de excitación del tono sonda, por lo que si se quiere mantener un nivel de excitación idéntico en ambas condiciones, se debe incrementar el nivel SPL de la sonda cuando la TMC se mide con CWN. Como el nivel de excitación del tono sonda es virtualmente idéntico con y $\sin C W N$, el nivel de excitación que debe generar la máscara es también idéntico en ambas condiciones. Para conseguir un mismo nivel de excitación de máscara, es necesario utilizar un mayor nivel de la máscara con CWN que sin CWN, que es lo que ocurre generalmente para los sujetos 
3. Efecto del MOCR contralateral sobre la tasa de recuperación del enmascaramiento postestimulatorio

S4 y S5.

En resumen, es posible que a pesar de intentarlo, no hayamos sido capaces de conseguir tonos sonda que provoquen idénticos niveles de excitación coclear con y $\sin$ CWN. Esto demuestra que es difícil obtener TMCs en condiciones de isoexcitación en presencia y ausencia de CWN. Esta dificultad se debe a que la reducción de la ganancia coclear inducida por el CWN puede ser muy pequeña en algunos sujetos, menor que la precisión con la que se mide el umbral absoluto de la sonda, lo que puede ocasionar que se subestime el efecto reductor de la ganancia (como ha ocurrido probablemente para los sujetos S1, S2, y S3). Por lo tanto, es prudente sugerir que, en el futuro, este tipo de mediciones psicoacústicas se realicen en condición de iso-SPL y posteriormente se analicen los resultados con un modelo matemático-computacional que permita comprender y analizar el efecto cualitativo y cuantitativo del CWN, y por tanto del MOCR, sobre la respuesta mecánica coclear (cf. Capítulo 5).

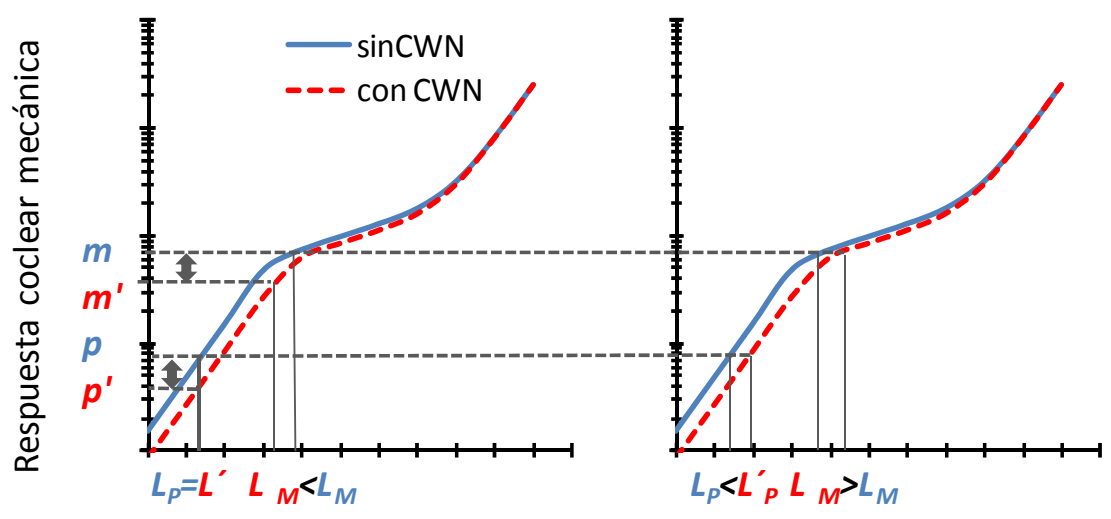

Nivel de entrada $(\mathrm{dB})$

Figura 3.9. Diagrama de apoyo para explicar el efecto del CWN sobre las TMCs medidas en condición de iso-SPL (A) o iso-excitación (B). Este diagrama se basa en el modelo computacional descrito en el Capítulo 5 del efecto del MOCR sobre la IOC coclear para la frecuencia de $500 \mathrm{~Hz}$. Cada panel representa el nivel de excitación relativo sobre el receptor auditivo en presencia (línea roja discontinua) y en ausencia (línea azul continua) de CWN. $L_{p}$ y $L_{p}^{\prime}$ representan el nivel sonoro del tono sonda en ausencia y en presencia de CWN respectivamente. $p$ y $p^{\prime}$ representan la excitación mecánica (coclear) producida por el tono sonda en ausencia y en presencia de CWN, respectivamente. $L_{M}$ y $L_{M}^{\prime}$ representan el nivel de la máscara necesario para enmascarar al tono sonda en ausencia y en presencia de CWN respectivamente. $m$ y $m^{\prime}$ representan el nivel de excitación mecánica que debe provocar la máscara sobre para enmascarar al tono de sonda en ausencia y presencia de CWN, respectivamente

Es importante destacar que la dificultad para conseguir sondas que produzcan idéntica excitación con y sin CWN puede haber afectado a los niveles sonoros de salida de las IOCs pero no a las pendientes de estas curvas. Es decir, los parámetros 
mostrados Tabla 3.2 y su análisis no están afectados por esta dificultad.

Como se puede desprender de lo mostrado por la Fig. 3.9 el efecto del CWN sobre tasa de recuperación del enmascaramiento post-estimulatorio puede ser explicado por una linealización de la función de entrada/salida del receptor auditivo. Esta linealización es provocada por un incremento del umbral de compresión, una disminución del umbral de retorno a la linealidad (lo que trae consigo una disminución del rango de compresión) y un incremento de la pendiente de la IOC. Este efecto ocurre para todas las frecuencias de máscara de la IOC de $500 \mathrm{~Hz}$. Este fenómeno, podría ser el correlato psicoacústico del efecto "desenmascarante" observado sobre las fibras del nervio auditivo producto de la activación del haz MOC en presencia de ruido de fondo (Kawase et al. 1993; Winslow y Sachs 1987). Los resultados aquí presentados son compatibles con lo observado en humanos por (Bhagat y Carter 2010), quienes observaron un incremento en el umbral de compresión de las DPOAE, producto de la estimulación acústica contralateral.

La linealización de la IOC podría facilitar la detección de un estímulo transitorio, mediante una mejoría en la resolución temporal. Existe evidencia psicoacústica que sugiere que esta función del MOCR es real. Se ha observado una relación entre la magnitud del efecto del CWN sobre el umbral de compresión (Bhagat y Carter 2010) o la disminución de la amplitud (Micheyl y Collet 1996) y la capacidad de detectar un tono en presencia de ruido. Es decir, una relación inversa entre la magnitud del efecto del CWN sobre las OAEs y la capacidad enmascarante del ruido.

Considerando que la voz es un estímulo transitorio, es posible sugerir que el MOCR contribuye a facilitar la detección del habla en ambiente ruidoso pues mediante esta linealización podría mejorar la resolución temporal de este estímulo. Diversos estudios se han planteado como objetivo evidenciar este fenómeno, pero con poco o ningún éxito. Considerando que los presentes resultados psicoacústicos sugieren que la magnitud del efecto varía en función de la región coclear estudiada (es considerablemente mayor a 500 que a $4000 \mathrm{~Hz}$ ), es posible que la mejoría esperable este limitada a algunas frecuencias.

\section{Conclusiones}

1. El efecto de la estimulación acústica contralateral y, por tanto, del MOCR contralateral, sobre la tasa de recuperación del enmascaramiento postestimulatorio es mayor a 500 que a $4000 \mathrm{~Hz}$.

2. La estimulación acústica contralateral y, por tanto, el MOCR contralateral, no altera la tasa de recuperación post-mecánica del enmascaramiento postestimulatorio.

3. El efecto de la estimulación acústica contralateral y, por tanto, del MOCR contralateral, es compatible con una reducción de la ganancia y una linealización de la respuesta coclear. 


\section{Capítulo 4}

\section{Efecto del MOCR contralateral sobre las curvas de sintonización psicoacústicas ${ }^{1}$}

\section{Introducción}

Los humanos tenemos la habilidad (parcial) de percibir por separado los múltiples componentes en frecuencia de un estímulo auditivo complejo. Esta propiedad, denominada selectividad frecuencial, tiene su origen en la selectividad en frecuencia otorgada por la membrana basilar (BM) de la cóclea (Shera et al. 2002) (Evans 2001). Esta propiedad, depende del funcionamiento de las CCEs (Robles y Ruggero 2001). Las neuronas del haz MOC inervan y transmiten información que permite controlar la sensibilidad y sintonización de la membrana basilar Cooper (Cooper y Guinan 2006; Murugasu y Russell 1996; Russell y Murugasu 1997). El reflejo MOCR contralateral puede ser activado por la presencia de estimulación acústica contralateral (Guinan 2006; Guinan 2010). Por tanto, la sintonización coclear puede cambiar de manera dinámica en una condición de escucha binaural.

Las PTCs (Small 1959) constituyen una aproximación cercana a la sintonización de la membrana basilar y a las curvas de sintonización de las neuronas del ganglio coclear Moore (Evans 2001; Kluk y Moore 2004; Lopez-Poveda et al. 2007; O'Loughlin y Moore 1981; Shera et al. 2002), incluso considerando que se trata de una técnica psicoacústica en donde están involucrados la mayoría de los componentes del sistema auditivo. Por tanto, el rol y la importancia del MOCR contralateral sobre la sintonización coclear humana pueden evaluarse midiendo la PTC en presencia y en ausencia de estimulación acústica contralateral. Algunos estudios han utilizado esta técnica y reportan mayores efectos en las colas (frecuencias lejanas a la frecuencia del tono sonda) que en la punta de la PTC (frecuencias cercanas de la frecuencia de

\footnotetext{
${ }^{1}$ Este capítulo está adaptado de un artículo científico ya publicado (Aguilar et al. 2013).
} 
la sonda) (Kawase et al. 2000; Quaranta et al. 2005; Vinay y Moore 2008). Aparentemente, este resultado es inconsistente con la evidencia fisiológica de que la activación eferente afecta sobre todo a la punta de las curvas de sintonización coclear (Guinan 2006; Guinan 2010). De hecho, existe evidencia psicoacústica en humanos (Jennings y Strickland 2012b; Jennings et al. 2009; Kawase et al. 2000; Strickland 2001) compatible con el efecto reductor de la ganancia descrito en experimentos fisiológicos (véase el Capítulo 1). Sin embargo, la magnitud del efecto es pequeña y su dirección no es siempre consistente entre los estudios.

Es posible argumentar que las condiciones usadas en los estudios psicoacústicos previos son insuficientes para revelar adecuadamente el efecto del MOCR contralateral. De hecho, los estudios realizados hasta la fecha, se han enfocado a medir el efecto sobre las PTCs a niveles cercanas al umbral. Considerando que el efecto eferente sobre la sintonización dependen del nivel sonoro (Cooper y Guinan 2006), el efecto de la estimulación acústica contralateral sobre las PTCs podría ser mayor para PTCs medidas en condiciones supra-umbrales. Además, con una única excepción (Vinay y Moore 2008), los estudios previos se han enfocado en la región de $1000 \mathrm{~Hz}$, donde el MOCR contralateral podría ser menor que a frecuencias más graves (Francis y Guinan 2010; Lilaonitkul y Guinan 2009a; Lilaonitkul y Guinan 2009b; Lilaonitkul y Guinan 2012).

El objetivo de este capítulo es caracterizar el efecto de la estimulación acústica contralateral sobre las PTCs medidas a nivel umbral y a nivel supra-umbral. Se emplean tonos sonda de 500 y $4000 \mathrm{~Hz}$ con el objetivo de caracterizar el efecto del MOCR sobre la selectividad frecuencial en el ápex y en la base de la cóclea humana. Aunque ya se ha demostrado en el Capítulo 3 que el CWN probablemente no altera la tasa de recuperación post-mecánica en el enmascaramiento post-estimulatorio, aquí se realizó un experimento control para confirmar este hecho. Repetir este control se consideró necesario ya que a diferencia del procedimiento empleado el medir las TMCs, aquí las PTCs se midieron empleando tonos sonda con idéntico nivel SPL en presencia y en ausencia de CWN.

\section{Materiales y métodos}

El principal experimento realizado consiste en presentar a los sujetos un tono sonda breve precedido de un tono enmascarante de mayor duración, y medir el nivel sonoro umbral de la máscara necesario para enmascarar al tono sonda. La representación gráfica del umbral de la máscara en función de distintas frecuencias de máscara es llamada PTC (Small 1959).

El CWN es efectivo para activar el MOCR contralateral (Capítulos 2 y 3). Por lo tanto, el efecto del MOCR contralateral se evalúa midiendo las PTCs en presencia y en usencia de CWN. El nivel del tono sonda se fijó unos pocos decibelios sobre el umbral de detección de dicho tono medido en ausencia de máscara y de CWN. Es importante destacar que, por lo tanto, las PTCs en presencia y ausencia de CWN se midieron con un tono de sonda de igual nivel SPL (condición iso-SPL). La intensidad 
del CWN se fijó a 60 dB SPL porque este nivel es suficiente para activar el MOCR contralateral e insuficiente para desencadenar el reflejo del oído medio (Lilaonitkul y Guinan 2009a; Lilaonitkul y Guinan 2009b).

En la condición de enmascaramiento post-estimulatorio, si el tono de sonda esta fijo en frecuencia e intensidad, el umbral de la máscara depende directamente del intervalo máscara-sonda. Por lo tanto, un incremento en el intervalo máscara-sonda facilita la detección de la sonda con el consiguiente incremento en el umbral de la máscara. Por lo tanto, bajo el supuesto de que la tasa de recuperación neural es independiente de la frecuencia de máscara, es posible evaluar la sintonización coclear a distintos niveles midiendo PTCs para distintos intervalos máscara-sonda. Aquí, se evalúa el efecto del CWN sobre las PTCs a un nivel cercano al umbral (intervalo máscara-sonda de $2 \mathrm{~ms}$ ) y a niveles supra-umbrales (intervalos máscarasonda de 10, $3050 \mathrm{~ms}$ ).

La tasa de recuperación del enmascaramiento post-estimulatorio se asume que depende simultáneamente de la respuesta coclear mecánica evocada por la máscara y de la tasa de recuperación post-mecánica de la excitación coclear (Nelson et al. 2001; Oxenham y Moore 1994). El CWN probablemente altera la respuesta coclear. Por lo tanto, es razonable sugerir que puede cambiar la tasa de recuperación del enmascaramiento post-estimulatorio (Krull y Strickland 2008). Una suposición implícita en este esquema de investigación es el CWN no altera la componente postmecánico de la tasa de recuperación del enmascaramiento post-estimulatorio (véase el Capítulo 3). No obstante aquí se realizó un experimento control para confirmar este supuesto.

\section{Estímulos y parámetros}

La fundamentación de los estímulos y los parámetros utilizados para medir las PTCs ya se desarrollado en el Capítulo 1.

La Fig. 4.1 muestra un esquema de los distintos parámetros de estimulación utilizados para medir las PTCs en presencia y en ausencia de CWN. Las PTCs se midieron usando tonos sonda con frecuencias de 500 y $4000 \mathrm{~Hz}$. La intensidad del tono sonda fue de $10 \mathrm{~dB} S \mathrm{SL}$ aproximadamente. La duración de la sonda fue de $10 \mathrm{~ms}$, con rampas de ataque/soltura de tipo coseno de $5 \mathrm{~ms}$ duración, sin meseta. Cada una de las PTCs se consiguió midiendo el umbral para 10 tonos puros empleados como máscaras con frecuencias de $0.5,0.7,0.8,0.9,0.95,1.0,1.05,1.1,1.2,1.3 \times f_{\mathrm{p}}$. La duración de las máscaras fue de $200 \mathrm{~ms}$ rampas ataque/soltura de tipo coseno de 5 ms de duración. Se midieron PTCs para intervalos máscara-sonda (definidos entre el final de la sonda y el inicio de la máscara) de 2, 10, 30 y 50 ms.

Considerando las propiedades del ruido como evocador del MOCR contralateral y para obtener una adecuada activación del MOCR sin desencadenar el MEMR, se empleó un CWN de 60 dB SPL (véase el Capítulo 2 y 3). El CWN 500 ms antes del inicio de la máscara (duración suficiente para evocar el MOCR) y su duración total 
fue de $1210 \mathrm{~ms}$.

Los estímulos se generaron con el mismo equipo y en las mismas condiciones que los utilizados para medir las TMCs (véase el Capítulo 3). La única diferencia destacable, sin embargo, es que las TMCs se intentaron medir empleando sondas de igual excitación con y sin CWN (iso-excitación) para lo cual en algunos casos se emplearon sondas con diferente nivel SPL en ambas condiciones, mientras que aquí las PTCs se miden empleando un tono sonda de idéntico nivel SPL en ambas condiciones.
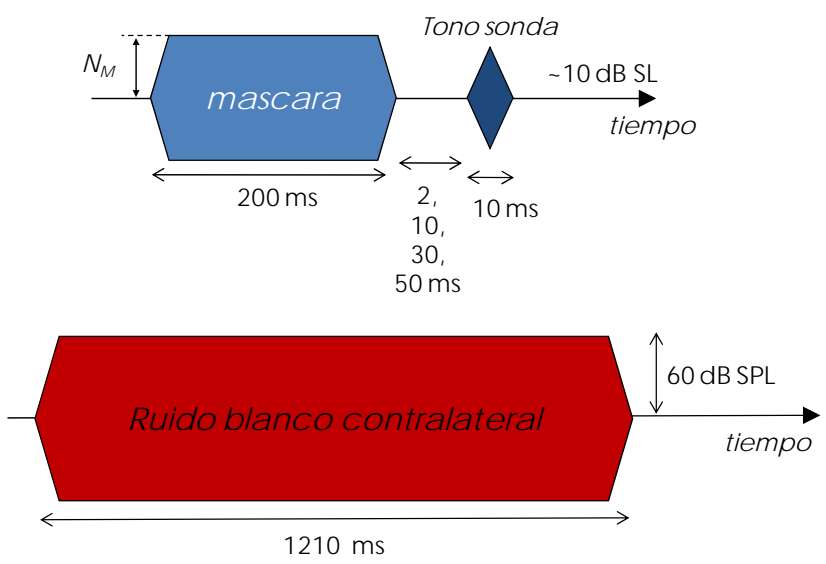

Figura 4.1. Representación esquemática de los estímulos y parámetros utilizados para medir las PTCs.

\section{Sujetos}

En este experimento participaron cinco voluntarios normoyentes: dos mujeres (S1 y S4) y tres hombres (S2, S3, S5), con edades (en años) de 31 (S1), 31 (S2), 43 (S3), 27 (S4), and 25 (S5). Previo a su inclusión en el estudio, a todos ellos se les realizó una audiometría tonal para descartar pérdidas auditivas. Los sujetos participaron en el estudio de forma voluntaria y no se les retribuyó por su servicio. No todos los sujetos participaron en todas las medidas. A los sujetos S1, S2 y S3 se les midieron PTCs para intervalos máscara-sonda de 2, 10, 30 y 50 ms; a los sujetos S4 y S5, sin embargo, sólo se les midieron PTCs para intervalos de máscara-sonda de 2 ms (PTC umbral).

\section{Procedimiento para medir las PTCs}

Los procedimientos para medir las PTCs y el equipamiento utilizado fueron idénticos empleados para la medir las TMCs (descritos en el Capítulo 3), exceptuando que aquí la frecuencia de máscara es la variable independiente y el intervalo máscara-sonda es el parámetro.

\section{Umbrales del tono sonda}

Los umbrales de los tonos sonda se midieron ( $\sin \mathrm{CWN}$ ) usando los procedimientos y 
equipamiento descritos en el Capítulo 2. Los umbrales absolutos para la sonda de $500 \mathrm{~Hz}$ fueron 23 (S1), 19 (S2), 21 (S3), 21 (S4), and 18 (S5) dB SPL, respectivamente. Los umbrales absolutos de la sonda de $4000 \mathrm{~Hz}$ fueron 18 (S1), 23 (S2), 20 (S3), 14 (S4), 13 (S5) dB SPL, respectivamente.

\section{Prueba de la tasa de recuperación post-mecánica del enmascaramiento post- estimulatorio}

En el Capítulo 3, se demostró que el CWN no cambia la tasa de recuperación postmecánica del enmascaramiento post-estimulatorio. No obstante, aquí se repitió el experimento control evaluando en una condición de iso-SPL. Esta medición es importante para determinar la ventana temporal del modelo de percepción auditiva que se presenta en el capítulo 5. El test se aplicó a los tres sujetos (S1, S2, S3) a los que se midieron PTCs supra-umbrales y se realizó siguiendo la metodología descrita en el Capítulo 3.

\section{Resultados}

\section{Efecto del CWN sobre la tasa de recuperación post-mecánica del enmascaramiento post-estimulatorio}

Los símbolos de la Fig. 4.2 ilustran las funciones de recuperación promedio (TMCs de referencia lineal) medidas con y sin CWN; las líneas continuas correspondientes ilustran líneas rectas ajustadas a los datos por el método de mínimos cuadrados. Como se puede observar, las dos rectas ajustadas tienen prácticamente idénticas pendientes $(0.16 \mathrm{~dB} / \mathrm{ms})$ y la diferencia no es estadísticamente significativa. Asumiendo que el efecto del CWN fue evocar el MOCR contralateral, este resultado sugiere que el MOCR no tiene efecto sobre la tasa de recuperación post-mecánica del enmascaramiento post-estimulatorio. En otras palabras, se sugiere que cualquier efecto del CWN sobre las PTCs puede ser con certeza el resultado de un cambio en la respuesta coclear. Este resultado confirma, por tanto, las conclusiones del Capítulo 3.

La Fig. 4.2 sugiere además que el CWN reduce los niveles sonoros de la TMC referencia lineal en $\sim 1.12 \mathrm{~dB}$. Esto es consistente con el efecto esperado por la activación del MOCR contralateral: una reducción de la ganancia coclear que reduce la respuesta al tono sonda (Capítulo 3). La magnitud del efecto, sin embargo, no es estadísticamente significativa ni consistente entre los sujetos, de hecho es menor que el rango mínimo usado en los pasos del procedimiento adaptativo utilizado para medir el umbral de máscara ( $2 \mathrm{~dB}$ ). Esto sugiere, por tanto, que el CWN no activa el MOCR contralateral a $4000 \mathrm{~Hz}$ o bien, que su efecto sobre el tono sonda de intensidad fija de $4000 \mathrm{~Hz}$ es tan pequeño que se hace indetectable por la técnica empleada. Hay estudios fisiológicos que demuestran que $60 \mathrm{~dB}$ SPL es suficiente para evocar la activación del MOCR contralateral en $4000 \mathrm{~Hz}$ (Lilaonitkul y Guinan 2009a). Por tanto, la segunda explicaciones más plausible. 


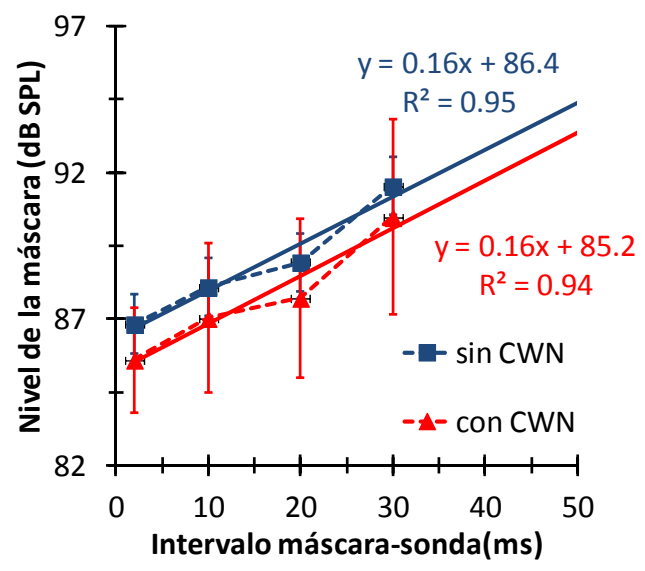

Figura 4.2. Tasa de recuperación postmecánica del enmascaramiento postestimulatorio con y sin CWN. La frecuencia del tono sonda y del tono máscara utilizadas son 1600 y $4000 \mathrm{~Hz}$, respectivamente. Las símbolos representan los umbrales promedios de las máscaras. Las líneas continuas representan un ajuste lineal a los datos experimentales con sus correspondientes ecuaciones.

\section{Efecto del CWN sobre las PTCs a nivel umbral}

La Fig. 4.3 muestra el efecto del CWN sobre las PTCs para un intervalo máscarasonda de $2 \mathrm{~ms}$; una condición que proporciona niveles sonoros cercanos al umbral. El CWN no tiene un efecto significativo a $4000 \mathrm{~Hz}$. A $500 \mathrm{~Hz}$, el CWN no cambia los niveles de máscara cercanos a la frecuencia de sonda, pero reduce el umbral de la máscara en las dos colas de las PTCs en todos los sujetos. En promedio, la reducción (mostrado en la Fig. 4.6) fue 5.1 y $5.8 \mathrm{~dB}$ para las frecuencias de máscara de 250 y $600 \mathrm{~Hz}$, respectivamente, y fue estadísticamente significativa (prueba $t$ pareada de una cola, $N=5 ; p=0.001$ y $p=0.0024$ para las frecuencias de $250 \mathrm{~Hz}$ y $600 \mathrm{~Hz}$ respectivamente). Por tanto, el efecto del CWN fue una leve disminución de la sintonización de la PTC de $500 \mathrm{~Hz}$ medida a niveles cercanos al umbral.

Estos resultados difieren de los del estudio de (Vinay y Moore 2008). Estos autores observan que un ruido de banda estrecha de $60 \mathrm{~dB}$ SPL tiene un efecto diferente sobre las PTCs dependiendo de la frecuencia del tono sonda. A $4000 \mathrm{~Hz}$, el ruido reduce el umbral de las máscaras sólo en las colas de la PTC sin alterar el nivel sonoro en la punta de la PTC. Este resultado a $4000 \mathrm{~Hz}$ es cualitativamente consistente con los presentes resultados a $500 \mathrm{~Hz}$. En la frecuencia de $500 \mathrm{~Hz}$, sin embargo, Vinay y Moore (2008) encuentran que el ruido contralateral incrementa el umbral de la máscara en la cola de las frecuencias graves, es decir, lo opuesto a los resultados del presente experimento. Por otro lado, sin embargo, los resultados de la Fig. 4.3 a $500 \mathrm{~Hz}$ son cualitativa y cuantitativamente consistentes con los de Kawase et al. (2000) en la frecuencia de $2000 \mathrm{~Hz}$, ya que estos autores observan una reducción del umbral de la máscara en ambas colas de las PTCs. 


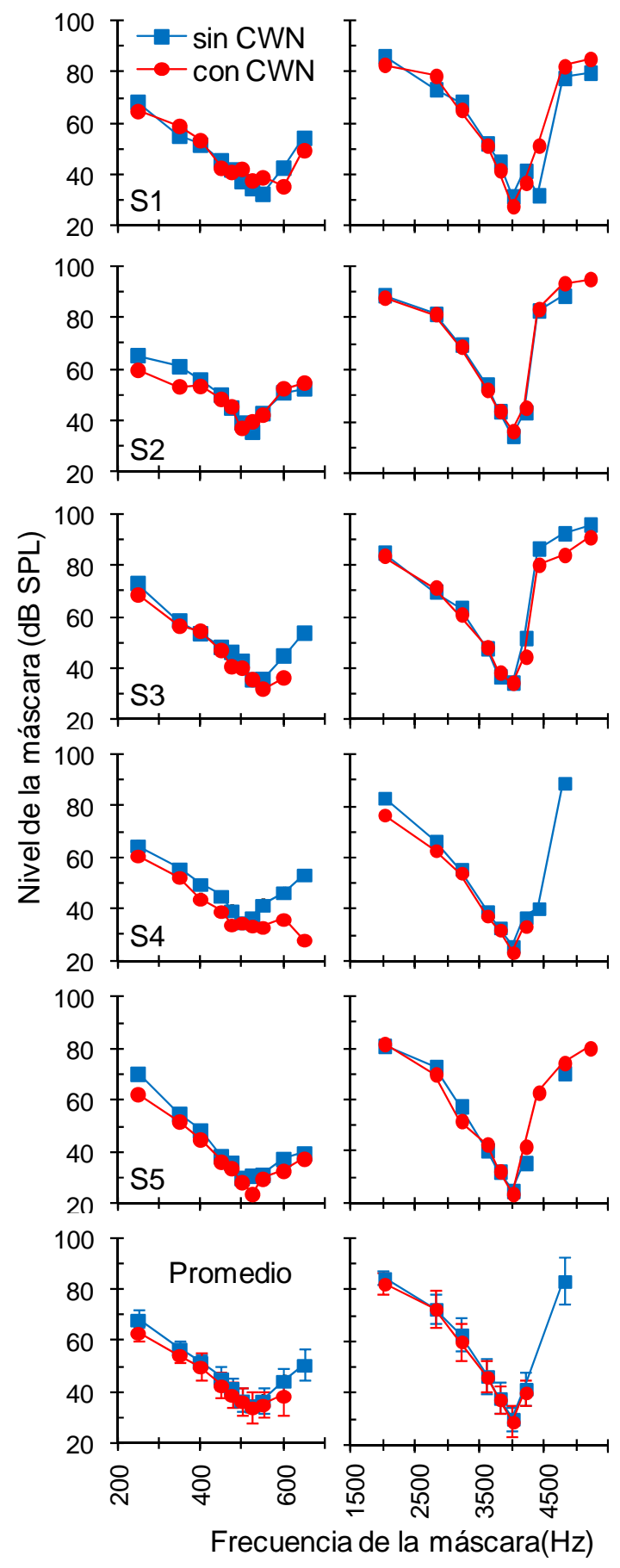

Figura 4.3. Efecto del CWN sobre las PTCs medidas a nivel cercano al umbral para frecuencias de tono sonda de $500 \mathrm{~Hz}$ (izquierda) y $4000 \mathrm{~Hz}$ (derecha). Las PTCs se midieron utilizando un intervalo máscara-sonda de 2 ms en presencia (círculo rojo) y ausencia (cuadrado azul) de CWN. Los símbolos representan los umbrales de máscara. Cada panel muestra los resultados para un sujeto o el promedio, tal y como se indica en la esquina inferior izquierda de la primera columna. Las barras de error en la última fila ilustran una desviación estándar. Los símbolos ausentes corresponden a aquellas condiciones en las que no fue posible obtener un mínimo de tres medidas válidas según los criterios descritos en la sección "Materiales y métodos".

La discrepancia entre los resultados de los diversos estudios puede reflejar diferencias metodológicas. Kawase et al. (2000) utilizaron un ruido de banda ancha como evocador del MOCR contralateral y midieron las PTCs utilizando ruidos de banda muy estrecha (1/6 octava) como máscaras. Vinay y Moore (2008) utilizaron un ruido banda estrecha como evocador del MOCR contralateral y ruidos comparativamente más anchos como máscaras ( $1 / 3$ y $1 / 2$ octava). Además Vinay y Moore (2008) midieron las PTCs usando enmascaramiento simultáneo. Kawase et al. 
(2000) emplearon enmascaramiento simultáneo y post-estimulatorio. En el enmascaramiento simultáneo, los umbrales de máscara son determinados parcialmente por la supresión de la excitación del tono sonda por la máscara (Moore et al. 1984) y la cantidad de supresión está relacionada con la sensibilidad coclear (véase la Fig. 11 de (Ruggero et al. 1992). Además de esperar que el MOCR contralateral reduzca la sensibilidad coclear, podría también variar la supresión coclear en una cantidad incierta. Es decir, es probable que en el enmascaramiento simultáneo el MOCR contralateral reduzca simultáneamente la ganancia coclear y la supresión, y esto puede confundir en la interpretación de los resultados. La supresión afecta comparativamente más en el ápex que en la base (Cooper 1996; Robles y Ruggero 2001). Por tanto, la confusión introducida por la supresión afectaría más a los resultados de $500 \mathrm{~Hz}$ de Vinay y Moore (2000) que a los de 2000 $\mathrm{Hz}$ de Kawase et al. (2000). En los experimentos aquí presentados en esta tesis se utilizó enmascaramiento post-estimulatorio, por lo que cabe esperar que los resultados no se encuentren afectados por la supresión.

\section{Efecto del CWN sobre las PTCs a niveles supra-umbrales}

La Figs. 4.4 y 4.5 muestran el efecto del CWN sobre las PTCs de gaps de 10, 30 y 50 ms, vale decir, a niveles supra-umbral, para sondas de 4000 y $500 \mathrm{~Hz}$, respectivamente. Como se puede observar, el CWN no produce un efecto significativo en $4000 \mathrm{~Hz}$. A $500 \mathrm{~Hz}$, por el contrario, el CWN reduce el umbral de las máscaras. La magnitud de esta reducción se muestra en la Fig. 4.6. Para el intervalo de $10 \mathrm{~ms}$, la reducción es mayor para frecuencias lejanas de la frecuencia del tono sonda, en consonancia con el efecto del CWN sobre las PTCs medidas a niveles cercanos al umbral (serie de $2 \mathrm{~ms}$ en la fig. 4.6). Para los intervalos de 30 y $50 \mathrm{~ms}$, el CWN reduce el nivel de todas las máscaras de la PTC, sean estas cercanas o lejanas a la frecuencia de sonda. En promedio, la reducción es mayor cuanto mayor es el intervalo máscara-sonda. El promedio de la reducción es $2.3,8.3$ y 14.7 dB para los intervalos de 10,30 y $50 \mathrm{~ms}$, respectivamente. Este patrón de resultados fue prácticamente idéntico para todos los sujetos.

En resumen, el CWN no afecta a las PTCs de $4000 \mathrm{~Hz}$. A $500 \mathrm{~Hz}$, por el contrario, el CWN reduce sólo el nivel de las máscaras de frecuencias lejas a la frecuencia de la sonda o el de todas las máscaras dependiendo de si la PTC es medida a condiciones umbral o supra-umbral, respectivamente. Considerando i) que el CWN empleado no activa el MEMR (Capítulo 3, Fig. 3.1); ii) que la tasa de recuperación post-mecánica del enmascaramiento post-estimulatorio no se ve afectada por el CWN (Fig. 4.2); y iii) que el CWN utilizado es suficiente para desencadenar el MOCR contralateral (Lilaonitkul y Guinan 2009a), los presentes resultados sugieren que el MOCR tiene un mayor efecto sobre la zona coclear apical que sobre la basal. 


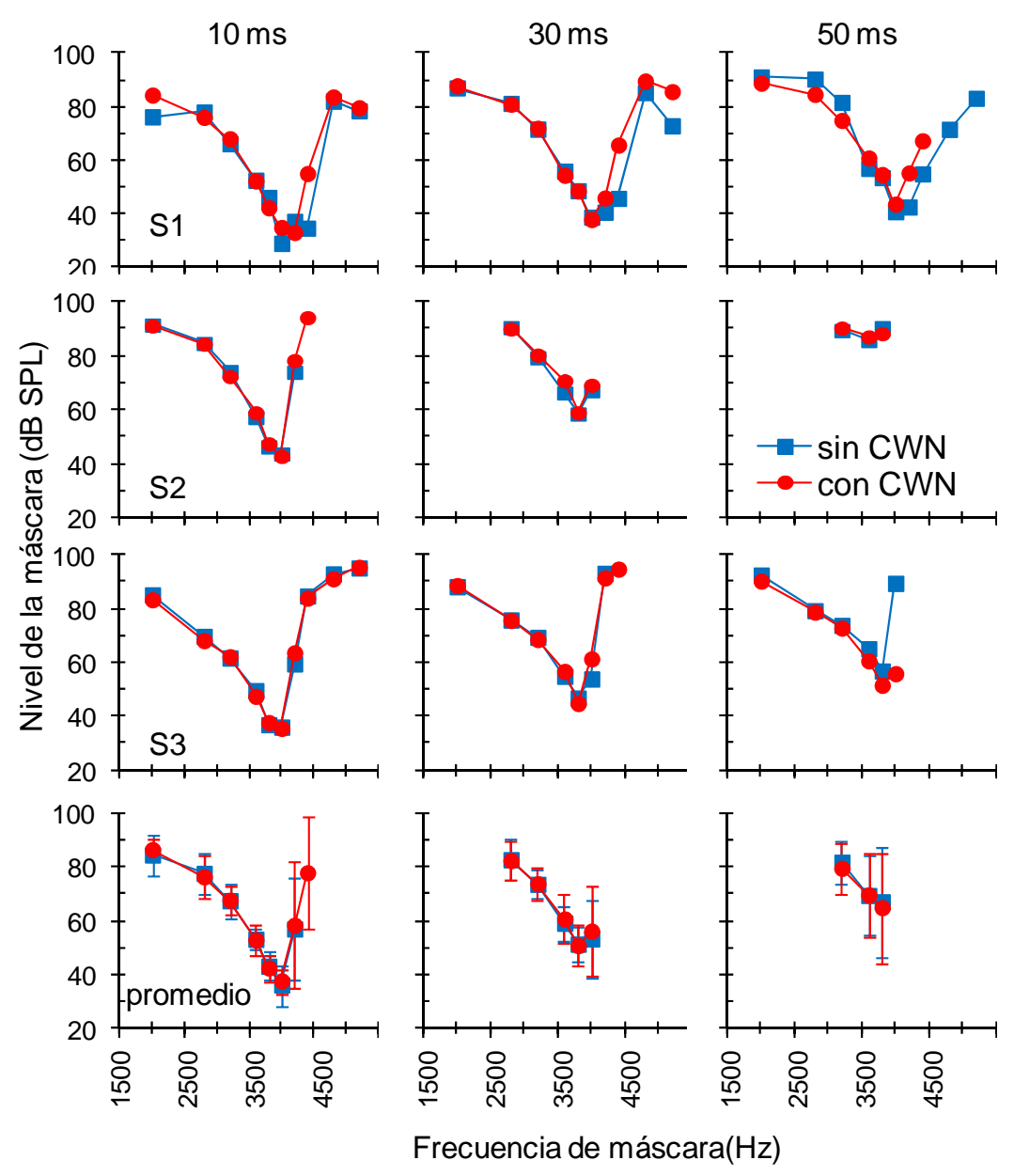

Figura 4.4. Efecto del CWN sobre las PTCs medidas a nivel supra umbral para un tono sonda de $4000 \mathrm{~Hz}$. Las PTCs se obtuvieron utilizando intervalos máscara-sonda de 10, 30 y $50 \mathrm{~ms}$, en presencia (círculo rojo) y en ausencia (cuadrado azul) de CWN. Los símbolos representan los umbrales de máscara. Cada panel muestra los resultados para cada sujeto o el promedio, tal y como se indica en la esquina inferior izquierda de los paneles de la primera columna. Las barras de error ilustran una desviación estándar. Los símbolos ausentes corresponden a aquellas condiciones en las que no fue posible obtener un mínimo de tres medidas válidas según los criterios descritos en la sección "Materiales y métodos". 


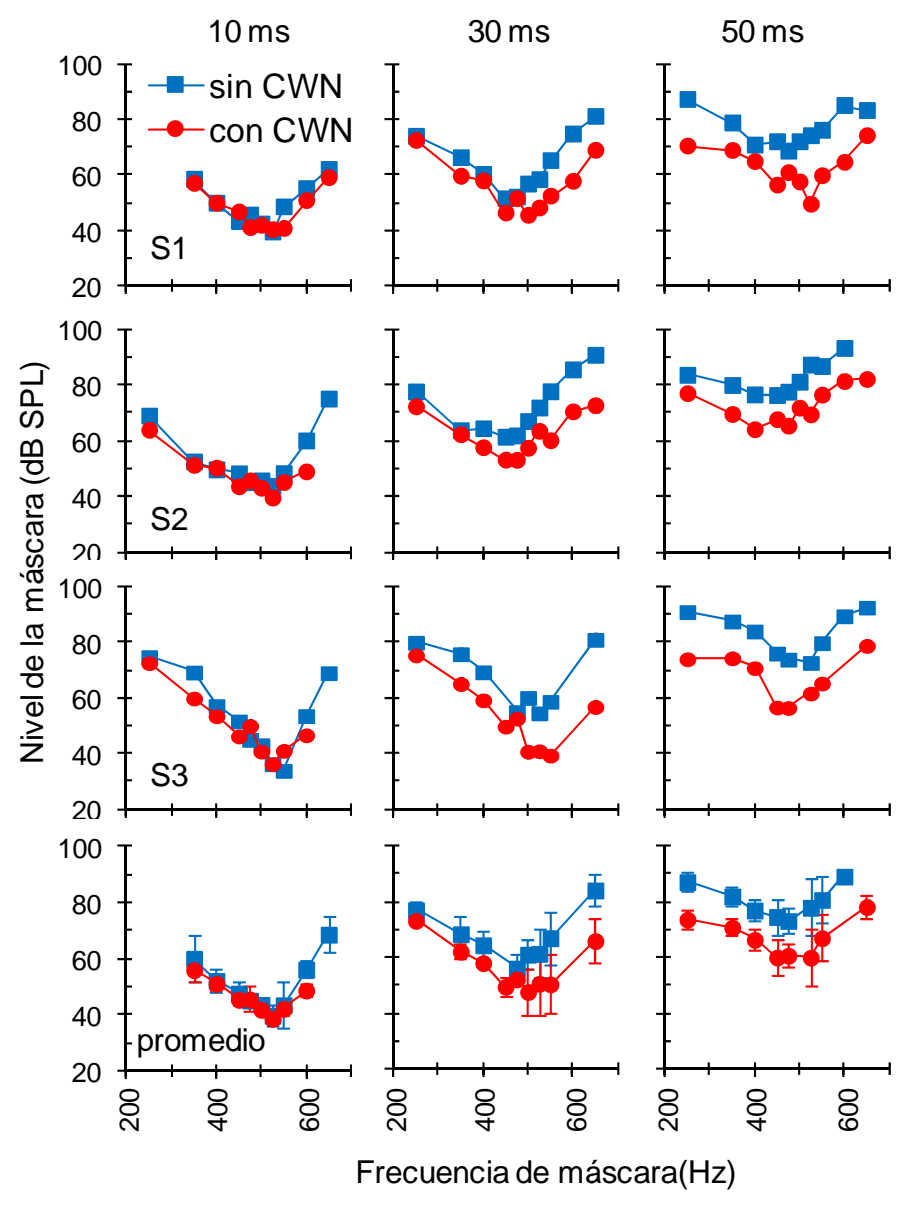

Figura 4.5. Igual que la Fig. 4.4 pero para un tono sonda de $500 \mathrm{~Hz}$

\section{Discusión}

Se ha demostrado que el CWN afecta a las PTCs de $500 \mathrm{~Hz}$ pero no a la de $4000 \mathrm{~Hz}$. A $500 \mathrm{~Hz}$ se puede destacar que: i) para las PTCs medidas a una intensidad cercanas al umbral, el CWN reduce el nivel sonoro de las máscaras con frecuencias lejanas a la frecuencia de sonda; ii) para las PTCs medidas a nivel supra-umbral, el efecto del CWN se extiende a todas las frecuencias de máscara. Estos efectos no se deben a la activación del MEMR por parte del CWN (Capítulo 3, Fig. 3.2), al menos cuando se utilizan máscaras con niveles inferiores a $80 \mathrm{~dB} \mathrm{SPL}$, que es la gran mayoría de máscaras. Se ha confirmado, además, que la activación del MOCR contralateral no cambia la tasa de recuperación post-mecánica para la región de $4000 \mathrm{~Hz}$. Quedaría pendiente investigar el efecto del CWN sobre la esta tasa para regiones apicales. 


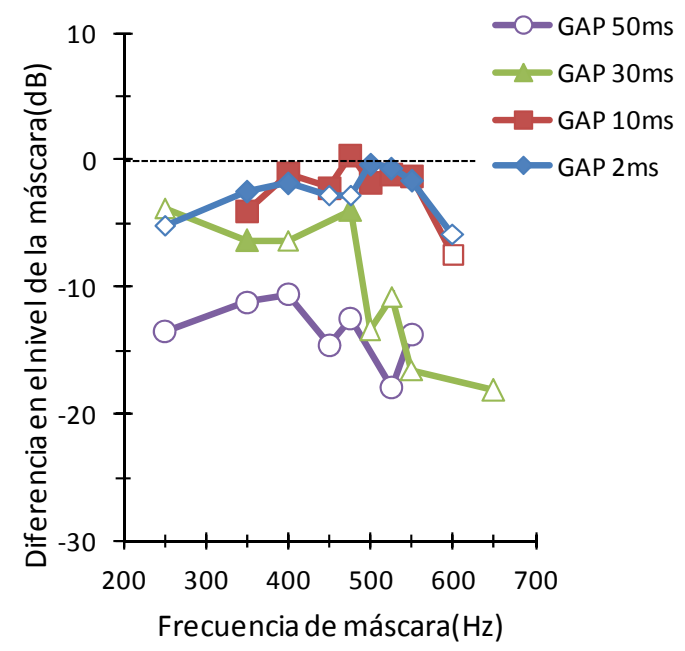

Figura 4.6. Efecto del CWN sobre las PTCs de $500 \mathrm{~Hz}$ en función de la frecuencia de máscara. El efecto se expresa como la diferencia promedio del nivel de máscara medido con CWN menos el medido sin CWN. Un valor negativo indica, por tanto, que el CWN reduce el umbral de la máscara. Cada serie es para un intervalo máscara-sonda distinto, como se indica en la leyenda. Los símbolos sin relleno indican diferencias estadísticamente significativas $(p<0.05$, prueba $t$ pareada de una cola con $N=5$ para la serie de $2 \mathrm{~ms}$ y $N=3$ para las otras series).

Los presentes resultados siguieren, por tanto, que el MOCR contralateral tiene mayor efecto sobre las regiones cocleares apicales que sobre las basales. Este resultado es consistente con lo observado en los Capítulos 2 y 3 y con estudios recientes en humanos que, utilizando la técnicas de OAEs, observan un mayor efecto de la activación del MOCR contralateral sobre el umbral de compresión (Bhagat y Carter 2010), la latencia de la respuesta coclear (Francis y Guinan 2010), y sobre la magnitud del cambio en las SFOAE (Lilaonitkul y Guinan 2009a; Lilaonitkul y Guinan $2009 b)$ en bajas que en altas frecuencias. Si bien los presentes resultados no muestran un efecto significativo a $4000 \mathrm{~Hz}$, no es posible descartarlo. De hecho, los presentes resultados así como los de estudios anteriores muestran una pequeña evidencia de que el MOCR contralateral en realidad sí tiene un efecto a $4000 \mathrm{~Hz}$. En concreto, aquí hemos demostrado que el CWN reduce el promedio de los niveles de máscara de la referencia lineal (Fig. 4.2). Esto es cualitativamente consistente con estudios previos que reportan que el ruido contralateral reduce el nivel de las máscaras post-estimulatorias entre una y dos octavas bajo la frecuencia de un tono sonda de $2000 \mathrm{~Hz}$ (Kawase et al. 2000). La reducción aquí observada fue, no obstante, más pequeña (1.12 dB) que la publicada por Kawase et al. ( $5 \mathrm{~dB})$. Esto podría deberse a diferencias en la frecuencia del tono sonda empleada [ $4000 \mathrm{~Hz}$ en este estudio frente a los $2000 \mathrm{~Hz}$ de Kawase et al. (2000)], en la definición de umbral de máscara [aquí hemos definido el umbral de máscara como el nivel sonoro con el que la sonda se detecta el $71 \%$ de las ocasiones frente al $50 \%$ de Kawase et al. (2000)], o la precisión en la medición [aquí hemos utilizados saltos de 2 dB frente a 1 dB en Kawase et al. (2000)]. Además, hay evidencia fisiológica de que el MOCR 
contralateral sí tiene un efecto a $4000 \mathrm{~Hz}$. (Guinan y Gifford 1988b) evaluaron el efecto de la activación del haz MOC sobre fibras aferentes del nervio auditivo mediante electrodos ubicados en la línea media del troco encefálico, y observaron un mayor efecto sobre las curvas de sintonización para las fibras del nervio auditivo sintonizadas a $4000 \mathrm{~Hz}$ que sobre las sintonizadas a $500 \mathrm{~Hz}$. Dicho esto, resulta difícil comparar este experimento fisiológico con los aquí descritos ya que los resultados de Guinan y Gifford son para gato mientras que los presentes resultados son para humano. Además, la activación eléctrica del MOCR podría activar las fibras involucradas en los reflejos ipsi- y contra-laterales. Otra prueba de que el MOCR contralateral actúa sobre la región de $4000 \mathrm{~Hz}$ en humanos es que un ruido de banda ancha contralateral reduce el nivel de las SFOAE humanas tanto a 500 como a 4000 $\mathrm{Hz}$, siendo la magnitud de la reducción 2.4 veces mayor a 500 que a $4000 \mathrm{~Hz}$ (Lilaonitkul y Guinan 2009a).

Los resultados aquí presentados son, sin embargo, inconsistentes con otros estudios psicoacústicos que muestran que un precursor ipsilateral, diseñado para activar el MOCR ipsilateral, cambia significativamente la ganancia y sintonización coclear a $4000 \mathrm{~Hz}$ (Jennings et al. 2009). En dicho estudio, sin embargo, no se comparó la magnitud del efecto del precursor a $500 \mathrm{~Hz}$. En todo caso, existe evidencia morfológica que indica que la proporción de fibras eferentes involucradas en el MOCR contralateral vs. MOCR ipsilateral es mayor en el ápex y menor en la base (Guinan 2006).

La máscara ipsilateral utilizada en estos experimentos, podría potencialmente activar el MOCR ipsilateral. Es, sin embargo, poco probable que el MOCR ipsilateral afecte a las PTCs (Jennings y Strickland 2012b). Aun así, si esto ocurriese, el efecto sería idéntico para las PTCs medidas en la condición sin y con CWN, a menos que los efectos del MOCR ipsi y contralateral se sumen de forma no lineal. Esto último parece improbable; de hecho, existe evidencia que permite suponer que esta los efectos se suman de forma más o menos lineal (Lilaonitkul y Guinan 2009a). Así pues, el experimento aquí empleado parece razonablemente efectivo para medir el efecto de un ruido contralateral sobre la respuesta coclear.

Resulta razonable preguntarse si los efectos del CWN sobre las PTCs aquí descritos son compatibles con la reducción de la ganancia coclear por parte del MOCR demostrada por experimentos fisiológicos (Cooper y Guinan 2006; Murugasu y Russell 1996; Russell y Murugasu 1997). Cabe destacar que, a primera vista, el efecto del CWN sobre las PTCs aquí descrito parece incongruente con estos estudios. Aquí se observa una disminución del nivel de mascara por tanto descenso de la curva, a diferencia de lo observado en estos estudios en donde se observa una elevación de la curva de sintonización de la $\mathrm{BM}$ en regiones basales producto de la activación eléctrica del haz MOC. En el siguiente capítulo se demostrará, sin embargo, que esta incompatibilidad es sólo aparente. 
4. Efecto del MOCR contralateral sobre las curvas de sintonización psicoacústicas

\section{Conclusiones}

1. El CWN tiene un efecto sobre las PTCS, y este efecto es mayor en 500 que en $4000 \mathrm{~Hz}$

2. En las PTCs de $500 \mathrm{~Hz}$ medidas a nivel umbral, el CWN disminuye el nivel sonoro de las máscaras con frecuencias alejadas de la frecuencia del tono sonda sin alterar el nivel sonoro de las máscaras con frecuencias próximas a las de la sonda.

3. En las PTCs de $500 \mathrm{~Hz}$ medidas a niveles supra-umbral, el CWN disminuye el umbral de las máscaras para todas las frecuencias de máscara.

4. Es probable que estos efectos se produzcan debido a una activación del MOCR contralateral por parte del CWN.

5. Falta por comprobar, sin embargo, si los efectos descritos son compatibles con la típica reducción de la ganancia coclear causada por el MOCR observada en experimentos fisiológicos. 



\section{Capítulo 5}

\section{Análisis de las PTCs utilizando un modelo computacional de enmascaramiento post-estimulatorio con control eferente ${ }^{2}$}

\section{Introducción}

Las técnicas psicoacústicas utilizadas en los capítulos anteriores han demostrado ser una valiosa herramienta al momento de evaluar el efecto del CWN sobre la respuesta del receptor auditivo humano, efecto que no podría evaluarse con técnicas fisiológicas invasivas directas. Como se ha señalado ya en dichos capítulos, la información obtenida con estas técnicas es la resultante de una compleja interacción de fenómenos mecánicos (cocleares) no lineales y post-mecánicos. Por lo tanto, pese a las precauciones adoptadas para evitar algunos factores de confusión (por ejemplo, para minimizar los efectos de la supresión coclear, o los de los latidos auditivos sobre la detección de la sonda), es lógico suponer que los datos psicoacústicos no proporcionan información cuantitativa directa del efecto del CWN sobre las propiedades no lineales del receptor auditivo.

El desarrollo de un modelo de enmascaramiento post-estimulatorio que esté basado en la fisiología e incluya los distintos fenómenos que potencialmente contribuyen a las observaciones psicoacústicas (como, por ejemplo, el enmascaramiento postestimulatorio, la compresión coclear, o la escucha fuera de frecuencia) permitiría no sólo reproducir e interpretar los resultados psicoacústicos, si no, además, extraer información cuantitativa sobre el efecto del CWN sobre de las propiedades no lineales del receptor auditivo.

\footnotetext{
${ }^{2}$ Este capítulo está adaptado de un artículo científico ya publicado (Aguilar et al. 2013).
} 
En este capítulo, se presenta un modelo computacional fenomenológico de enmascaramiento post-estimulatorio con control eferente. El modelo se utiliza para simular y explicar los efectos del CWN sobre las PTCs presentadas en el Capítulo 4. Se optó por simular estas PTCs, ya que tienen la ventaja de haberse obtenido con un nivel sonoro del tono sonda idéntico (iso-SPL) en presencia y en ausencia de CWN y ser, por tanto, más fácilmente interpretables.

El modelo es solo una aproximación somera al funcionamiento de la cóclea y del sistema auditivo. No obstante, se demostrará útil para contrastar la hipótesis de que el principal efecto del CWN fue activar el MOCR y, por lo tanto, reducir la ganancia coclear de manera diferente en función de la frecuencia y la intensidad del estímulo.

\section{Materiales y métodos}

Se desarrolló un modelo computacional fenomenológico de enmascaramiento postestimulatorio para reproducir las PTCs descritas en el Capítulo 4. Los parámetros del modelo se optimizaron para simular simultáneamente las PTCs umbral y supraumbral; por tanto, sólo se consideraron los datos obtenidos en los tres sujetos ( $\mathrm{S} 1$, S2 y S3) que participaron en dichas pruebas. El modelo está inspirado en el modelo de integración temporal de la respuesta de la BM (Plack et al. 2002). Como muestra la Fig. 5.1A, el modelo consiste en una etapa que simula la respuesta mecánica no lineal de la cóclea, seguida de un integrador (o ventana) temporal, seguido de un algoritmo de decisión.

En este modelo, se asume que el enmascaramiento post-estimulatorio ocurre por una persistencia de la actividad neural producida por la máscara (Oxenham 2001). La ventana temporal representa la tasa de recuperación post-mecánica del enmascaramiento post-estimulatorio y está centrada en el momento en el que ocurre el tono sonda. Se calcula la respuesta del modelo frente a la máscara+sonda y frente a la máscara sola y se asume que la detección del tono sonda ocurre cuando la relación entre ambas respuestas excede un cierto valor $k$ que puede interpretarse como la eficiencia en la detección (Plack et al. 2002). En la versión original del modelo (Plack et al. 2002), la respuesta mecánica coclear se simulaba utilizando un filtro no lineal de doble resonancia (DRNL) (Lopez-Poveda y Meddis 2001; Meddis et al. 2001). En el presente modelo, el filtro DRNL se reemplaza por una versión más moderna con control eferente (Ferry y Meddis 2007), que aquí denominaremos EDRNL. Este filtro EDRNL reproduce el efecto de la activación del sistema eferente sobre la respuesta BM y sobre el nervio auditivo con la sola inclusión de un atenuador en la rama no lineal del filtro DRNL (ATT en la Fig. 5.1B) (Ferry y Meddis 2007).

Otra novedad del presente modelo de enmascaramiento post-estimulatorio con respecto al original de Plack et al. (2002), es que intenta reproducir el fenómeno de escucha fuera de frecuencia en $500 \mathrm{~Hz}$. Cuando se utiliza la técnica de enmascaramiento post-estimulatorio (por ejemplo, para medir TMCs o PTCs), se asume que la detección del tono sonda ocurre con la región coclear en la que se 
produce una mayor relación máscara-tono sonda. Esta región coclear, sin embargo, no es necesariamente aquella que responde con más fuerza frente a la sonda. Por ejemplo, si la sintonización coclear fuese asimétrica en frecuencia y más estrecha que el ancho de banda del tono sonda, entonces la sonda podría detectarse a través de una región coclear diferente de la de la sonda. Este fenómeno se conoce como "escucha fuera de frecuencia"(Patterson y Nimmo-Smith 1980). Las PTCs descritas en el Capítulo 4 se obtuvieron utilizando una sonda breve (de $10 \mathrm{~ms}$ de duración), que pudo haber producido dispersión de energía, y por lo tanto, escucha fuera de frecuencia en $500 \mathrm{~Hz}$. Con el fin de simular el potencial efecto de la escucha fuera de frecuencia en $500 \mathrm{~Hz}$, en el modelo se utilizó un banco de filtros local con 11 filtros EDRNL para simular la respuesta coclear mecánica en 11 regiones cocleares con CFs entre 250 y $850 \mathrm{~Hz}$. El banco de filtros local se construyó asumiendo una dependencia lineal entre el valor de cada uno de los parámetros del filtro EDRNL y la CF en una escala log-log, de la siguiente forma:

$$
\log _{10}(v a l)=s_{0}+s \cdot \log _{10}(C F)
$$

donde $s_{0}$ y $s$ son los coeficientes de regresión, y val denota el valor del parámetro del filtro EDRNL correspondiente. Este procedimiento es razonable considerando que cualquier función continua puede aproximarse por un segmento lineal en un dominio local.

\section{A}

Plack et al (2002)

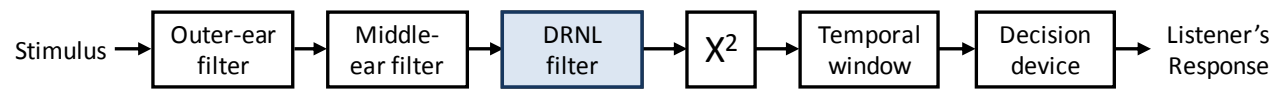

B

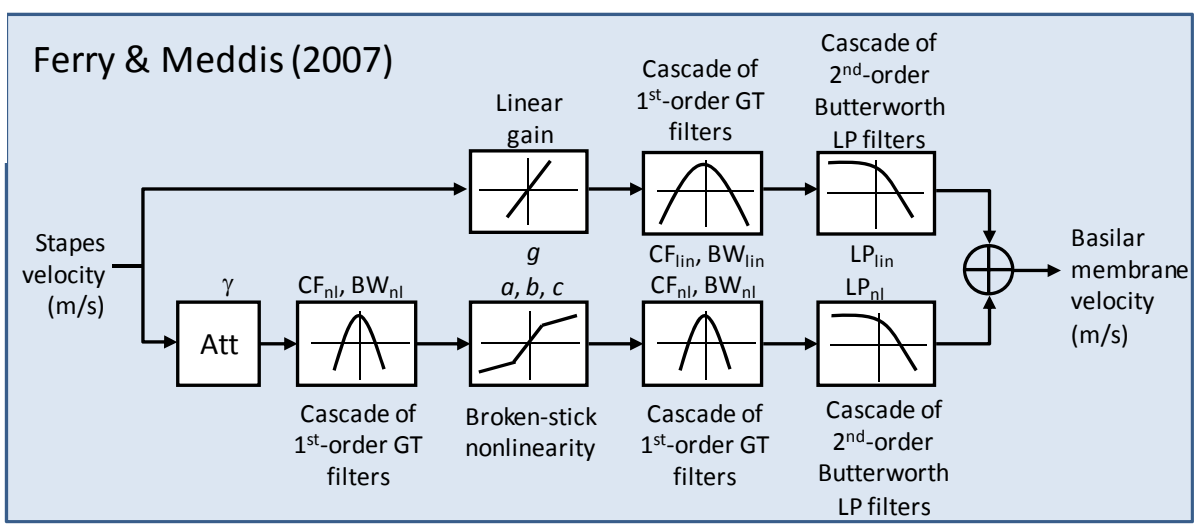

Figura 5.1. A. Estructura del modelo de enmascaramiento post-estimulatorio [basado en (Plack et al. 2002)]. El modelo consta de una etapa que simula la respuesta mecánica de la cóclea (consta de un filtro que simula la respuesta de los oídos externo y medio, más el filtro DRNL con control eferente), seguida de una función cuadrática, seguida de un integrador temporal o ventana temporal, seguido, por último, de un algoritmo de decisión B. Estructura del filtro DRNL con control eferente, basado en (Ferry y Meddis 2007). Extraído de (Aguilar et al. 2013) 
El modelo se implementó digitalmente en el dominio temporal (frecuencia de muestreo de $44100 \mathrm{~Hz}$ ) y se evaluó para estímulos y condiciones idénticas a las utilizadas en los experimentos (véase la sección de Materiales y métodos del Capítulo 4). Los parámetros del modelo se optimizaron automáticamente de la siguiente manera. En primer lugar, se optimizaron los parámetros del filtro DRNL estándar (sin atenuación eferente) y de la ventana temporal con el fin de simular simultáneamente las PTCs de $4000 \mathrm{~Hz}$ y la TMC de referencia lineal medidas sin CWN. Los parámetros de la ventana temporal resultante se utilizaron para todas las otras frecuencias de máscara y condiciones. Es decir, se asumió que la tasa de recuperación post-mecánica del enmascaramiento post-estimulatorio es constante para todas las frecuencias de máscara y condiciones (este supuesto es razonable y se evidencia en el Capítulo 3, Fig. 3.3). En segundo lugar, se optimizaron los parámetros del filtro DRNL estándar (sin atenuación eferente) a $500 \mathrm{~Hz}$ utilizando las mediciones de las PTCs sin CWN. Por último, se ajustó el parámetro que controla la cantidad de atenuación eferente (ATT en la Fig. 5.1) para conseguir reproducir las PTCs medidas con CWN a 500 y $4000 \mathrm{~Hz}$. En otras palabras, se asumió que el único efecto del CWN fue disminuir la ganancia coclear a través de la activación del MOCR contralateral (o de reducción de la ganancia ATT en el modelo).

Tabla 5.1. Valores individuales de los parámetros del filtro EDRNL a $4000 \mathrm{~Hz}$. Véase (LopezPoveda y Meddis 2001) y (Ferry y Meddis 2007) para obtener una descripción más detallada de estos parámetros. El número de filtros gammatone (GT) y Butterworth de paso-bajo (LP) en la rama lineal y no lineal de 4000 y de $500 \mathrm{~Hz}$ son idénticos y están representados en esta tabla.

\begin{tabular}{|c|c|c|c|}
\hline Parámetro & S1 & S2 & S3 \\
\hline \multicolumn{4}{|c|}{ EDRNL Rama lineal } \\
\hline № filtros GT & 2 & 2 & 2 \\
\hline $\mathrm{CF}_{\text {lin }}(\mathrm{Hz})$ & 3971.90 & 3590.70 & 3306.80 \\
\hline $\mathrm{BW}_{\text {lin }}(\mathrm{Hz})$ & 358.85 & 418.20 & 318.13 \\
\hline$g$ & 1000.00 & 299.02 & 999.17 \\
\hline $\mathrm{LP}_{\text {lin }}(\mathrm{Hz})$ & 5999.70 & 5947.50 & 5993.30 \\
\hline No filtros LP & 2 & 2 & 2 \\
\hline \multicolumn{4}{|c|}{ EDRNL Rama no lineal } \\
\hline No filtros GT & 3 & 3 & 3 \\
\hline $\mathrm{CF}_{\mathrm{nl}}(\mathrm{Hz})$ & 4142.60 & 3946.40 & 3861.90 \\
\hline $\mathrm{BW}_{\mathrm{nl}}(\mathrm{Hz})$ & 421.75 & 474.64 & 523.10 \\
\hline$a$ & 54574.97 & 17420.05 & 54574.97 \\
\hline$b$ & 0.384 & 0.087 & 0.347 \\
\hline$c$ & 0.24 & 0.25 & 0.25 \\
\hline $\mathrm{LP}_{\mathrm{nl}}(\mathrm{Hz})$ & 3900.60 & 4640.00 & 3753.00 \\
\hline No filtros LP & 3 & 3 & 3 \\
\hline ATT $(\mathrm{dB})$ & 4.36 & 0.5 & -1.5 \\
\hline
\end{tabular}

Fundamentado en hallazgos fisiológicos, se permitió que el valor de este parámetro ATT variara con la frecuencia (Ferry y Meddis 2007). Es importante destacar que los parámetros del filtro EDRNL se optimizaron de manera individual para cada sujeto y se promediaron las respuestas de cada modelo individual para compararla con el promedio de los resultados experimentales. Los parámetros resultantes del EDRNL para 4000 y $500 \mathrm{~Hz}$ se presentan en las Tablas 5.1 y 5.2 , respectivamente. Los parámetros de la ventana temporal y de la eficiencia de detección, $k$, se muestran en 
la Tabla 5.3.

Tabla 5.2. Valores individuales de los parámetros del filtro EDRNL a $500 \mathrm{~Hz}$ * Obsérvese que la Ec. (1) no afecta al parámetro ATT; su valor fue idéntico para los filtros del banco local e idéntico al mostrado en esta tabla.

\begin{tabular}{lrrrrrr}
\hline & \multicolumn{2}{c}{$\mathrm{S} 1$} & \multicolumn{2}{c}{$\mathrm{S} 2$} & \multicolumn{3}{c}{$\mathrm{S} 3$} \\
\hline Parámetro & \multicolumn{1}{c}{$s_{0}$} & \multicolumn{1}{c}{$s$} & \multicolumn{1}{c}{$s_{0}$} & \multicolumn{1}{c}{$s_{0}$} & \multicolumn{1}{c}{$s$} \\
\hline \multicolumn{7}{c}{ EDRNL Rama lineal } \\
\hline $\mathrm{CF}_{\text {lin }}(\mathrm{Hz})$ & 1.218 & 0.675 & 0.850 & 0.756 & 1.673 & 0.513 \\
$\mathrm{BW}_{\text {lin }}(\mathrm{Hz})$ & 2.918 & -0.120 & 3.535 & -0.183 & 3.526 & -0.248 \\
$g$ & 0.472 & 0.693 & 2.521 & -0.0062 & 0.858 & 0.622 \\
$\mathrm{LP}_{\text {lin }}(\mathrm{Hz})$ & -0.749 & 1.346 & -1.074 & 1.372 & -0.923 & 1.347 \\
\hline \multicolumn{7}{c}{ EDRNL Rama no lineal } \\
$\mathrm{CF}_{\mathrm{nl}}(\mathrm{Hz})$ & 0.023 & 0.994 & 0.073 & 0.977 & 0.159 & 0.953 \\
$\mathrm{BW}$ & 1.907 & 0.207 & 1.818 & 0.197 & 1.313 & 0.376 \\
$a$ & 3.382 & 0 & 3.900 & 0 & 3.803 & 0 \\
$b$ & -4.654 & 1.087 & -2.669 & 0.568 & -4.008 & 0.975 \\
$c$ & -1.176 & 0.204 & -0.677 & 0.024 & -1.212 & 0.199 \\
$\mathrm{LP}_{\mathrm{nl}}(\mathrm{Hz})$ & 1.119 & 0.742 & 0.478 & 0.885 & 1.127 & 0.761 \\
$\mathrm{ATT}(\mathrm{dB})^{*}$ & -5.06 & $\mathrm{n} / \mathrm{a}$ & -6.89 & $\mathrm{n} / \mathrm{a}$ & -8.32 & $\mathrm{n} / \mathrm{a}$ \\
\hline
\end{tabular}

\section{Resultados}

La Fig. 5.2 muestra la TMC de referencia lineal resultante de optimizar el modelo para reproducir simultáneamente la TMC de referencia lineal y las PTCs de $4000 \mathrm{~Hz}$. Su pendiente es levemente mayor que la de la TMC experimental correspondiente ( 0.22 vs. $0.16 \mathrm{~dB} / \mathrm{ms}$ ) aunque la diferencia no fue estadísticamente significativa. Cabe destacar que el parecido entre las PTCs simuladas y las experimentales fue menor cuando la ventana temporal se optimizó para reproducir la TMC de referencia lineal independientemente de las PTCs. Esto sugiere que la tasa de recuperación del enmascaramiento post-mecánico podría ser, en realidad, levemente mayor que la sugerida por la TMC de referencia lineal experimental. Esto tiene sentido si se considera que en la obtención de las TMCs experimentales se descartaron aquellas mediciones que sobrepasaron el nivel máximo de seguridad permitido por nuestro sistema (100 dB SPL). Es decir, la pendiente de las TMCs de referencia lineal podría ser más pronunciada si se pudiesen incluir como válidas aquellas mediciones que sobrepasaron el nivel máximo del sistema.

Tabla 5.3. Los parámetros de la ventana temporal y de la eficiencia de detección, $k$. Para una descripción detallada del significado de estos parámetros, véase (Oxenham 2001)

\begin{tabular}{lrrr}
\hline Parámetro & $\mathrm{S} 1$ & $\mathrm{~S} 2$ & $\mathrm{~S} 3$ \\
\hline$w$ & 0.93 & 0.92 & 0.93 \\
$\tau_{\mathrm{b} 1}(\mathrm{~ms})$ & 0.00168 & 9.47 & 6.88 \\
$\tau_{\mathrm{b} 2}(\mathrm{~ms})$ & 31.32 & 19.22 & 31.97 \\
$\tau_{\mathrm{a}}(\mathrm{ms})$ & 3.50 & 3.50 & 3.50 \\
$k \mathrm{a} 500 \mathrm{~Hz}(\mathrm{~dB})$ & 8.01 & 3.08 & 5.63 \\
$k \mathrm{a} 4000 \mathrm{~Hz}(\mathrm{~dB})$ & 1.66 & 0.90 & 0.83 \\
\hline
\end{tabular}


Cabe destacar, además, que el modelo predice una suave elevación en vez de una disminución de la de los niveles sonoros de las TMC de referencia lineal. Esto se debe a que a $4000 \mathrm{~Hz}$, en promedio, el efecto del CWN en el modelo es un suave incremento en la sensibilidad coclear; es decir, el valor del parámetro ATT fue positivo $(+1.12 \mathrm{~dB})$. Los valores individuales del parámetro ATT se muestran en la Tabla 5.1. No obstante, la diferencia entre los niveles de máscara simulados y experimentales no fue estadísticamente significativa.

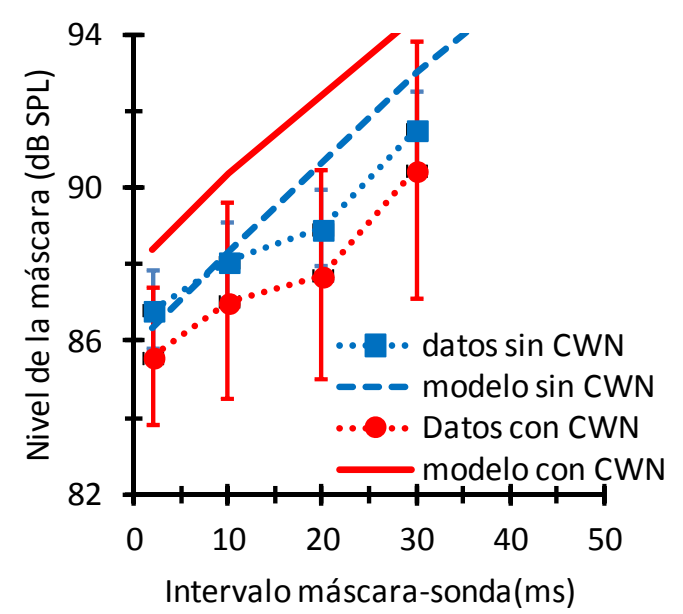

Figura 5.2. Tasa de recuperación postmecánica del enmascaramiento postestimulatorio con y sin CWN. Las frecuencias del tono sonda y de la máscara fueron 4000 y $1600 \mathrm{~Hz}$, respectivamente. Los símbolos y líneas punteadas ilustran el promedio de los datos experimentales; las barras de error ilustran una desviación estándar (datos reproducidos de la Fig. 4.2). Las líneas gruesas (continua roja y discontinua azul) ilustran los resultados del modelo.

Las PTCs simuladas con el modelo se ilustran mediante líneas en las Figs. 5.3, 5.4 y 5.5. El modelo reproduce relativamente bien las PTCS individuales y promedios, medidas tanto en presencia como en ausencia de CWN, tanto de manera cualitativa, como cuantitativa. El error cuadrático de los ajustes se muestra en la Tabla 5.4.

Tabla 5.4. Error cuadrático del ajuste del modelo (en $\mathrm{dB}$ ) para los distintos sujetos (o el promedio) y las diferentes condiciones. En $4000 \mathrm{~Hz}$, el error incluye el error del ajuste de las PTCs y de la TMC de referencia lineal.

\begin{tabular}{llrrrr}
\hline Frecuencia & Condición & S1 & S2 & S3 & Promedio \\
\hline $500 \mathrm{~Hz}$ & sin CWN & 5.37 & 4.77 & 4.79 & 3.60 \\
& con CWN & 5.69 & 4.79 & 5.65 & 2.70 \\
$4000 \mathrm{~Hz}$ & sin CWN & 4.54 & 4.55 & 3.77 & 2.99 \\
& con CWN & 5.65 & 5.15 & 5.14 & 3.27 \\
\hline
\end{tabular}

Respecto al efecto del CWN sobre las PTCs medidas a nivel umbral, el modelo reproduce el principal efecto de reducción del umbral de las máscaras en las colas de las PTCs de $500 \mathrm{~Hz}$ sin presentar cambios en la punta de la PTC (Fig. 5.3). El modelo también reproduce el efecto del CWN sobre las PTCs a nivel supra-umbral, en donde la reducción del nivel sonoro de las máscaras se hace extensiva a todas las frecuencias conforme se incrementa el intervalo máscara-sonda (Figs. 5.4 y 5.5).

El buen desempeño del modelo en términos generales destaca especialmente 
cuando se considera que el único parámetro que se modifica para simular la respuesta del CWN es el atenuador eferente (ATT). Los valores de este parámetro para los diferentes sujetos se muestran en la última fila de las Tablas 5.1 y 5.2. Los valores medios fueron -6.76 y $+1.12 \mathrm{~dB}$ a 500 y $4000 \mathrm{~Hz}$, respectivamente. La diferencia entre estos valores fue significativa $(p=0.0098, N=3$, prueba $t$ pareada de dos colas). Como la atenuación eferente se atribuye aquí a la activación del MOCR por el CWN, el modelo sugiere que la reducción de ganancia coclear atribuida al MOCR contralateral es significativamente mayor en 500 que en $4000 \mathrm{~Hz}$.

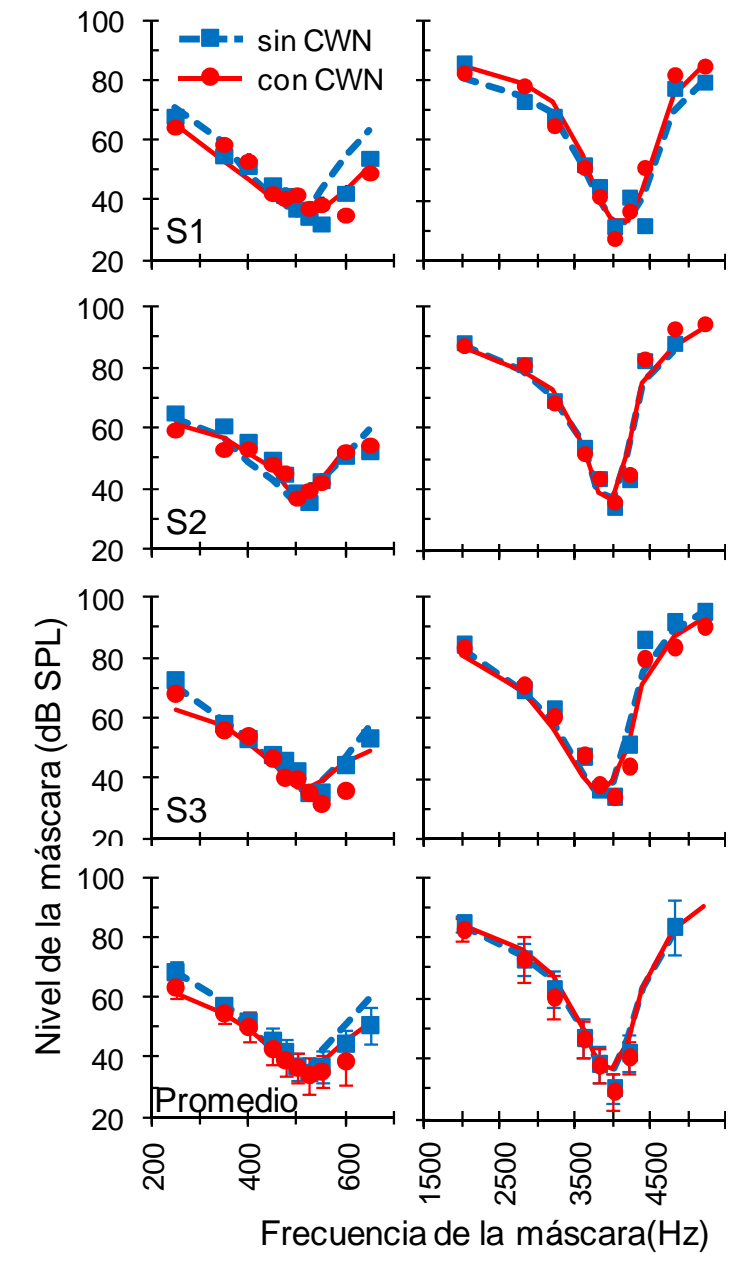

Figura 5.3. Simulación con el modelo computacional del efecto del CWN sobre las PTCs medidas a nivel cercano al umbral para tonos sonda de $500 \mathrm{~Hz}$ (izquierda) y $4000 \mathrm{~Hz}$ (derecha). Los símbolos ilustran las PTCs experimentales (reproducidos de la Fig. 4.3) para un intervalo máscara-sonda de $2 \mathrm{~ms}$ en presencia (en rojo) y en ausencia (en azul) de CWN. Las barras de error ilustran una desviación estándar. Las líneas continuas ilustran las PTCs simuladas con el modelo con (en rojo) y sin (en azul) atenuación eferente, respectivamente. Cada panel ilustra los resultados para cada sujeto, o el promedio, tal y como se indica en la esquina inferior izquierda del panel. 


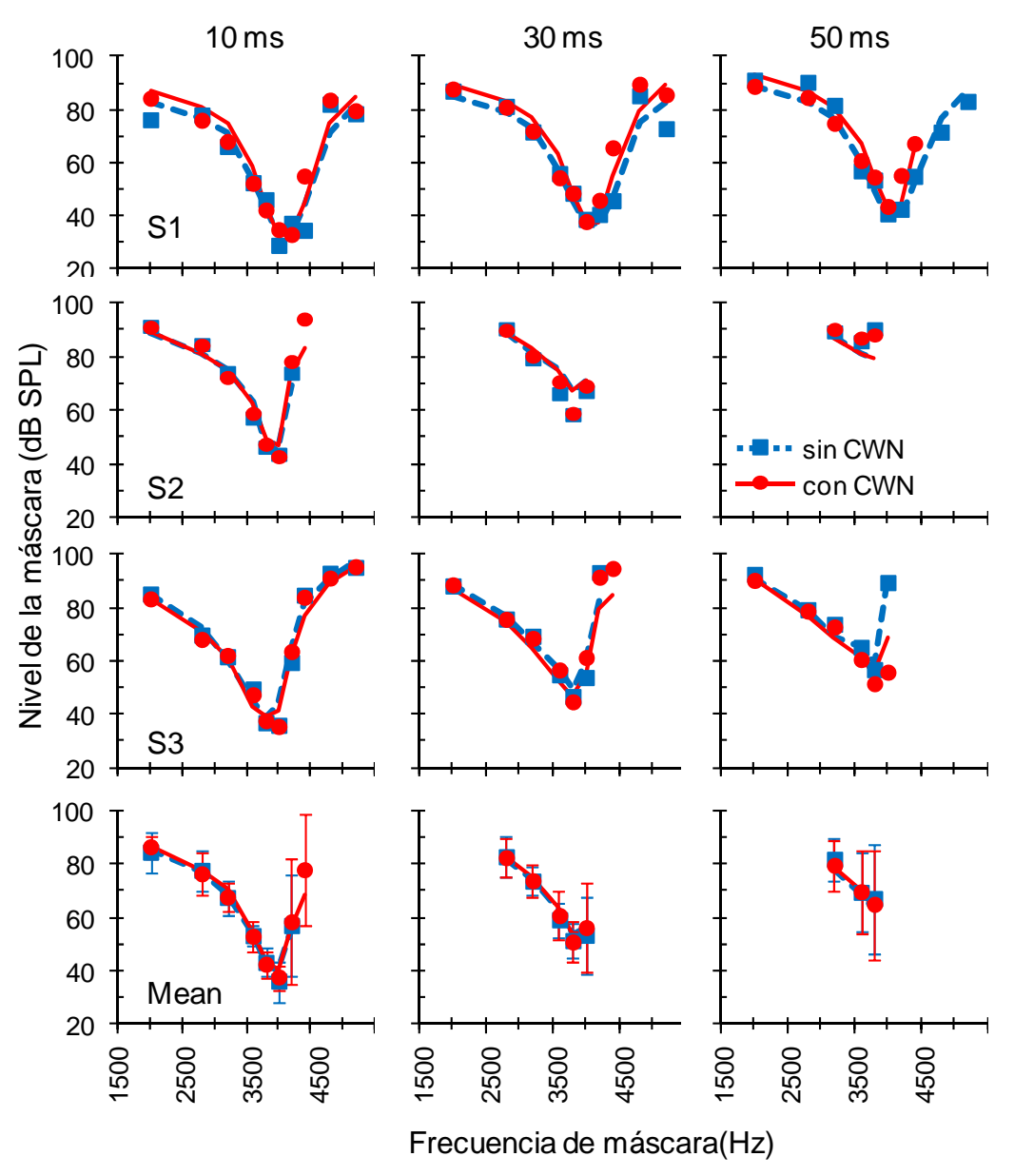

Figura 5.4. Simulación del efecto del CWN sobre las PTCs supra-umbral para un tono sonda de $4000 \mathrm{~Hz}$. Los símbolos representan las PTCs experimentales (reproducidas de la Fig. 4.4) obtenidas con intervalos máscara-sonda de 10 (izquierda), 30 (medio) y 50 ms (derecha) en presencia (en rojo) y ausencia (en azul) de CWN. Las líneas continuas ilustran las PTCS simuladas con el modelo con (en rojo) y sin (en azul) atenuación eferente, respectivamente. Cada panel ilustra los resultados para cada sujeto, o el promedio, tal y como se indica en la esquina inferior izquierda de los paneles de la primera columna.

La Fig. 5.6 ilustra el efecto de la atenuación eferente sobre la respuesta mecánica simulada con el modelo configurado con los parámetros de un sujeto en particular (S2). En el panel superior e inferior se ilustran las IOCs y las curvas de sintonización, respectivamente. Como se ha explicado anteriormente, en el modelo, se asume que el CWN activa a el MOCR contralateral, que reduce la ganancia en una cantidad determinada por el atenuador eferente (ATT); $6.89 \mathrm{~dB}$ para este sujeto. Este efecto, cambia la IOC a niveles bajos y medios. Y por lo tanto produce una elevación de la curva de sintonización (Fig. 5.5B). Este efecto es cualitativamente consistente con los hallazgos fisiológicos (Cooper y Guinan 2006), y permite evidenciar, que la inconsistencia en la dirección del cambio de las PTCs experimentales (en estas ocurre un descenso de la curva) es solo aparente y se debe a que las PTCs experimentales se 
midieron y se simularon en una condición de iso-SPL. Cada una de las parejas de curvas mostradas en la Fig. 5.6B representan, por el contrario, respuestas mecánicas cocleares para un mismo criterio de excitación (condición de iso-excitación). El presente modelo predice que a la atenuación eferente en el ápex se extiende sobre un amplio rango de frecuencias. Esto se debe a que, con el fin de reproducir las PTCS experimentales, las respuestas compresivas en el modelo afecta comparativamente a un rango más amplio de frecuencias (relativo a la CF) a 500 que a $4000 \mathrm{~Hz}$. Esta predicción no es nueva; ya ha sido propuesta por antiguos estudios fisiológicos (Rhode y Cooper 1996) así como por estudios psicoacústicos anteriores que han empleado metodología y supuestos tanto similares (Lopez-Poveda y Alves-Pinto 2008; Plack y Drga 2003) como distintos a los aquí utilizados (Lopez-Poveda et al. 2008). Por lo tanto, tanto el modelo como los datos experimentales son consistentes con estudios previos. Este es el primer modelo, sin embargo, que reproduce este fenómeno, algo que resulta imprescindible para simular las PTCs.

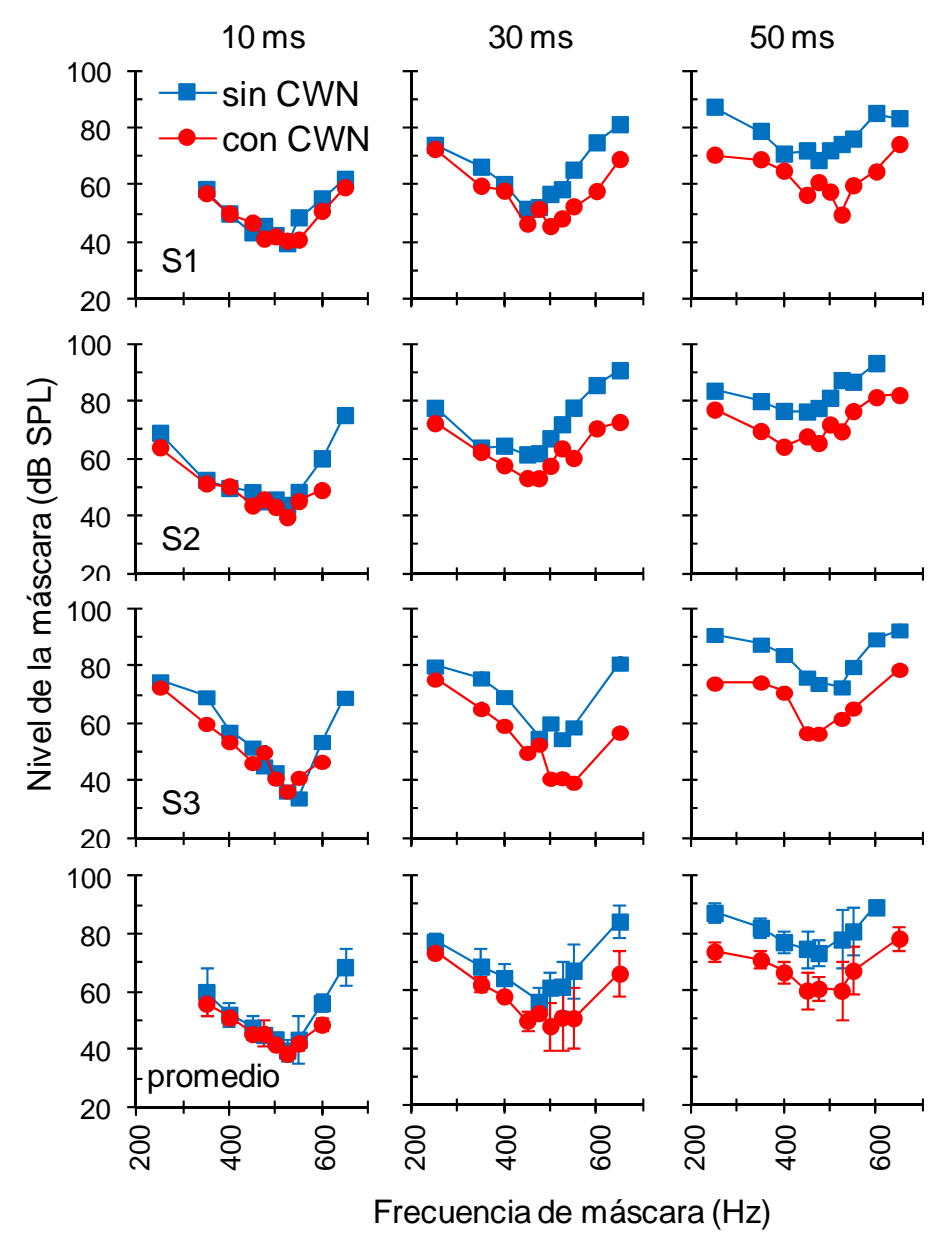

Figura 5.5. Igual que en Fig. 5.4 pero para la frecuencia de tono sonda de $500 \mathrm{~Hz}$ 


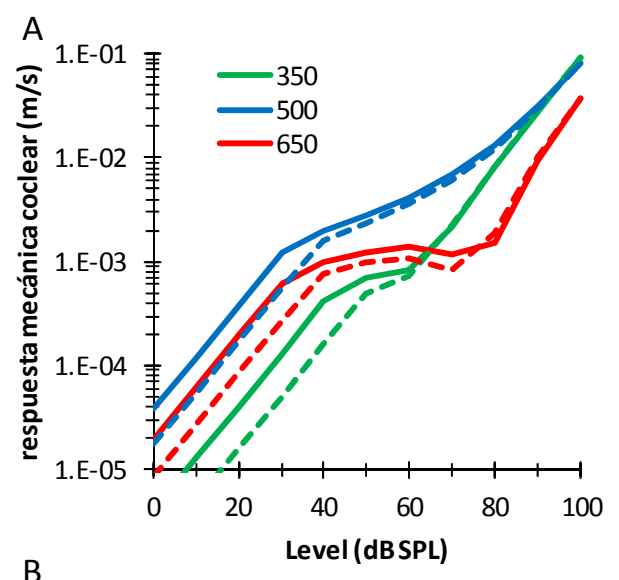

B

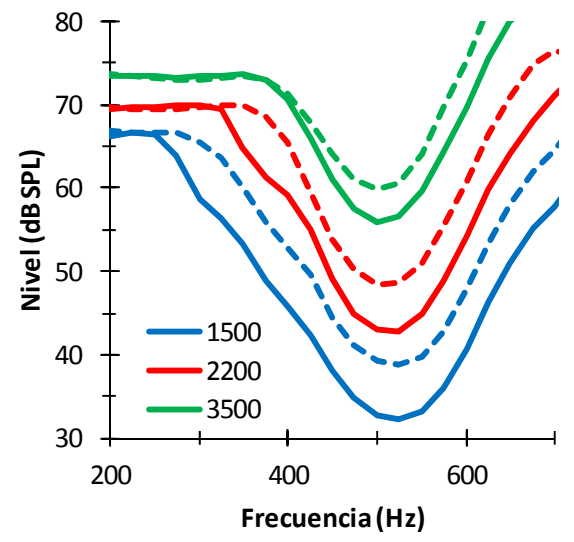

Figura 5.6. Respuesta mecánica coclear simulada con el configurado con los parámetros del sujeto S2 sin (línea continua) y con (línea discontinua) atenuación eferente (ATT $=6.9 \mathrm{~dB}$ ). A. IOCs para tres tonos enmascarantes cuya frecuencia se indica en la leyenda (en $\mathrm{Hz}$ ). B. Curvas de sintonización para tres distintos criterios de respuesta, como se indica $\mathrm{n}$ la leyenda (en $\mu \mathrm{m} / \mathrm{s}$ )

Las respuestas mecánicas de la Fig. 5.6 emergieron al ajustar el modelo para simular las PTCs experimentales. Además de sugerir que la compresión se extiende a un amplio rango de frecuencias en el ápex coclear, también demuestran que el modelo predice mayor compresión para algunos tonos de frecuencia mayor a la CF que para tonos de frecuencia igual a la CF, e incluso en algunos casos una 'muesca' o valle en la IOC (por ejemplo, en la Fig.5.6A, estas dos características ocurren en la IOC del tono de $650 \mathrm{~Hz}$ ). Debido a las dificultades técnicas existen pocos registros experimentales del ápex de la membrana basilar que permitan confirmar estas predicciones del modelo. Sin embargo, y pese al escaso número de registros, existe evidencia que apoya estas predicciones del modelo. Por ejemplo, la respuesta de la membrana tectoria en la región de $600 \mathrm{~Hz}$ muestra una mayor compresión para un tono de $800 \mathrm{~Hz}$ que para un tono a la CF [véase la Fig. 6A de (Rhode y Cooper 1996)]. También pueden observarse casos de mayor compresión para tonos de frecuencia mayor que CF que para tonos iguales a la CF, así como muescas, en las IOCs de la membrana de Reissner [véase, por ejemplo, las Figs. 3 y 4 de (Cooper y Rhode 1995)]. Igualmente, se han observado muescas en las respuestas individuales de fibras del nervio auditivo con CF baja (Gifford y Guinan 1983). Además, es relativamente frecuente encontrar mayor compresión para tonos de frecuencia mayor que la CF que para tonos de frecuencia igual a la CF, al igual que las muescas en las respuestas de la BM en las regiones basales o medias (véase las Figs. 3 y 11 de 
(Rhode y Recio 2000)]. En el presente modelo, las muescas ocurren como resultado de una cancelación entre las señales de salida de cada una de las dos resonancias del filtro DRNL, como han explicado Lopez-Poveda y Meddis (2001).

umbral
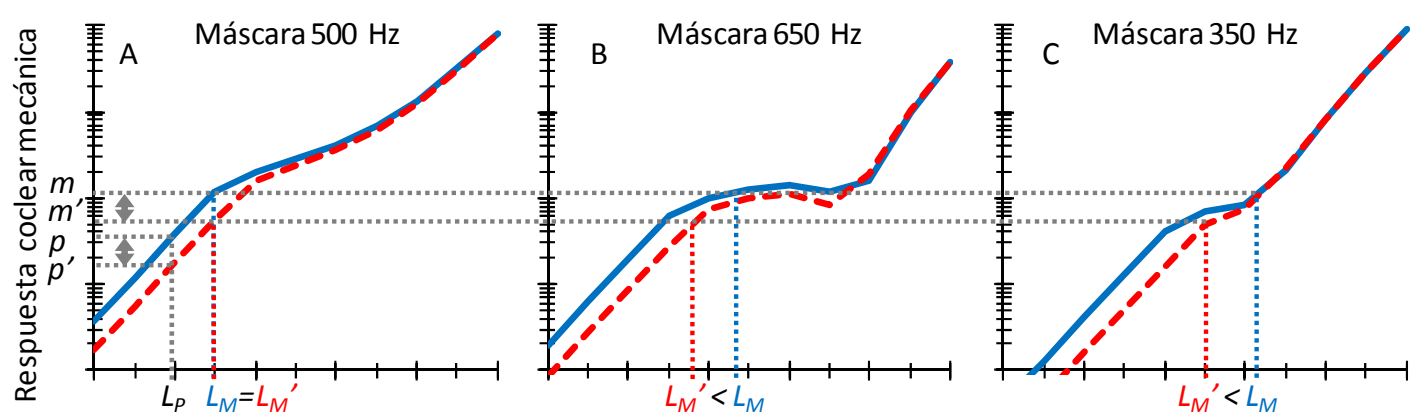

Supra umbral
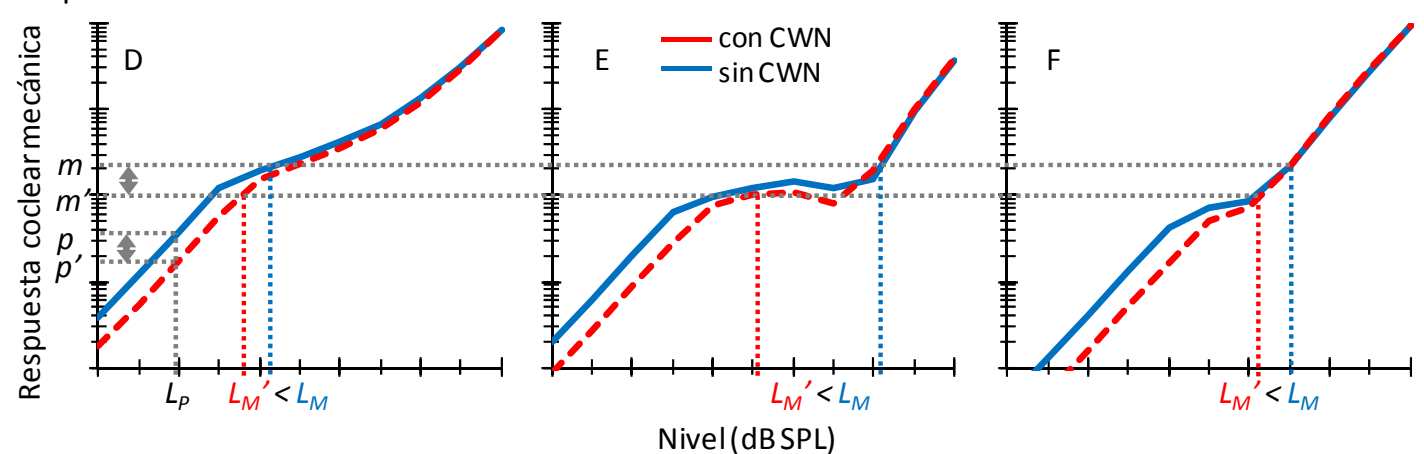

Figura 5.7. Diagrama de apoyo para explicar el efecto del CWN sobre las PTCs de $500 \mathrm{~Hz}$, basado en la respuesta mecánica coclear individual del modelo para el sujeto S2. Paneles superiores: Explican lo que ocurre en una condición cercana al umbral. Cada panel representa la curva de entrada-salida mecánica en presencia (línea discontinua) y en ausencia (línea continua) de atenuación eferente. Cada panel es para una frecuencia de estimulación (máscara) diferente, como se indica en la parte superior de cada panel. $L_{p}$ y $L^{\prime}{ }_{p}$ representan en nivel del tono sonda en ausencia y en presencia de CWN, respectivamente. $p$ y $p^{\prime}$ representan el nivel de excitación mecánica evocado por el tono sonda en ausencia y en presencia de CWN, respectivamente. $L_{M}$ y $L_{M}^{\prime}$ representan el nivel de la máscara necesario para enmascarar al tono sonda en ausencia y en presencia de CWN, respectivamente. $m$ y $m^{\prime}$ representan el nivel de excitación mecánica que debe provocar la máscara para enmascarar al tono de sonda en ausencia y en presencia de CWN, respectivamente. Paneles inferiores: Igual que los paneles superiores pero para una condición supra-umbral. Las curvas de entrada-salida son idénticas en los paneles superiores e inferiores. Véase el texto principal. 


\section{Discusión}

El análisis del modelo permite obtener una explicación sobre los mecanismos que subyacen al efecto del CWN sobre las PTCs (mostrado en la Fig. 5.7). Como ya se mencionó en los Capítulos 2, 3 y 4, los efectos del CWN probablemente se deben a una reducción de ganancia coclear mediada por la activación del MOCR. El modelo aquí descrito, no obstante, permite hacer un análisis más preciso y explicar cómo la manifestación psicoacústica de este efecto reductor de la ganancia depende de la compleja interacción entre la reducción de la ganancia dependiente de la frecuencia y del nivel sonoro, la sintonización, la compresión y la escucha fuera de frecuencia.

Se puede obtener una explicación general, pero esclarecedora, al analizar la respuesta de un filtro del modelo con una CF cercana a la frecuencia del tono sonda. En el modelo, se asume que el umbral de enmascaramiento ocurre cuando la relación entre la excitación sobre el receptor auditivo tiene un valor fijo $(p / m)$ (donde $p$ corresponde a la excitación provocada por la sonda y $m$ a la excitación provocada por la máscara) y esta relación no varía con el CWN. Es decir $p / m=p^{\prime} / m^{\prime}$, donde el superíndice prima se utiliza para representar la respuesta coclear mecánica en presencia de CWN (con atenuación eferente). La expresión anterior es equivalente a $m / m^{\prime}=p / p^{\prime}$. En otras palabras, en el modelo, el umbral de enmascaramiento ocurre cuando la relación de la excitación mecánica producida por cualquier máscara en la ausencia y presencia de CWN es igual a la relación de la excitación mecánica que provoca el tono de sonda en ausencia y presencia de CWN.

En los experimentos de las PTCs, el nivel SPL del tono sonda utilizado fue fijo e idéntico en las mediciones con y $\sin C W N$. Por lo tanto $p / p^{\prime}$ es un valor mayor que 1 como resultado de la atenuación eferente. La clave está en que el nivel de máscara necesario para producir la relación de excitación $\left(\mathrm{m} / \mathrm{m}^{\prime}\right)$ depende de la cantidad de compresión a la que está sujeta la máscara y que varía en el rango de excitación bajo el estudio. La Fig. 5.7 ilustra distintas posibilidades, utilizando el esquema de la respuesta mecánica predicha por el modelo para el sujeto S2 (adaptada de la Fig. $5.6 A)$. La relación de excitación $\left(p / p^{\prime}\right)$ se ilustra mediante una flecha vertical de dos puntas próxima al eje de ordenadas en las Figs. 5.7A y 5.7D. Los paneles superiores e inferiores ilustran lo que ocurriría en condiciones de excitación cercanas y lejanas al umbral, respectivamente. Vale decir, la excitación de la máscara en los paneles superiores es inferior que la excitación producida por la máscara en los paneles en los paneles inferiores. Es importante destacar que la relación de excitación de la máscara $\left(\mathrm{m} / \mathrm{m}^{\prime}\right)$ es idéntica en ambos casos e igual a la relación de excitación del tono sonda.

Analicemos primero lo que ocurre a niveles cercanos al umbral (paneles superiores de la Fig. 5.7). Para la máscara con $f_{m}=f_{p}$ (Fig. 5.7A), la atenuación eferente afecta de manera similar a la máscara y al tono sonda. Por lo tanto, se requieren idénticos niveles de máscara para enmascarar el tono sonda con y $\sin$ CWN $\left(L_{m}^{\prime}=L_{m}\right)$. Las máscaras de frecuencia lejana a la $f_{p}$ (altas y bajas) están sujetas a la compresión (Figs. 5.7B y $5.7 C$, respectivamente). Por ello, los niveles de máscara son inferiores 
con CWN que sin CWN $\left(L^{\prime}{ }_{m}<L_{m}\right)$. Esto explica por qué (en el modelo) el CWN no cambia los niveles de máscara de la punta de las PTCs cercanas al umbral pero reduce el nivel de máscara en los extremos de la PTC (Fig. 5.3).

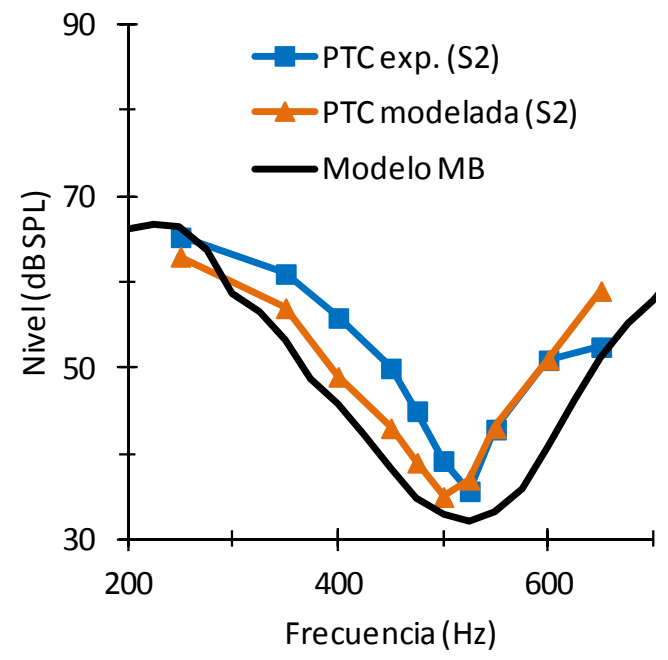

Figura 5.8. La importancia de la "escucha fuera de frecuencia" en las PTCs experimentales $y$ en las simuladas. Es importante destacar que la PTC modelada (y su correspondiente contraparte experimental) están más sintonizadas que las curvas de sintonización mecánicas del filtro coclear sintonizado a la frecuencia de la sonda como resultado de la escucha fuera de frecuencia. Es decir, la escucha fuera de frecuencia hace que la PTC parezca más sintonizada que la respuesta mecánica coclear correspondiente.

Los paneles de la fila de debajo de la Fig. 5.7 permiten analizar lo que ocurre en una situación supra-umbral. En este caso, como resultado de utilizar intervalos máscarasonda más prolongados, se necesitan mayores niveles de máscara para enmascarar de manera efectiva al tono de sonda. La respuesta de la máscara de frecuencia cercana a la $f_{p}$ (Fig. 5.7D) es compresiva en el rango de excitación de la máscara. Por lo tanto, el nivel de máscara necesario para enmascarar al tono sonda es menor en la condición con CWN $\left(L^{\prime}{ }_{m}<L_{m}\right)$. La respuesta para máscara con frecuencia mucho menor que la de la sonda (Fig. 5.7F) es prácticamente lineal sobre el rango de excitación en estudio, pero, sobre este rango de excitación, esta máscara no está afectada por la atenuación eferente. Por lo tanto, el nivel de máscara necesario es menor en presencia que en ausencia de CWN. La respuesta de una máscara de frecuencia alta, mayor que la de la sonda (Fig. 5.7E) es lineal sin CWN pero cae en una región compresiva con CWN. Por ello, el nivel de la máscara de frecuencia alta es significativamente más bajo en presencia que en ausencia de CWN; vale decir, es consistente con los resultados psicoacústicos. Esto puede explicar por qué el CWN reduce el nivel de todas las máscaras en la condición supra-umbral, pero la magnitud de la reducción fue mayor para frecuencias de máscara de frecuencia mayor que las de frecuencia menor a la de la sonda (Fig. 4.6).

En resumen, el efecto del CWN y por lo tanto el efecto de la atenuación eferente sobre las PTCs, depende tanto de la reducción de la ganancia coclear sobre la excitación del tono sonda como de la cantidad de compresión a la que están sujetas las máscaras.

Por supuesto, esta explicación del efecto del CWN sobre las PTCs de $500 \mathrm{~Hz}$ es solo aproximada. De hecho, no es posible obtener exactamente los valores de máscara 
simulados por el modelo (Fig. 5.3 y 5.5) directamente desde la Fig. 5.7. Una reproducción precisa involucraría una compleja interacción del fenómeno previamente descrito como el fenómeno de "escucha fuera de frecuencia". La escucha fuera de frecuencia, facilita la detección del tono sonda, lo que conduce a niveles de máscara más altos y a una mayor sintonización (O'Loughlin y Moore 1981). Una manera de evaluar la importancia de la escucha fuera de frecuencia es comparando la PTC simulada con la curva de sintonización para un filtro coclear de CF igual a la frecuencia del tono sonda. Esta comparación se muestra en la Fig. 5.8. Claramente, la PTC simulada es más sintonizada que la curva de sintonización del filtro coclear correspondiente (del modelo). Esto sugiere que la PTC simulada es más angosta como resultado de la escucha fuera de frecuencia. Dado que la PTC simulada se asemeja a la PTC experimental, es muy probable que las PTCs experimentales estén afectadas por la escucha fuera de frecuencia. De hecho no fue posible realizar una adecuada simulación de las PTCs experimentales con una versión del modelo sin escucha fuera de frecuencia (resultados no mostrados). En síntesis, es probable que la sintonización coclear real sea menor que la sugerida por las PTCs experimentales.

El modelo fenomenológico de enmascaramiento post-estimulatorio con control eferente reproduce de manera satisfactoria los principales hallazgos experimentales, reproduciendo el efecto del CWN con solo aplicar un control eferente. De hecho, el modelo sugiere que el efecto observado es el resultado de utilizar idéntico nivel SPL del tono sonda igual en la condición con y sin WCN combinado con la compresión (dependiente del nivel y la frecuencia) y la escucha fuera de frecuencia. En otras palabras, la presente evidencia sugiere que el efecto observado del CWN sobre las PTCs de $500 \mathrm{~Hz}$ se debe a la activación del MOCR contralateral y que la magnitud de la atenuación eferente es significativamente mayor a 500 que a $4000 \mathrm{~Hz}$.

El modelo de enmascaramiento post-estimulatorio aquí presentado es útil para explicar la compleja interacción entre los estímulos involucrados en la medición de las PTCs, pero constituye solo una representación somera de la cóclea y del funcionamiento del sistema auditivo. Por ejemplo, en el modelo se considera que la salida mecánica de la cóclea es el desplazamiento de la BM. Esto es probablemente incorrecto. De hecho, sería más correcto suponer que la salida mecánica de la cóclea viene dada por el accionar mecánico de los estereocilios de las $\mathrm{CCls}$, y este podría ser muy distinto al desplazamiento de la MB (Chen et al. 2011; Guinan 2012). De hecho, Chen et al. (2011) han demostrado directamente que la compresión es mayor en la lámina reticular, que se aproxima más al accionar mecánico de los estereocilios de las $\mathrm{CCl}$, que en la $\mathrm{MB}$.

El presente modelo y su interpretación contienen tres supuestos importantes sobre la tasa de recuperación post-mecánico del enmascaramiento post-estimulatorio, es decir, sobre la linealidad de la ventana temporal: 1) que es idéntica en las distintas regiones cocleares; 2 ) que es idéntica para las distintas frecuencias y niveles sonoros de las máscaras utilizados en las pruebas; y 3) que no está afectada por el CWN. Un estudio cuestiona el primer supuesto (Stainsby y Moore 2006) pero otro estudio lo apoya (Lopez-Poveda et al. 2008). Si la tasa de recuperación post-mecánico fuese 
más rápida en el ápex que en la base, como sugieren algunos autores (Stainsby y Moore 2006), entonces, la compresión en el ápex podría ser menor que la sugerida por el presente modelo. Respecto al segundo supuesto, es cierto para frecuencias de sonda de $4000 \mathrm{~Hz}$ y para máscaras de frecuencia lejanas a la de la sonda a niveles sonoro de máscaras $\leq 83 \mathrm{~dB}$, pero no para niveles $\geq 93 \mathrm{~dB}$ (Wojtczak y Oxenham 2009). Falta por demostrar si el supuesto se mantiene para $500 \mathrm{~Hz}$. En todo caso, casi todos los niveles de máscaras medidos están por debajo de $83 \mathrm{~dB}$, en especial para la frecuencia de $500 \mathrm{~Hz}$ (Fig. 5.3, 5.4 y 5.5). Respecto al tercer supuesto, en esta tesis se ha evidenciado que el CWN no altera la tasa de recuperación post-mecánica en la región de $4000 \mathrm{~Hz}$ (véase el Capítulo 3, Fig. 3.3, y el Capítulo 4, Fig. 4.2) pero no se puede asegurar que lo mismo ocurra en el ápex. Si el CWN disminuyese la tasa de recuperación post-mecánica, este fenómeno podría explicar, al menos en parte los resultados psicoacústicos. La compresión en el ápex se extiende a un rango amplio de frecuencias (Lopez-Poveda et al. 2003; Rhode y Cooper 1996) y, por tanto, no es posible realizar un experimento como el descrito en el Capítulo 4 (Fig. 11) para la frecuencia de $500 \mathrm{~Hz}$. En cualquier caso, el presente modelo incorpora los tres supuestos en cuestión (es decir, la ventana temporal fue idéntica en todas las condiciones) y reproduce las PTCs bastante bien, lo que sugiere que estos tres supuestos no son ilógicos.

Los resultados psicoacústicos y su análisis con el modelo sugieren que las PTCs apicales son afectadas por el CWN vía activación del haz MOC. Es importante destacar, además, que la forma y la magnitud de este efecto probablemente no puede obtenerse directamente de las pruebas psicoacústicas, por lo que se hace necesario un modelo computacional no lineal para inferir adecuadamente la magnitud del efecto del MOCR contralateral sobre las pruebas psicoacústicas.

El presente modelo ofrece una explicación para el efecto del CWN sobre las PTCS basado en la magnitud relativa de atenuación eferente sobre la respuesta mecánica de la máscara y del tono sonda. Esto es cualitativamente similar a lo propuesto para explicar el efecto contralateral (Kawase et al. 2000) e ipsilateral (Jennings et al. 2009; Strickland 2001) del MOCR. En un reciente estudio, se explica el efecto del MOCR ipsilateral sobre las PTCs a nivel umbral y supra-umbral a $4000 \mathrm{~Hz}$ utilizando un modelo conceptualmente similar al aquí presentado (Jennings y Strickland 2012b). Sin embargo, este último estudio proporciona sólo una explicación cualitativa a los resultados en humanos. El presente modelo ha sido cuidadosamente ajustado para reproducir cualitativa y cuantitativamente las PTCs en humanos a 500 y $4000 \mathrm{~Hz}$, y permite obtener, por tanto, una aproximación a la magnitud de la reducción de la ganancia coclear asociada al MOCR. Una característica destacable del modelo es que predice que la compresión se extiende a un rango amplio de frecuencias en $500 \mathrm{~Hz}$, en consonancia con estudios fisiológicos y psicoacústicos anteriores (Lopez-Poveda 2003; Plack y Drga 2003; Rhode y Cooper 1996).

\section{Conclusiones}

El modelo de enmascaramiento post-estimulatorio con control eferente logra 
reproducir adecuadamente de manera cualitativa y cuantitativa el efecto del CWN sobre las PTCs bajo el único supuesto que el CWN activa el MOCR y reduce la ganancia coclear de forma compatible con la fisiología. A partir de esto, el análisis de los resultados con el modelo sugieren que:

1. El efecto principal del CWN sobre las PTCs consiste en una disminución de la ganancia coclear, y que esta disminución es significativamente mayor en el ápex que en la base.

2. La manifestación del efecto $\mathrm{CWN}$ en las pruebas psicoacústica de enmascaramiento post-estimulatorio dependen de una compleja interacción de componentes mecánicos no lineales (por ejemplo, compresión y reducción de la ganancia coclear) y post-mecánicos (tasa de recuperación post-mecánica y escucha fuera de frecuencia).

3. No es posible obtener de manera directa información cualitativa respecto al efecto del CWN sobre las propiedades del receptor auditivo, por lo que se hace necesario el desarrollo de un modelo matemático-computacional que permita inferir dicha información.

4. La magnitud del efecto del CWN y, por tanto, del MOCR depende tanto de la reducción de la ganancia coclear sobre la excitación del tono sonda como de la cantidad de compresión a la que están sujetas las máscaras, vale decir, de las propiedades no lineales de la respuesta coclear. 


\section{Capítulo 6}

\section{Discusión general}

En este trabajo, se ha explorado el efecto de la estimulación acústica contralateral sobre la respuesta del receptor auditivo humano utilizando para ello técnicas psicoacústicas. En particular, se ha evaluado el efecto de un CWN sobre los umbrales absolutos de detección de tonos puros y la integración temporal, la tasa de recuperación del enmascaramiento post-estimulatorio (las TMCs), la componente post-mecánica del enmascaramiento post-estimulatorio (la TMC de referencia lineal), la ganancia y la compresión coclear (las IOCs inferidas a partir de las TMCs), y, finalmente, la selectividad frecuencial (las PTCs). Mediante experimentos de control, se ha descartado que los efectos observados sean producto de la activación del MEMR por parte del CWN (Capítulo 2, Fig. 2.1) o producto de la interacción del CWN con los estímulos ipsilaterales utilizados en las mediciones psicoacústicas (Capítulo 3, Fig. 3.2). Además, se ha demostrado que el efecto del CWN sobre las pruebas psicoacústicas de enmascaramiento post-estimulatorio se deben a una alteración del componente mecánico de éstas y no a alteraciones en la componente post-mecánica del enmascaramiento post-estimulatorio (Capítulo 3, Fig. 3.3, y Capítulo 4, Fig. 4.2). El análisis de las PTCs con un modelo computacional de enmascaramiento postestimulatorio desarrollado para este propósito sugiere que el CWN modifica la respuesta mecánica de la cóclea, afectando en particular a sus propiedades no lineales. De hecho, el modelo sugiere que los resultados psicoacústicos, aunque paradójicos, son, en realidad, compatibles con los efectos de activación del MOCR descritos por estudios fisiológicos en mamíferos (Guinan 2006). Esto permite sugerir, que los efectos del CWN sobre las medidas psicoacústicas aquí descritas se deben a una activación del MOCR contralateral. Los efectos principales se resumen en cada una de las siguientes secciones.

\section{El efecto del MOCR contralateral es mayor en la región coclear apical que en la basal}

Uno de los principales resultados de esta tesis es la demostración de que el efecto 
del CWN y, por tanto, del MOCR contralateral, es mayor en el ápex que en la base de la cóclea. Esto es consistente con las conclusiones de otros estudios realizados en humanos con técnicas de OAEs (Lilaonitkul y Guinan 2009a; Lilaonitkul y Guinan 2009b). Otros estudios psicoacústicos han descrito un importante efecto del MOCR ipsilateral en $4000 \mathrm{~Hz}$ (Jennings et al. 2009), pero no existe evidencia sobre la magnitud del MOCR ipsilateral en $500 \mathrm{~Hz}$. No obstante existe evidencia morfológica que señala que la relación de fibras involucradas en el MOCR contralateral vs el ipsilateral es mayor en el ápex (Guinan 2006). Lo contrario ocurriría en la base. Pese a que los resultados observados no muestran un efecto significativo del MOCR en $4000 \mathrm{~Hz}$, no es posible descartarlo del todo, entre otras cosas porque el método adaptativo utilizado en los experimentos no detecta variaciones de nivel sonoro menores a $2 \mathrm{~dB}$.

\section{El MOCR contralateral reduce la ganancia coclear y por tanto la sensibilidad auditiva}

En el Capítulo 2, se ha evidenciado una pequeña disminución del umbral absoluto de tonos puros por la presencia de CWN. En el Capítulo 3, se ha descrito que el CWN afecta a las TMCs de manera distinta, dependiendo de si fueron medidas con sondas de idéntico nivel sonoro (SPL) o idéntica excitación: el umbral de las máscaras disminuye o aumenta en cada uno de los dos casos, respectivamente. En el Capítulo 4, se ha demostrado que el nivel de las máscaras implicadas en una PTC desciende producto de la presencia de un CWN. En todos estos casos, los hallazgos son compatibles con una disminución de la ganancia producto de la presencia del CWN. Esta idea, que ya ha sido discutida con detalle en cada uno de los capítulos, se ha corroborado en el Capítulo 5 al demostrar que se puede reproducir el efecto del CWN sobre las PTCs con la sola atenuación de la ganancia coclear inspirada en (y, por tanto, consistente con) un amplio número de estudios fisiológicos previos.

\section{El MOCR contralateral provoca una linealización de la función coclear de entrada-salida}

Se ha demostrado que el CWN linealiza la curva de entrada/salida coclear inferida a partir de la TMCs. Este resultado concuerda con las conclusiones de estudios relacionados dirigidos a explorar el papel del MOCR ipsilateral sobre la no linealidad coclear (Jennings y Strickland 2012a; Jennings y Strickland 2012b; Jennings et al. 2009; Krull y Strickland 2008; Roverud y Strickland 2010), si bien estos anteriores sólo explicitan una reducción de la ganancia coclear. Como ya se ha discutido con detalle en el Capítulo 3, este efecto podría tratarse de un correlato psicoacústico del efecto "desenmascarante" del MOCR descrito a partir de los efectos de activación del MOCR sobre las curvas de descarga/intensidad de las fibras del nervio auditivo (Kawase et al. 1993; Winslow y Sachs 1987). Como también se discutió en el Capítulo 3 , es posible que esta linealización tenga como función mejorar la detección de estímulos transitorios en ambiente ruidoso (Bhagat y Carter 2010; Micheyl y Collet 1996) y, por lo tanto, la discriminación verbal en ambiente ruidoso por una mejora 
de la resolución temporal del estímulo verbal. En el apartado de Desafíos futuros del presente capítulo se propone un experimento diseñado para evaluar esta posibilidad.

\section{Las manifestaciones psicoacústicas del efecto del MOCR contralateral depende de las propiedades no lineales de la respuesta coclear humana}

A lo largo de este trabajo, se ha sugerido que los efectos del CWN sobre los umbrales absolutos de detección de tonos puros y sobre el enmascaramiento postestimulatorio son compatibles con una reducción de la ganancia coclear. Sin embargo, los efectos del CWN, y, por tanto, del MOCR contralateral, sobre las pruebas psicoacústicas empleadas son diversos. Por ejemplo, hemos demostrado que en el caso de las PTCs de niveles cercanos al umbral, el CWN reduce el nivel sonoro de las máscaras en las colas pero no en la punta de la PTC de $500 \mathrm{~Hz}$; en las PTCs supra-umbral, por el contrario, la reducción en el nivel sonoro se extiende a todas las frecuencias de máscara. El análisis de estos resultados con el modelo computacional, sugiere que estos resultados, aunque aparentemente paradójicos, son, en realidad, compatibles con una reducción de la ganancia coclear cuya magnitud varía en función de la frecuencia y el nivel sonoro de las máscaras, combinada con la cantidad de compresión a la que están sujetas las máscaras. También hemos demostrado que al momento de analizar los resultados psicoacústicos, se deben considerar también otros efectos propios de estas pruebas como la escucha fuera de frecuencia. En síntesis, la manifestación del efecto del CWN sobre las pruebas psicoacústicas depende de una compleja interacción de componentes fundamentalmente derivados de la no linealidad coclear que sólo pueden desvelarse empleando un modelo computacional que incorpore respuestas cocleares mecánicas y un control eferente compatible con la fisiología.

\section{Implicaciones teóricas, prácticas y tecnológicas}

Muchas teorías y modelos de percepción auditiva humana están basadas en mediciones psicoacústicas. En el desarrollo de estas teorías y sus aplicaciones tecnológicas (por ejemplo, audífonos, implantes cocleares o sistemas de compresión de audio tipo MP3) se suele considerar a la respuesta de nuestros receptores auditivos como fija e independiente el uno del otro. Es decir, se suele considerar que las características inferidas en mediciones experimentales monoaurales son representativas de la respuesta del receptor auditivo en un ambiente natural de escucha binaural. La evidencia presentada en esta tesis pone de manifiesto que este supuesto es probablemente erróneo, y que la respuesta coclear puede cambiar dependiendo de la presencia de un sonido contralateral. Este hecho debería tenerse en cuenta en el futuro, a la hora de desarrollar teorías auditivas y sus aplicaciones tecnológicas. 


\section{Desafíos futuros}

El conocimiento aquí generado respecto al efecto del MOCR contralateral sobre la respuesta coclear humana conduce es limitado y abre numerosas nuevas interrogantes que complementan las cuestiones abordadas en esta tesis. Entre ellos, cabe mencionar los siguientes:

1. Ampliar el espectro de frecuencias estudiadas. En esta tesis, se ha evidenciado que las técnicas utilizadas son adecuadas para evaluar el impacto del MOCR contralateral sobre las propiedades no lineales del receptor auditivo. Por otro lado, se sospecha que las características de la respuesta coclear mecánica cambian de forma significativa en torno a $1000-1500 \mathrm{~Hz}$ (Robles y Ruggero 2001). Parece, por tanto, razonable extender el protocolo de experimentación aquí propuesto a otras frecuencias de sonda con el fin de conocer el potencial efecto del MOCR contralateral en otras regiones cocleares, en particular en frecuencias medias y en frecuencias extremas (muy altas o muy bajas).

2. Conocer el efecto de la intensidad del estímulo acústico sobre la magnitud de MOCR contralateral. En condiciones reales de escucha binaural la intensidad del estímulo contralateral varía en el tiempo. Por otro lado, existe evidencia fisiológica obtenida con técnicas de OAEs, de que la magnitud de la reducción de las OAEs es proporcional a la intensidad del estímulo evocador del MOCR a partir de una intensidad de $40 \mathrm{~dB}$ (cf. Capítulo 1). En esta tesis, el MOCR contralateral se ha desencadenado empleando un ruido blanco contralateral de intensidad fija de $60 \mathrm{~dB}$ SPL. Por tanto, parece lógico plantearse hasta qué punto el efecto del MOCR contralateral dependería de la intensidad del CWN evocador del MOCR. Dado que aquí hemos descartado que el CWN de $60 \mathrm{~dB}$ SPL desencadene el MEMR, al menos para frecuencias entre 400 y $4000 \mathrm{~Hz}$, resultaría posible realizar el experimento propuesto empleando CWNs con intensidades entre 40 y $60 \mathrm{~dB}$ SPL.

3. Caracterizar el efecto del MOCR contralateral sobre la respuesta coclear humana, en función de las características espectrales del estímulo acústico contralateral evocador. Se ha observado mediante técnicas fisiológicas de OAEs que la reducción en el nivel de OAEs es mayor cuanto mayor es el ancho de banda del estímulo acústico contralateral evocador del MOCR (Lisowska et al. 2002; Maison et al. 2000; Velenovsky y Glattke 2002). Queda por demostrar, sin embargo, cuál es el correlato perceptual de esta observación fisiológica, si es que existe. Con este fin, se podría aplicar el protocolo experimental aquí descrito variando el ancho de banda del ruido contralateral evocador del MOCR.

4. Caracterizar la magnitud del MOCR contralateral en función de la frecuencia del estímulo contralateral evocador del MOCR. Se sabe que un estímulo contralateral evocador del MOCR reduce el nivel de OAEs y que la reducción es mayor cuando la frecuencia del estímulo evocador es ligeramente mayor que la frecuencia del tono sonda (Lilaonitkul y Guinan 2009b). Se desconoce, sin embargo, si este 
fenómeno fisiológico tiene un correlato perceptual. Con el fin de comprobar esta posibilidad, se podría utilizar ruidos de banda estrecha como evocadores del MOCR y comprobar sus efectos sobre las PTCs y/o TMCs, variando la frecuencia central de dichos ruidos.

5. Evidenciar el supuesto efecto desenmascarante del MOCR sobre la percepción del habla en ambiente ruidoso. Uno de los principales hallazgos del presente estudio es que el CWN linealiza la función de entrada/salida coclear humana. Esta linealización podría ir en línea con el "efecto desenmascarante" observado sobre las fibras del nervio auditivo producto de la activación del haz olivococlear (Kawase et al. 1993; Winslow y Sachs 1987), que facilitaría la detección de sonidos transitorios en presencia de ruido. De este fenómeno se desprende que una de las utilidades del sistema auditivo eferente sería la de facilitar la discriminación del habla en ambiente ruidoso. De hecho, estudios recientes de simulación computacional predicen una mejoría en la discriminación en ambiente ruidoso producto de la activación del sistema eferente (Brown et al. 2010; Clark et al. 2012; Messing et al. 2009). Sin embargo, todavía no se ha logrado evidenciar este efecto desenmascarante sobre la inteligibilidad del habla en ambiente ruidoso en situaciones reales de escucha (de Boer et al. 2012; Mukari y Mamat 2008; Wagner et al. 2008).

Considerando los resultados obtenidos en los resultados experimentales aquí presentados, es posible sugerir que la metodología empleada en dichos estudios podría haber sido inadecuada. Aquí hemos puesto de manifiesto que el efecto del CWN es mayor a 500 que a $4000 \mathrm{~Hz}$. Por lo tanto es probable que el potencial impacto beneficioso de sistema eferente esté limitado a un rango de frecuencias. En la mayoría de estudios anteriores, sin embargo, se han empleado estímulos verbales que poseen un rango de frecuencias amplio, por lo que el posible efecto beneficioso del MOCR, al estar limitado en frecuencia, podría ser "enmascarado". Es decir, si se considera que el habla posee una cantidad importante de información redundante, el cerebro podría utilizar más de una pista para discriminar el estímulo verbal en una situación compleja como es en ambiente ruidoso, y por ello el supuesto efecto beneficioso de la activación del MOCR pasaría desapercibido.

Durante el desarrollo de esta tesis se realizó un experimento piloto, orientado a diseñar una prueba de percepción del habla que permita evidenciar el efecto beneficioso del MOCR sobre la inteligibilidad en ambiente ruidoso y relacionar estos hallazgos con la reducción de la ganancia observada en los experimentos anteriores de este proyecto. La manera de sensibilizar la prueba fue reducir el contenido frecuencial de los estímulos verbales con el objetivo de estudiar regiones cocleares en torno a $500 \mathrm{~Hz}$ (que corresponde con la región donde se observaron mayores efectos del MOCR en esta tesis). Se midió la percepción de tripletes de dígitos filtrados en presencia y en ausencia de ruido de fondo y las mediciones se realizaron en presencia y ausencia de CWN. Los resultados preliminares obtenidos muestran una pequeña mejoría en la identificación verbal 
cuando se activa el MOCR contralateral. Esta mejoría depende de la relación señal/ruido utilizada. Este hallazgo anima a continuar con esta línea de investigación. En principio se propone evaluar este potencial efecto beneficioso sobre la discriminación del habla en ambiente ruidoso, en sujetos normoyentes y con estímulos verbales filtrados de manera que permitan medir el efecto del MOCR sobre distintas regiones cocleares. 


\section{Conclusiones}

Los distintos experimentos descritos en esta tesis evidencian que el ruido blanco contralateral tiene un efecto sobre la percepción auditiva. Dos experimentos control han permitido descartar que dicho efectos se deban a la activación del reflejo muscular del oído medio y dado que el ruido blanco empleado puede evocar el MOCR, es probable que los efectos observados se deban a una activación de éste.

El análisis e integración de los resultados experimentales permite concluir que:

1. EI MOCR contralateral reduce la sensibilidad auditiva y eleva los umbrales absolutos de detección de tonos puros. Este incremento es independiente de la duración del tono sonda.

2. EI MOCR contralateral linealiza la función de entrada-salida coclear inferida por métodos psicoacústicos.

3. El MOCR contralateral disminuye el nivel sonoro de las máscaras implicadas en la obtención de las curvas psicoacústicas de sintonización. La magnitud de la reducción depende de la frecuencia y el nivel sonoro de las máscaras. Aunque paradójicos en apariencia, estos efectos son compatibles con los de activación del MOCR sobre las curvas de sintonización de la membrana basilar descritos en otros mamíferos.

4. El análisis de las curvas psicoacústicas de sintonización con un modelo computacional sugiere que el ruido blanco contralateral activa el MOCR quien, a su vez, reduce la ganancia coclear. La magnitud de esta reducción depende de la intensidad y de la frecuencia del estímulo.

5. Todas las pruebas psicoacústicas utilizadas evidencian un mayor efecto del MOCR contralateral sobre la región apical de la cóclea que sobre la región basal. 



\section{Referencias}

Aguilar E, Eustaquio-Martin A, Lopez-Poveda EA (2013) Contralateral efferent reflex effects on threshold and suprathreshold psychoacoustical tuning curves at low and high frequencies. J Assoc Res Otolaryngol 14:341-357.

Atcherson SR, Martin MJ, Lintvedt R (2008) Contralateral noise has possible asymmetric frequency-sensitive effect on the 2F1-F2 otoacoustic emission in humans. Neurosci Lett 438:107-110.

Bacon SP, Fay RR, Popper AN. (2004). Compression: From cochlea to cochlear implants. Springer-Verlag, New York.

Berlin Cl, Hood LJ, Wen H, Szabo P, Cecola RP, Rigby P, Jackson DF (1993) Contralateral suppression of non-linear click-evoked otoacoustic emissions. Hear Res 71:1-11.

Bhagat SP, Carter PH (2010) Efferent-induced change in human cochlear compression and its influence on masking of tones. Neurosci Lett 485:94-97.

Brown GJ, Ferry RT, Meddis R (2010) A computer model of auditory efferent suppression: implications for the recognition of speech in noise. J Acoust Soc Am 127:943-954.

Brown MC (1989) Morphology and response properties of single olivocochlear fibers in the guinea pig. Hear Res 40:93-109.

Chambers AR, Hancock KE, Maison SF, Liberman MC, Polley DB (2012) Sound-evoked olivocochlear activation in unanesthetized mice. J Assoc Res Otolaryngol 13:209-217.

Chen F, Zha D, Fridberger A, Zheng J, Choudhury N, Jacques SL, Wang RK, Shi X, Nuttall AL (2011) A differentially amplified motion in the ear for near-threshold sound detection. Nat Neurosci 14:770-774.

Chery-Croze S, Moulin A, Collet L (1993) Effect of contralateral sound stimulation on the distortion product 2f1-f2 in humans: evidence of a frequency specificity. Hear Res 68:53-58.

Clark NR, Brown GJ, Jurgens T, Meddis R (2012) A frequency-selective feedback model of auditory efferent suppression and its implications for the recognition 
of speech in noise. J Acoust Soc Am 132:1535-1541.

Collet L, Kemp DT, Veuillet E, Duclaux R, Moulin A, Morgon A (1990) Effect of contralateral auditory stimuli on active cochlear micro-mechanical properties in human subjects. Hear Res 43:251-261.

Cooper NP (1996) Two-tone suppresion in cochlear mechanics. J Acoust Soc Am 99:3087-3098.

Cooper NP (2004) Compression in the peripheral auditoy system. In: Bacon SP, Fay RR, Popper AN (eds) Compression: From cochlea to cochlear implants: Springer-Verlag, New York, pp. 18-61.

Cooper NP, Guinan JJ (2006) Efferent-mediated control of basilar membrane motion. J Physiol 576:49-54.

Cooper NP, Rhode WS (1995) Nonlinear mechanics at the apex of the guinea-pig cochlea. Hearing Research 82:225-243.

de Boer J, Thornton AR, Krumbholz K (2012) What is the role of the medial olivocochlear system in speech-in-noise processing? J Neurophysiol 107:13011312.

Dolan DF, Guo MH, Nuttall AL (1997) Frequency-dependent enhancement of basilar membrane velocity during olivocochlear bundle stimulation. J Acoust Soc Am 102:3587-3596.

Elgueda D, Delano PH, Robles L (2011) Effects of electrical stimulation of olivocochlear fibers in cochlear potentials in the chinchilla. J Assoc Res Otolaryngol 12:317-327.

Eustaquio-Martin A, Lopez-Poveda EA (2011) Isoresponse versus isoinput estimates of cochlear filter tuning. J Assoc Res Otolaryngol 12:281-299.

Evans EF (2001) Latest comparison between physiological and behavioral frequency selectivity. In: Breebaart J, Houtsma AJM, Kohlraush A, Prijs VF, Schoonhoven R (eds) Physiological and psychophysical bases of auditory function: Shaker, Maastricht, pp. 382-387.

Ferry RT, Meddis R (2007) A computer model of medial efferent suppression in the mammalian auditory system. J Acoust Soc Am 122:3519-3526.

Francis NA, Guinan JJ (2010) Acoustic stimulation of human medial olivocochlear efferents reduces stimulus-frequency and click-evoked otoacoustic emission delays: Implications for cochlear filter bandwidths. Hear Res 267:36-45.

Gifford ML, Guinan JJ (1983) Effects of crossed-olivocochlear-bundle stimulation on cat auditory nerve fiber responses to tones. J Acoust Soc Am 74:115-123.

Guinan JJ (1996) Physiology of Olivocochlear Efferents. In: Dallos P, Popper AN, Fay RR (eds) The Cochlea: Springer-Verlag, New York, pp. 435-502.

Guinan JJ (2006) Olivocochlear efferents: Anatomy, physiology, function, and the measurement of efferent effects in humans. Ear Hear 27:589-607.

Guinan JJ (2010) Cochlear efferent innervation and function. Curr Opin Otolaryngol Head Neck Surg 18:447-453.

Guinan JJ (2012) How are inner hair cells stimulated? Evidence for multiple mechanical drives. Hear Res 292:35-50.

Guinan JJ, Backus BC, Lilaonitkul W, Aharonson V (2003) Medial olivocochlear efferent reflex in humans: Otoacoustic emission (OAE) measurement issues 
and the advantages of stimulus frequency OAEs. J Assoc Res Otolaryngol 4:521540.

Guinan JJ, Cooper NP (2008) Medial olivocochlear efferent inhibition of basilarmembrane responses to clicks: evidence for two modes of cochlear mechanical excitation. J Acoust Soc Am 124:1080-1092.

Guinan JJ, Gifford ML (1988a) Effects of electrical stimulation of efferent olivocochlear neurons on cat auditory-nerve fibers. I. Rate-level functions. Hear Res 33:97-113.

Guinan JJ, Gifford ML (1988b) Effects of electrical stimulation of efferent olivocochlear neurons on cat auditory-nerve fibers. III. Tuning curves and thresholds at CF. Hear Res 37:29-45.

Heil P, Neubauer H (2001) Temporal integration of sound pressure determines thresholds of auditory-nerve fibers. Journal of Neuroscience 21:7404-7415.

Heil P, Neubauer H (2003) A unifying basis of auditory thresholds based on temporal summation. PNAS 100:6151-6156.

Heil P, Neubauer H, Brown M, Irvine DR (2008) Towards a unifying basis of auditory thresholds: distributions of the first-spike latencies of auditory-nerve fibers. Hear Res 238:25-38.

Hood LJ, Berlin Cl, Hurley A, Cecola RP, Bell B (1996) Contralateral suppression of transient-evoked otoacoustic emissions in humans: intensity effects. Hear Res 101:113-118.

Irino T, Patterson R (2006) A dynamic, copressive gammachirp auditroy filterbank. IEEE Transactions on Audio, Speech and Language Processing In press.

Jennings SG, Strickland EA (2012a) Auditory filter tuning inferred with short sinusoidal and notched-noise maskers. J Acoust Soc Am 132:2497-2513.

Jennings SG, Strickland EA (2012b) Evaluating the effects of olivocochlear feedback on psychophysical measures of frequency selectivity. J Acoust Soc Am 132:2483-2496.

Jennings SG, Strickland EA, Heinz MG (2009) Precursor effects on behavioral estimates of frequency selectivity and gain in forward masking. J Acoust Soc Am 125:2172-2181.

Johannesen PT, Lopez-Poveda EA (2008) Cochlear nonlinearity in normal-hearing subjects as inferred psychophysically and from distortion-product otoacoustic emissions. J Acoust Soc Am 124:2149-2163.

Johannesen PT, Lopez-Poveda EA (2010) Correspondence between behavioral and individually "optimized" otoacoustic emission estimates of human cochlear input/output curves. J Acoust Soc Am 127:3602-3613.

Kawase T, Delgutte B, Liberman MC (1993) Antimasking effects of the olivocochlear reflex. II. Enhancement of auditory-nerve response to masked tones. J Neurophysiol 70:2533-2549.

Kawase T, Ogura M, Hidaka H, Sasaki N, Suzuki Y, Takasaka T (2000) Effects of contralateral noise on measurement of the psychophysical tuning curve. Hear Res 142:63-70.

Kidd GJ, Feth LL (1981) Patterns of residual masking. Hear Res 5:49-67.

Kluk K, Moore BC (2004) Factors affecting psychophysical tuning curves for normally 
hearing subjects. Hear Res 194:118-134.

Krull V, Strickland EA (2008) The effect of a precursor on growth of forward masking. J Acoust Soc Am 123:4352-4357.

Levitt H (1971) Transformed Up-Down Methods in Psychoacoustics. Journal of the Acoustical Society of America 49:467-\&.

Lilaonitkul W, Guinan JJ (2009a) Human medial olivocochlear reflex: effects as functions of contralateral, ipsilateral, and bilateral elicitor bandwidths. J Assoc Res Otolaryngol 10:459-470.

Lilaonitkul W, Guinan JJ (2009b) Reflex control of the human inner ear: a half-octave offset in medial efferent feedback that is consistent with an efferent role in the control of masking. J Neurophysiol 101:1394-1406.

Lilaonitkul W, Guinan JJ (2012) Frequency tuning of medial-olivocochlear-efferent acoustic reflexes in humans as functions of probe frequency. J Neurophysiol 107:1598-1611.

Lisowska G, Smurzynski J, Morawski K, Namyslowski G, Probst R (2002) Influence of contralateral stimulation by two-tone complexes, narrow-band and broad-band noise signals on the 2f1-f2 distortion product otoacoustic emission levels in humans. Acta Otolaryngol 122:613-619.

Lopez-Poveda EA (2003) An aproximate transfer function for the dual-resonance nonlinear filter model of auditory frequency selectivity. J Acoust Soc Am 114:2112-2117.

Lopez-Poveda EA (2005) Spectral processing by the peripheral auditory system: Facts and models. Auditory Spectral Processing 70:7-48.

Lopez-Poveda EA, Aguilar E, Johannesen PT, Eustaquio-Martin A (2013) Contralateral efferent regulation of human cochlear tuning: behavioural observations and computer model simulations. Adv Exp Med Biol 787:47-54.

Lopez-Poveda EA, Alves-Pinto A (2008) A variant temporal-masking-curve method for inferring peripheral auditory compression. J Acoust Soc Am 123:1544-1554.

Lopez-Poveda EA, Alves-Pinto A, Palmer AR, Eustaquio-Martin A (2008) Rate versus time representation of high-frequency spectral notches in the peripheral auditory system: A computational modeling study. Neurocomput 71:693-703.

Lopez-Poveda EA, Barrios LF, Alves-Pinto A (2007) Psychophysical estimates of leveldependent best-frequency shifts in the apical region of the human basilar membrane. J Acoust Soc Am 121:3646-3654.

Lopez-Poveda EA, Eustaquio-Martin A (2013) On the Controversy About the Sharpness of Human Cochlear Tuning. J Assoc Res Otolaryngol.

Lopez-Poveda EA, Johannesen PT (2010) Otoacoustic emission theories can be tested with behavioral methods. In: Lopez-Poveda EA, Palmer AR, Meddis R (eds) The neurophysiological bases of auditory perception: Springer, New York, pp. 3-14.

Lopez-Poveda EA, Johannesen PT (2012) Behavioral estimates of the contribution of inner and outer hair cell dysfunction to individualized audiometric loss. J Assoc Res Otolaryngol 13:485-504.

Lopez-Poveda EA, Meddis R (2001) A human nonlinear cochlear filterbank. J Acoust Soc Am 110:3107-3118.

Lopez-Poveda EA, Plack CJ, Meddis R (2003) Cochlear nonlinearity between 500 and 
$8000 \mathrm{~Hz}$ in listeners with normal hearing. J Acoust Soc Am 113:951-960.

Lopez-Poveda EA, Plack CJ, Meddis R, Blanco JL (2005) Cochlear compression in listeners with moderate sensorineural hearing loss. Hearing Research 205:172183.

Maison S, Micheyl C, Andeol G, Gallego S, Collet L (2000) Activation of medial olivocochlear efferent system in humans: influence of stimulus bandwidth. Hear Res 140:111-125.

Maison S, Micheyl C, Collet L (1997) Medial olivocochlear efferent system in humans studied with amplitude-modulated tones. J Neurophysiol 77:1759-1768.

Meddis R (2006) Auditory-nerve first-spike latency and auditory absolute threshold: A computer model. J Acoust Soc Am 119:406-417.

Meddis R, O'Mard L, Lopez-Poveda EA (2001) A computational algorithm for computing nonlinear auditory frequency selectivity. J Acoust Soc Am 109:28522861.

Meddis R, Lopez-Poveda EA, Popper AN, Fay RR. (2010). Computational Models of the Auditory System. Springer, New York.

Messing DP, Delhorne L, Bruckert E, Braida LD, Ghitza O (2009) A non-linear efferentinspired model of the auditory system; matching human confusions in stationary noise. Speech Com 51:668-683.

Micheyl C, Collet $L$ (1996) Involvement of the olivocochlear bundle in the detection of tones in noise. J Acoust Soc Am 99:1604-1610.

Moore BCJ. (2007). Cochlear Hearing Loss. John Wiley \& Sons, Ltd., Chichester.

Moore BCJ, Glasberg BR, Roberts B (1984) Refining the measurement of psychophysical tuning curves. J Acoust Soc Am 76:1057-1066.

Mukari SZ, Mamat WH (2008) Medial olivocochlear functioning and speech perception in noise in older adults. Audiol Neurootol 13:328-334.

Murugasu E, Russell IJ (1996) The effect of efferent stimulation on basilar membrane displacement in the basal turn of the guinea pig cochlea. J Neurosci 16:325332.

Nelson DA, Schroder AC, Wojtczak M (2001) A new procedure for measuring peripheral compression in normal-hearing and hearing-impaired listeners. J Acoust Soc Am 110:2045-2064.

O'Loughlin BJ, Moore BCJ (1981) Off-frequency listening: effects on psychoacoustical tuning curves obtained in simultaneous and forward masking. J Acoust Soc Am 69:1119-1125.

Oxenham AJ (2001) Forward masking: Adaptation or integration? J Acoust Soc Am 109:732-741.

Oxenham AJ, Bacon SP (2003) Cochlear compression: perceptual measures and implications for normal and impaired hearing. Ear \& Hearing 24:352-366.

Oxenham AJ, Moore BC (1994) Modeling the additivity of nonsimultaneous masking. Hear Res 80:105-118.

Patterson R, Unoki M, Irino T (2003) Extending the domain of center frequencies for the compressive gammachirp auditory filter. J Acoust Soc Am 114:1529-1542.

Patterson RD, Nimmo-Smith I (1980) Off-frequency listening and auditory-filter asymmetry. J Acoust Soc Am 67:229-245. 
Philibert B, Veuillet E, Collet L (1998) Functional asymmetries of crossed and uncrossed medial olivocochlear efferent pathways in humans. Neurosci Lett 253:99-102.

Plack CJ, Drga V (2003) Psychophysical evidence for auditory compression at low characteristic frequencies. J Acoust Soc Am 113:1574-1586.

Plack CJ, Drga V, Lopez-Poveda EA (2004) Inferred basilar-membrane response functions for listeners with mild to moderate sensorineural hearing loss. J Acoust Soc Am 115:1684-1695.

Plack CJ, Oxenham AJ, Drga V (2002) Linear and nonlinear processes in temporal masking. Acta Acustica united with Acustica 88:348-358.

Plack CJ, Skeels V (2007) Temporal integration and compression near absolute threshold in normal and impaired ears. J Acoust Soc Am 122:2236-2244.

Quaranta N, Scaringi A, Nahum S, Quaranta A (2005) Effects of efferent acoustic reflex activation on psychoacoustical tuning curves in humans. Acta Otolaryngol 125:520-523.

Rhode WS, Cooper NP (1996) Nonlinear mechanics in the apical turn of the chinchilla cochlea in vivo. Aud Neurosci 3:101-121.

Rhode WS, Recio A (2000) Study of mechanical motions in the basal region of the chinchilla cochlea. J Acoust Soc Am 107:3317-3332.

Robertson D, Gummer M (1985) Physiological and morphological characterization of efferent neurones in the guinea pig cochlea. Hear Res 20:63-77.

Robles L, Ruggero MA (2001) Mechanics of the mammalian cochlea. Physiol Rev 81:1305-1352.

Roverud E, Strickland EA (2010) The time course of cochlear gain reduction measured using a more efficient psychophysical technique. J Acoust Soc Am 128:1203-1214.

Ruggero MA, Rich NC, Recio A, Narayan SS, Robles L (1997) Basilar-membrane responses to tones at the base of the chinchilla cochlea. J Acoust Soc Am 101:2151-2163.

Ruggero MA, Robles L, Rich NC (1992) Two-tone suppression in the basilar membrane of the cochlea: mechanical basis of auditory-nerve rate suppression. J Neurophysiol 68:1087-1099.

Russell IJ, Murugasu E (1997) Medial efferent inhibition suppresses basilar membrane responses to near characteristic frequency tones of moderate to high intensities. J Acoust Soc Am 102:1734-1738.

Shera CA, Guinan JJ, Oxenham AJ (2002) Revised estimates of human cochlear tuning from otoacoustic and behavioral measurements. Proc Natl Acad Sci U S A 99:3318-3323.

Small AM (1959) Pure-tone masking. J Acoust Soc Am 31:1619-1625.

Souter M (1995) Suppression of stimulus frequency otoacoustic emissions by contralateral noise. Hear Res 91:167-177.

Stainsby TH, Moore BC (2006) Temporal masking curves for hearing-impaired listeners. Hear Res 218:98-111.

Strickland EA (2001) The relationship between frequency selectivity and overshoot. J Acoust Soc Am 109:2062-2073. 
Sumner CJ, O'Mard LP, Lopez-Poveda EA, Meddis R (2003) A nonlinear filter-bank model of the guinea-pig cochlear nerve: rate responses. Journal of the Acoustical Society of America 113:3264-3274.

Sun XM (2008) Contralateral suppression of distortion product otoacoustic emissions and the middle-ear muscle reflex in human ears. Hear Res 237:66-75.

van Zyl A, Swanepoel D, Hall JW, III (2009) Effect of prolonged contralateral acoustic stimulation on transient evoked otoacoustic emissions. Hear Res 254:77-81.

Velenovsky DS, Glattke TJ (2002) The effect of noise bandwidth on the contralateral suppression of transient evoked otoacoustic emissions. Hearing Research 164:39-48.

Viemeister NF, Wakefield GH (1991) Temporal integration and multiple looks. J Acoust Soc Am 90:858-865.

Vinay, Moore BCJ (2008) Effects of activation of the efferent system on psychophysical tuning curves as a function of signal frequency. Hear Res 240:93-101.

Wagner W, Frey K, Heppelmann G, Plontke SK, Zenner HP (2008) Speech-in-noise intelligibility does not correlate with efferent olivocochlear reflex in humans with normal hearing. Acta Otolaryngol 128:53-60.

Warr WB, Guinan JJ (1979) Efferent innervation of the organ of corti: two separate systems. Brain Res 173:152-155.

Warren EH, Liberman MC (1989a) Effects of contralateral sound on auditory-nerve responses. I. Contributions of cochlear efferents. Hear Res 37:89-104.

Warren EH, Liberman MC (1989b) Effects of contralateral sound on auditory-nerve responses. II. Dependence on stimulus variables. Hear Res 37:105-121.

Watson CS, Gengel RW (1969) Signal duration and signal frequency in relation to auditoy sensitivitiy. J Acoust Soc Am 46:989-997.

Winslow RL, Sachs MB (1987) Effect of electrical stimulation of the crossed olivocochlear bundle on auditory nerve response to tones in noise. J Neurophysiol 57:1002-1021.

Wojtczak M, Oxenham AJ (2009) Pitfalls in behavioral estimates of basilar-membrane compression in humans. J Acoust Soc Am 125:270-281. 


\section{Publicaciones y comunicaciones resultantes de esta tesis}

\section{Publicaciones científicas}

- Aguilar E, Eustaquio-Martin A, Lopez-Poveda EA (2013). Contralateral efferent reflex effects on threshold and supra-threshold psychoacoustical tuning curves at low and high frequencies. J. Assoc. Res. Otolaryngol. 14(3):341-57. doi: 10.1007/s10162-013-0373-4

- Lopez-Poveda EA, Aguilar E, Johannesen PT, Eustaquio-Martin A. (2013). "Contralateral efferent regulation of human cochlear tuning: Behavioural observations and computer simulations," in Moore BCJ, Patterson RD, Winter I, Carlyon RP, Gockel HE (eds.) Basic Aspects of Hearing: Physiology and Perception, Springer, New York, pp. 47-54. doi: 10.1007/978-1-4614-1590-9_6.

\section{Resúmenes publicados}

- Aguilar E, Johannesen P, Lopez-Poveda EA. "Psychoacoustical characterization of medial olivocochlear reflex effects on human cochlear responses" (\#182, Abstract Book) 34th Midwinter Meeting of the Association for Research in Otolaryngology, 19-23 de febrero de 2011, Baltimore, Maryland, USA.

- Aguilar E, Johannesen P, Eustaquio-Martín A, Lopez-Poveda EA. “Psychoacoustical characterization of the effects of medial olivocochlear reflex activation on apical and basal cochlear nonlinearity. (\#625, Abstract Book) 35th Midwinter of the Association for Research in Otolaryngology, 25-29 de febrero de 2012, San Diego, California, USA.

\section{Comunicaciones en jornadas, congresos y seminarios}

- Aguilar E, Johannesen P, Lopez-Poveda EA. "Psychoacoustical characterization of medial olivocochlear reflex effects on human cochlear responses" Póster. 34th Midwinter Meeting of the Association for Research in Otolaryngology, 19-23 de febrero de 2011, Baltimore, Maryland, USA.

- Aguilar E, Johannesen P, Eustaquio-Martín A, Lopez-Poveda EA. “Psychoacoustical characterization of the effects of medial olivocochlear reflex activation on apical and basal cochlear nonlinearity. Póster. 35th Midwinter Meeting of the Association for Research in Otolaryngology, 25-29 de febrero de 2012 San Diego, 
California, USA.

- Aguilar E, Johannesen P, Eustaquio-Martín A, Lopez-Poveda EA. "Efecto de la activación del reflejo olivococlear contralateral sobre la respuesta coclear humana". VI Jornadas Internacionales sobre Avances en Audiología, 7-9 de junio de 2012, Salamanca, España.

- Lopez-Poveda EA, Aguilar E, Johannesen P, Eustaquio-martín A. "Contralateral efferent regulation of human cochlear tuning: Behavioural observations and computer model simulations" 16th International Symposium on Hearing, 23-27 de julio de 2012, Cambridge, United Kingdom.

- Aguilar E. "Modulación eferente contralateral de la respuesta coclear humana". Seminarios Internacionales del Instituto de Neurociencias de Castilla y León, 3 de mayo 2013, Salamanca, España. 